Emeryy Techmolociv UVIsion

Energy Technology DIUSim

Energy Tachnology Dificlon

Energy achmology Wristurn

Entryy Tohnology DIVion

Energy Technology Division

Energy Technology Division

Energy Technology Division

Energy Technology Division Energy Technology Division Energy Technology Division

Energy Technology Division

Energy Technology Division

\title{
Dynamic Stability Experiment of Maglev Systems
}

Energy Technology Division

Energy Technology Division

Energy Technology Division

Evergy Technology Division

Energy Technology Division

Energy Technology Division

Energy Technology Division

Energy Techmology Dvision

Energy Technology Division

Energy Technology Division

Energy Technology Division

Energy Technology Division

Energy Technology Division

Energy Technology Division

Energy Technology Division

Energy Technology Division

Energy Technology Division

Energy Technology Division

by Y. Cai, D. M. Rote, T. M. Mulcahy, Z. Wang, S. S. Chen, and S. Zhu

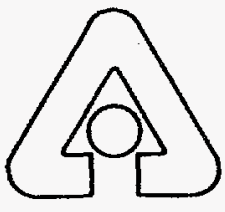

Argonne National Laboratory, Argonne, Illinois 60439

operated by The University of Chicago

for the United States Department of Energy under Contract W-31-109-Eng-38

Energy Technology Division

Energy Technology Division

Energy Technology Division

Energy Technology Division

Energy Technology Division

Energy Technology Division

Energy Technology Division

Energy Technology Division

DIFTRIBUTION OF THIS DOCUMENT IS UNLIMITED 
Argonne National Laboratory, with facilities in the states of Illinois and Idaho, is owned by the United States government, and operated by The University of Chicago under the provisions of a contract with the Department of Energy.

\section{DISCLAIMER}

This report was prepared as an account of work sponsored by an agency of the United States Government. Neither the United States Government nor any agency thereof, nor any of their employees, makes any warranty, express or implied, or assumes any legal liability or responsibility for the accuracy, completeness, or usefulness of any information, apparatus, product, or process disclosed, or represents that its use would not infringe privately owned rights. Reference herein to any specific commercial product, process, or service by trade name, trademark, manufacturer, or otherwise, does not necessarily constitute or imply its endorsement, recommendation, or favoring by the United States Government or any agency thereof. The views and opinions of authors expressed herein do not necessarily state or reflect those of the United States Government or any agency thereof.

Reproduced from the best available copy.

Available to DOE and DOE contractors from the Office of Scientific and Technical Information P.O. Box 62

Oak Ridge, TN 37831

Prices available from (615) 576-8401

Available to the public from the National Technical Information Service

U.S. Department of Commerce 5285 Port Royal Road Springfield, VA 22161 


\section{DISCLAIMER}

Portions of this document may be illegible in electronic image products. Images are produced from the best available original document. 
ARGONNE NATIONAL LABORATORY

9700 South Cass Avenue, Argonne, Illinois 60439
ANL-95/10

Distribution

Category:

All Transportation Systems

Reports (UC

1500

\section{Dynamic Stability Experiment of Maglev Systems}

by

Y. Cai, T. M. Mulcahy, S. S. Chen, and S. Zhu

Energy Technology Division

D. M. Rote and Z. Wang

Center for Transportation Research

April 1995

Work supported by

U.S. DEPARTMENT OF ENERGY

Office of Transportation Technologies 


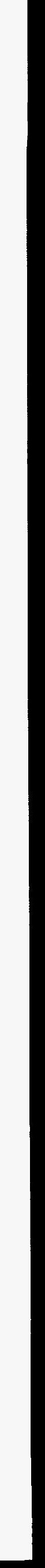




\section{Contents}

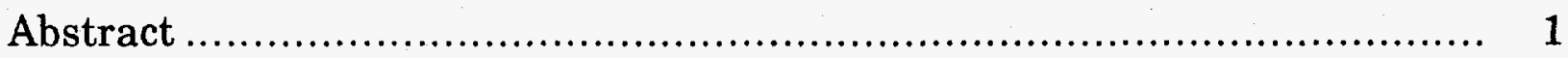

1 Introduction ..................................................................... 1

2 Measurement of Magnetic Forces ............................................... $\quad 5$

2.1 Experimental Setup for Measuring Magnetic Forces …............... 5

2.2 Results and Discussion of Measured Magnetic Forces ................... 8

2.3 Magnetic Force Computations .......................................... 12

2.4 Measuring Magnetic Forces of Guidance Magnets...................... 22

3 Dynamic Stability Experiments............................................ 23

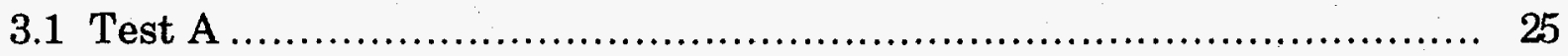

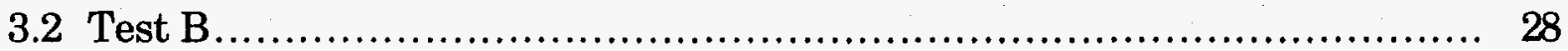

4 Numerical Simulation of Maglev Vehicles with Five DOF ................... 33

4.1 Theoretical Aspects ......................................................... 33

4.2 Computer Code for Maglev Systems................................... 36

4.3 Numerical Simulation and Comparison with Test A ................... 37

4.4 Numerical Simulation and Comparison with Test B...................... 40

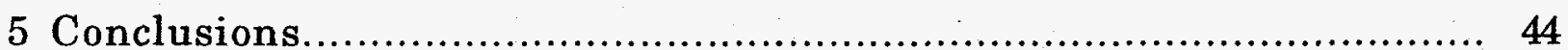

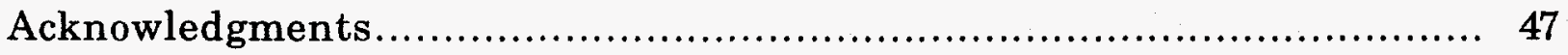

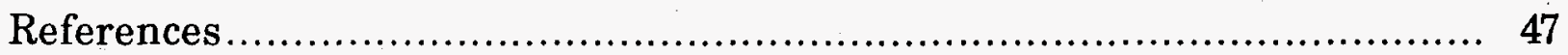

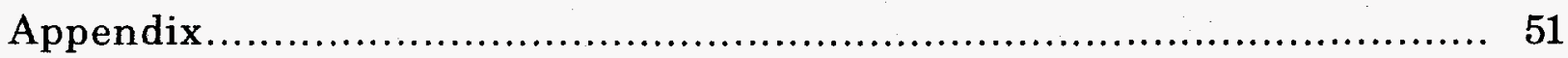




\section{Figures}

1 Experimental setup of rotating wheel with aluminum L-shaped ring mounted on top.

2 Experimental apparatus for measuring magnetic force

3 Schematic diagram of apparatus used to measure magnetic forces on L-shaped aluminum sheet guideway.

4 Measured lift magnetic force, for various wheel surface velocities $\mathrm{V}$, as a function of lift height

5 Measured guidance magnetic force, for various wheel surface velocities $\mathrm{V}$, as a function of lift height

6 Measured drag magnetic force, for various wheel surface velocities V, as a function of lift height

7 Measured lift magnetic force, for various values of $h$ and $\mathrm{Y}^{*}$, as a function of velocity

8 Measured guidance magnetic force, for various values of $h$ and $\mathrm{Y}^{*}$, as a function of velocity.

9 Measured drag magnetic force, for various values of $h$ and $\mathrm{Y}^{*}$, as a function of velocity

10 Magnet and equivalent coil

11 Measured and MAGFORCE-calculated lift forces when $\mathrm{Y}^{*}=12.7 \mathrm{~mm}$

12 Measured and MAGFORCE-calculated guidance forces when $\mathrm{Y}^{*}=12.7 \mathrm{~mm}$

13 Measured and MAGFORCE-calculated drag forces when $\mathrm{Y}^{*}=12.7 \mathrm{~mm}$

14 Measured and MAGFORCE-calculated lift forces when $\mathrm{Y}^{*}=5 \mathrm{~mm} \ldots$ 16 
15 Measured and MAGFORCE-calculated drag forces when $\mathrm{Y}^{*}=5 \mathrm{~mm}$

16 Alternative magnet and equivalent coil

17 Measured and MAGFORCE-calculated lift forces when $\mathrm{Y}^{*}=12.7 \mathrm{~mm}$

18 Measured and MAGFORCE-calculated guidance forces when $\mathrm{Y}^{*}=12.7 \mathrm{~mm}$

19 Measured and MAGFORCE-calculated drag forces when $\mathrm{Y}^{*}=12.7 \mathrm{~mm}$

20 Measured and ELEKTRA-calculated lift, guidance, and drag forces when $\mathrm{Y}^{*}=12.7 \mathrm{~mm}$

21 Measured and ELEKTRA-calculated lift forces when $\mathrm{Y}^{*}=5 \mathrm{~mm}$

22 Measured and ELEKTRA-calculated guidance forces when $\mathrm{Y}^{*}=5 \mathrm{~mm}$

23 Measured and ELEKTRA-calculated drag forces when $\mathrm{Y}^{*}=5 \mathrm{~mm} \ldots .$. 20

24 Measured and ELEKTRA-calculated lift forces when $\mathrm{h}=7 \mathrm{~mm}$ 21

25 Measured and ELEKTRA-calculated guidance forces when $\mathrm{h}=7 \mathrm{~mm}$ 21

26 Measured and ELEKTRA-calculated drag forces when $\mathrm{h}=7 \mathrm{~mm}$....... 21

27 Guidance magnet on aluminum sheet guideway

28 Measured lift and drag magnetic forces of guidance magnet as a function of velocity

29 Schematic diagram of experimental apparatus for testing maglev dynamic stability

30 Vehicle model with four levitation magnets in Test A 26 
31 Experimental results from Test A

32 Vehicle model with four levitation and four guidance magnets in Test $B$

33 Accelerometer arrangement for vehicle model in Test B

34 Experimental results from Test B 32

35 Displacement components of a maglev system 34

36 Experimental results from Case 1 in Test A..................................

37 Simulation results of lateral and mass center displacements in Test $A$ at various vehicle speeds

38 Simulated time histories of lateral and vertical displacement of vehicle that contacts side wall of guideway

39 Simulation results of displacements and rotations in Test A with vehicle speed $=20 \mathrm{~m} / \mathrm{s}$

40 Experimental results with guidance magnet gap $=13.5 \mathrm{~mm}$ in Test B

41 Simulation results of displacement and rotation in Test B with vehicle speed $=15 \mathrm{~m} / \mathrm{s}$

42 Simulation results of displacement and rotation in Test B with vehicle speed $=20 \mathrm{~m} / \mathrm{s}$

43 Simulation results of displacement and rotation in Test B with vehicle speed $=25 \mathrm{~m} / \mathrm{s}$

44 Simulation results of displacement and rotation in Test B with vehicle speed $=30 \mathrm{~m} / \mathrm{s}$

45 Comparison of vehicle guidance and drag forces as a function of velocity

46 Comparison of vertical gap and drag force as a function of velocity when vehicle is at equilibrium 


\section{Tables}

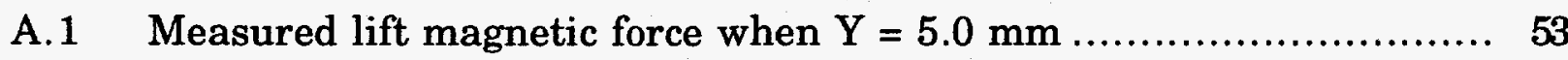

A.2 Measured lift magnetic force when $\mathrm{Y}=12.7 \mathrm{~mm} \ldots \ldots \ldots \ldots \ldots \ldots \ldots . \ldots \ldots$

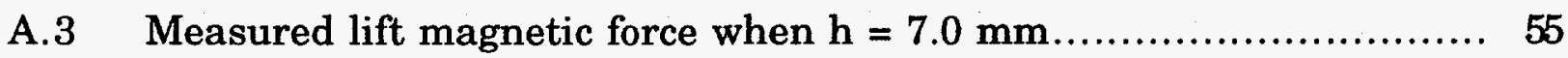

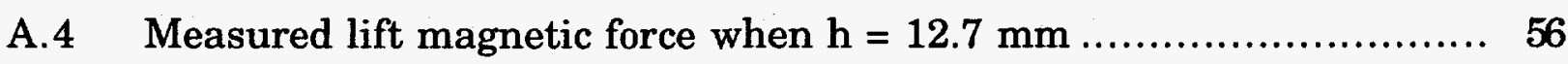

A.5 Measured guidance magnetic force when $\mathrm{Y}=5.0 \mathrm{~mm} \ldots \ldots \ldots \ldots \ldots \ldots . \ldots 57$

A.6 Measured guidance magnetic force when $\mathrm{Y}=12.7 \mathrm{~mm} \ldots \ldots \ldots \ldots \ldots \ldots . \ldots 58$

A.7 Measured guidance magnetic force when $\mathrm{h}=7.0 \mathrm{~mm} \ldots \ldots \ldots \ldots \ldots \ldots . . \ldots 59$

A.8 Measured guidance magnetic force when $\mathrm{h}=12.7 \mathrm{~mm} \ldots \ldots \ldots \ldots \ldots \ldots 61$

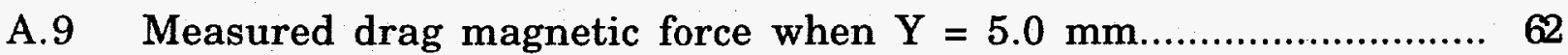

A.10 Measured drag magnetic force when $\mathrm{Y}=12.7 \mathrm{~mm} \ldots \ldots \ldots \ldots \ldots \ldots \ldots . \ldots 3$

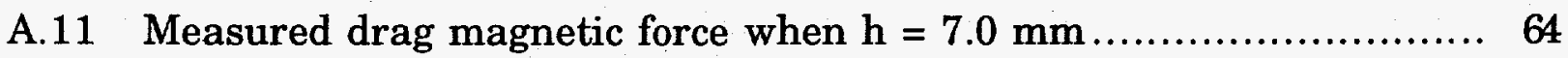

A.12 Measured drag magnetic force when $h=12.7 \mathrm{~mm} \ldots \ldots \ldots \ldots \ldots \ldots \ldots \ldots . . . \ldots 6$

A.13 Measured lift and drag magnetic force for guidance magnet .......... 66 


\section{Dynamic Stability Experiment of Maglev Systems}

by

Y. Cai, D. M. Rote, T. M. Mulcahy, Z. Wang, S. S. Chen, and S. Zhu

\section{Abstract}

This report summarizes the research performed on maglev vehicle dynamic stability at Argonne National Laboratory during the past few years. It also documents magnetic-force data obtained from both measurements and calculations. Because dynamic instability is not acceptable for any commercial maglev system, it is important to consider this phenomenon in the development of all maglev systems. This report presents dynamic stability experiments on maglev systems and compares their numerical simulation with predictions calculated by a nonlinear dynamic computer code. Instabilities of an electrodynamic system (EDS)-type vehicle model were obtained from both experimental observations and computer simulations for a five-degree-of-freedom maglev vehicle moving on a guideway consisting of double L-shaped aluminum segments attached to a rotating wheel. The experimental and theoretical analyses developed in this study identify basic stability characteristics and future research needs of maglev systems.

\section{Introduction}

The dynamic response of maglev systems is important for safety and ride quality, guideway design, and system costs. Ride quality is determined by vehicle response and environmental factors such as humidity and noise. The dynamic response of vehicles is the key element in the determination of ride quality, and vehicle stability is one of the important elements relative to safety. To design a guideway that provides acceptable ride quality in the stable region, the vehicle dynamics must be understood. Furthermore, the trade-off between guideway smoothness and levitation and control systems must be considered if maglev systems are to be economically feasible. Vehicle dynamics, which link the guideway with other maglev components, must be analyzed and tested in detail when considering a maglev system for commercial use (Chen et al., 1992; Coffey et al., 1991). 
For safety, maglev systems should be stable. Because dynamic instabilities are not acceptable for any commercial maglev system, it is important to consider these phenomena when designing and developing maglev suspension systems. However, to date, this issue has not received much attention worldwide (Masada, 1993; Wiescholek et al., 1993; Coffey, 1993; Ozeki, 1993; Kim et al., 1993; Martinelli and Morini, 1993; Lian et al., 1993; and Wyczalek, 1993) even though instabilities of maglev systems were confirmed earlier by several investigators (Chu and Moon, 1983; Chen et al., 1992; Cai et al., 1992b).

Therefore, the objective of the R\&D program on dynamic stability of maglev systems at Argonne National Laboratory (ANL) during the past four years (Chen et al., 1992; Cai et al., 1992a; 1992b; 1992c; 1993a; 1993b; and 1993c; Chen et al., 1993; Zhu et al., 1994; Cai and Chen, 1995) has been to develop a general approach for investigating and predicting the occurrence of instabilities in maglev suspension systems and to provide a better understanding of the conditions (design features and parameter values) that can lead to dynamic instabilities.

The repulsive levitation system, or the so-called electrodynamic system (EDS), is often thought to be inherently stable. However, its response to perturbations is frequently unstable and susceptible to catastrophic oscillations, particularly in rectangular-trough configurations. So far, only a few analytical and experimental studies (Cai et al., 1992a; 1992b; 1993a; and 1993b) have been performed to gain an understanding of the stability characteristics of EDS-type maglev systems. Davis and Wilkie (1971) studied a magnetic coil moving over a conducting track and concluded that negative damping occurs at velocities greater than the characteristic velocity based on thin-track theory. Ohno et al. (1973) studied the pulsating lift forces in a linear synchronous motor. These pulsating forces may cause parametric and combination resonance, in addition to heaving and pitching oscillations. Experiments on the Massachusetts Institute of Technology (MIT) magneplane showed obvious evidence of dynamic instabilities on film in the early 1970 s, but dynamic stability was not studied in detail. An experimental vehicle with three degrees of freedom (DOF), floating above a large rotating wheel, was found by Moon (1974) to have a lateral-roll-yaw instability. Also, experiments performed at MIT on a test track showed pitch-heave instability. Negative magnetic damping was demonstrated, but was dominated by aerodynamic damping (Moon, 1977). A conducting guideway, consisting of Lshaped aluminum segments attached to a rotating wheel to simulate the fullscale Japanese guideway at Miyazaki, was studied experimentally and analytically by Chu and Moon (1983). Divergence and flutter of a vehicle model with two DOF were obtained for coupled yaw-lateral vibration; the divergence 
leads to two stable equilibrium yaw positions, and the flutter instability leads to a limit cycle of coupled yaw and lateral motions near the magnetic drag peak.

Because very limited studies have been published and many stability issues remain unresolved, the theory of motion-dependent magnetic-force-induced instability (which consists of both quasistatic motion and unsteady motion theories) was developed in our previous work (Cai et al., 1992a; 1992b; 1993a). A method of obtaining motion-dependent magnetic-force coefficients experimentally was identified and used to measure quasistatic motion-dependent magnetic-force coefficients of a maglev system with a double L-shaped guideway from an experimental investigation at Argonne National Laboratory (Cai et al., 1992b). Motion-dependent magnetic forces are the controlling elements in the stability of maglev systems. Therefore, this earlier integrated analytical/experimental study presented a systematic method to determine the stability of maglev systems and answered a series of questions on maglev stability. With a simplified analytical three-DOF vehicle model, divergence and flutter were observed for coupled vibration of a vehicle on a guideway consisting of double L-shaped aluminum segments (Cai et al., 1992a; 1992b). Divergence and flutter of this analytical model were later verified by numerical solution of a case with the same vehicle configuration (Cai et al., 1993a; 1993b; Cai and Chen, 1995).

At Argonne National Laboratory (ANL), an analysis of dynamic instabilities of an EDS-type maglev suspension system, with three- and five-DOF vehicles traveling on a double-L shaped set of guideway conductors, was conducted (Cai et al., 1993a; 1993b; Cai and Chen, 1995). Both analytical and numerical approaches were used, and various magnetic suspension forces, compiled from experimental data, were incorporated into the theoretical models. Divergence and flutter were obtained from analytical and numerical solutions for coupled vibration of the three-DOF maglev vehicle model. A computer code for numerically simulating dynamic stability of the five-DOF vehicle model was developed, and extensive computations with various parameters were performed to determine the stability characteristics of EDS-type maglev systems. Instabilities of five directions of motion (heave, slip, roll, pitch, and yaw) of the dynamic vehicle model were observed and it was demonstrated that system parameters such as system damping, vehicle geometry, and coupling effects among five different motions play very important roles in the occurrence of dynamic instabilities in maglev systems (Cai et al., 1993a).

Magnetic forces are basically position-dependent, although some are also velocity-dependent. These motion-dependent magnetic forces can induce various 
types of instability. In addition, the periodic structure of the motion-dependent magnetic forces may, in some cases, also induce parametric and combination resonances (Cai et al., 1992b). To date, magnetic forces are obtained mainly from experimental measurements. At ANL, two different experiments to measure force were performed. In the first experiment, a quasistatic method was applied to measure magnetic forces when a permanent magnet was moving over an aluminum L-shaped ring mounted on the top surface of a 1.2-m diameter rotating wheel. The measured forces are a function of position at a given steady speed (Cai et al., 1992b). In the second experiment, dynamic (motion-dependent) magnetic force measurements were based on an unsteady-motion theory. A direct method was used to measure magnetic damping and stiffness, and to investigate the effect of various parameters, such as conductivity, gap, excitation frequency, and oscillation amplitude (Chen et al., 1993; Zhu et al., 1994). Experimental results indicated that negative magnetic damping will develop once the characteristic speed is exceeded. In the maglev system, instability will occur when the damping value becomes negative. A computer model simulation of magnetic damping forces in a maglev system confirmed the existence of negative damping phenomenon (He et al., 1994).

However, in this report, we include only the magnetic force data measured by the quasistatic method. In recent years, experiments were conducted at ANL to measure those magnetic forces. We summarize those magnetic forces in this report because those data, obtained from steady state experiments, play a very important role in numerical simulation of dynamic stability analysis of maglev vehicles. All of the experimental data have been incorporated into an existing computer program for nonlinear-dynamics simulation of maglev vehicles. We also believe that integrating magnetic force data that have never been published will provide potential references for future maglev programs.

The main purpose of this report is to present an overview of recent extensive experimental investigation on the dynamic stability of maglev systems at ANL. Two series of tests were performed with a free vehicle moving on a double L-shaped aluminum guideway mounted on the top of a rotating wheel. In Test 1 , a vehicle model was supported by four permanent magnets on four corners, whereas, in Test 2, four magnets for levitation and four magnets for guidance were attached to the vehicle. In both tests, the vehicle, constrained in its longitudinal direction by a metal tether attached to its front, was free to move in up to five modes (vertical heave, lateral slip, pitch, yaw, and roll). Several accelerometers and a force transducer (only for drag direction) were placed on the vehicle. The vehicle's motion in five directions was measured by double analog 
integration. When the rotating speed of the wheel varied, stable and unstable motions of the maglev vehicle were observed and recorded.

A computer program, incorporating all of the quasistatic magnetic forces that we measured, was developed at ANL for simulating the dynamic response of maglev systems. The program can simulate nonlinear dynamic response of maglev systems with six DOF when the user inputs vehicle and track configurations; it was employed in this study to calculate the dynamic response and onset of instability in a maglev vehicle model with five DOF. The simulations and predictions were compared with results obtained from dynamic stability experiments.

\section{Measurement of Magnetic Forces}

Magnetic forces are needed for any analysis of vehicle dynamics, design of guideway structures and fastening, and prediction of ride quality. These force components are considered from the standpoint of vehicle stability.

As a significant part of ANL's maglev R\&D program, magnetic forces of a permanent magnet moving over an aluminum L-shaped sheet guideway were measured experimentally with a quasistatic method; this report provides an overview of that effort. Details of the experimental setup and measured force data are presented in this section. The measured magnetic forces are compared with magnetic forces calculated by various commercial computer codes, including MAGFORCE and ELEKTRA.

We integrated the experimentally determined magnetic forces in this report because data yielded by experiments play a very important role in numerical simulation of dynamic stability analysis of maglev vehicles. All of the experimental data have been incorporated into an existing computer program for nonlinear-dynamics simulation of maglev vehicles.

\subsection{Experimental Setup for Measuring Magnetic Forces}

An experiment was conducted at ANL to investigate the lift, drag, and guidance magnetic forces on an $\mathrm{NdFeB}$ permanent magnet moving over an aluminum (6061-T6) L-shaped ring mounted on the top surface of a 1.2-m diameter rotating wheel (shown in Figs. 1 and 2). For a given rotating speed of 


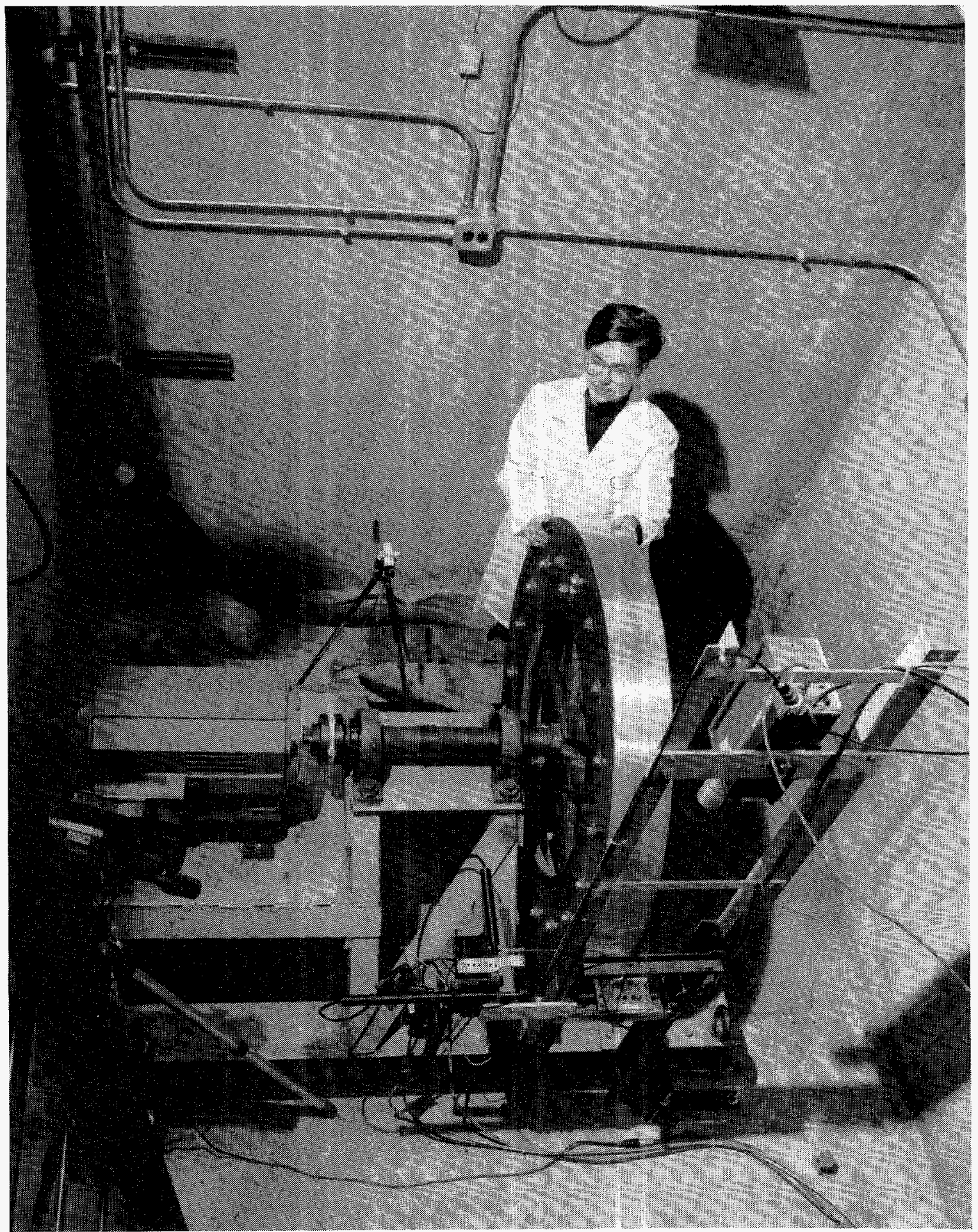

Fig. 1. Experimental setup of rotating wheel with aluminum L-shaped ring mounted on top 


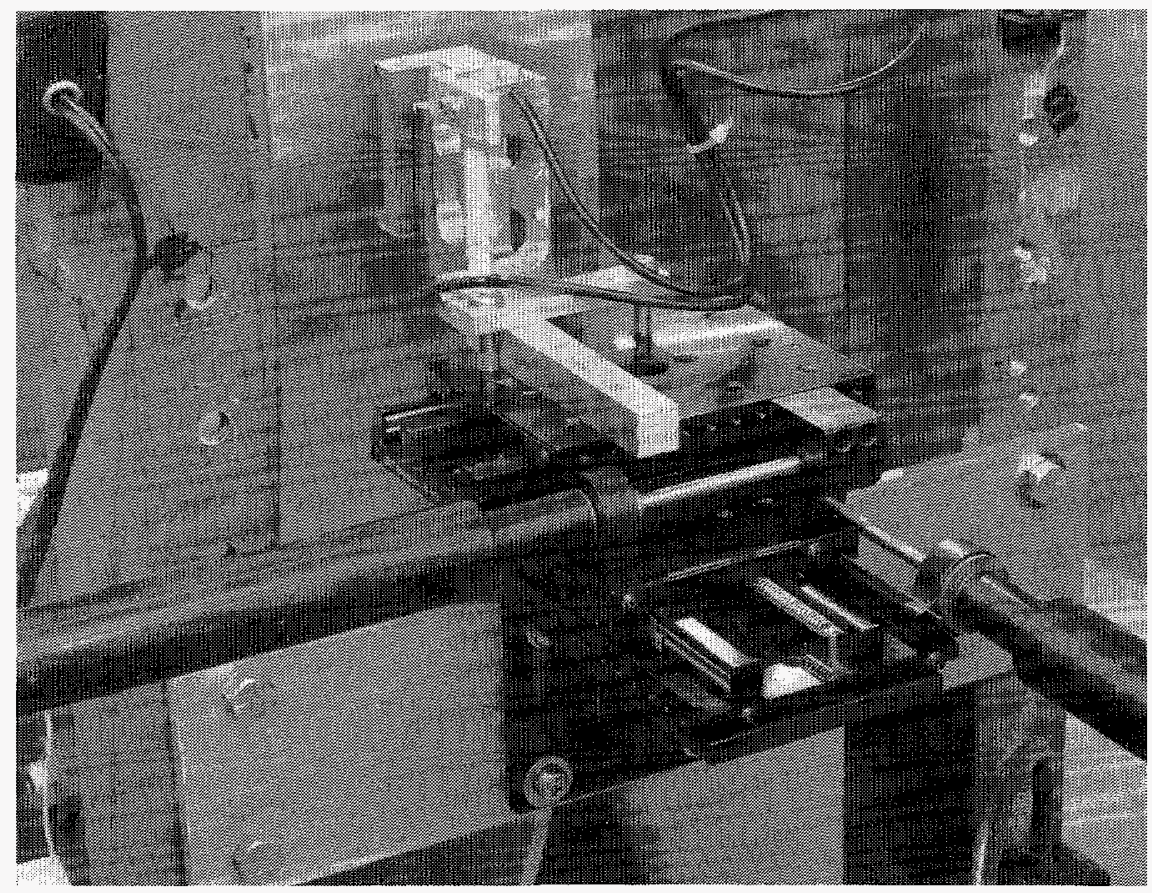

Fig. 2. Experimental apparatus for measuring magnetic force

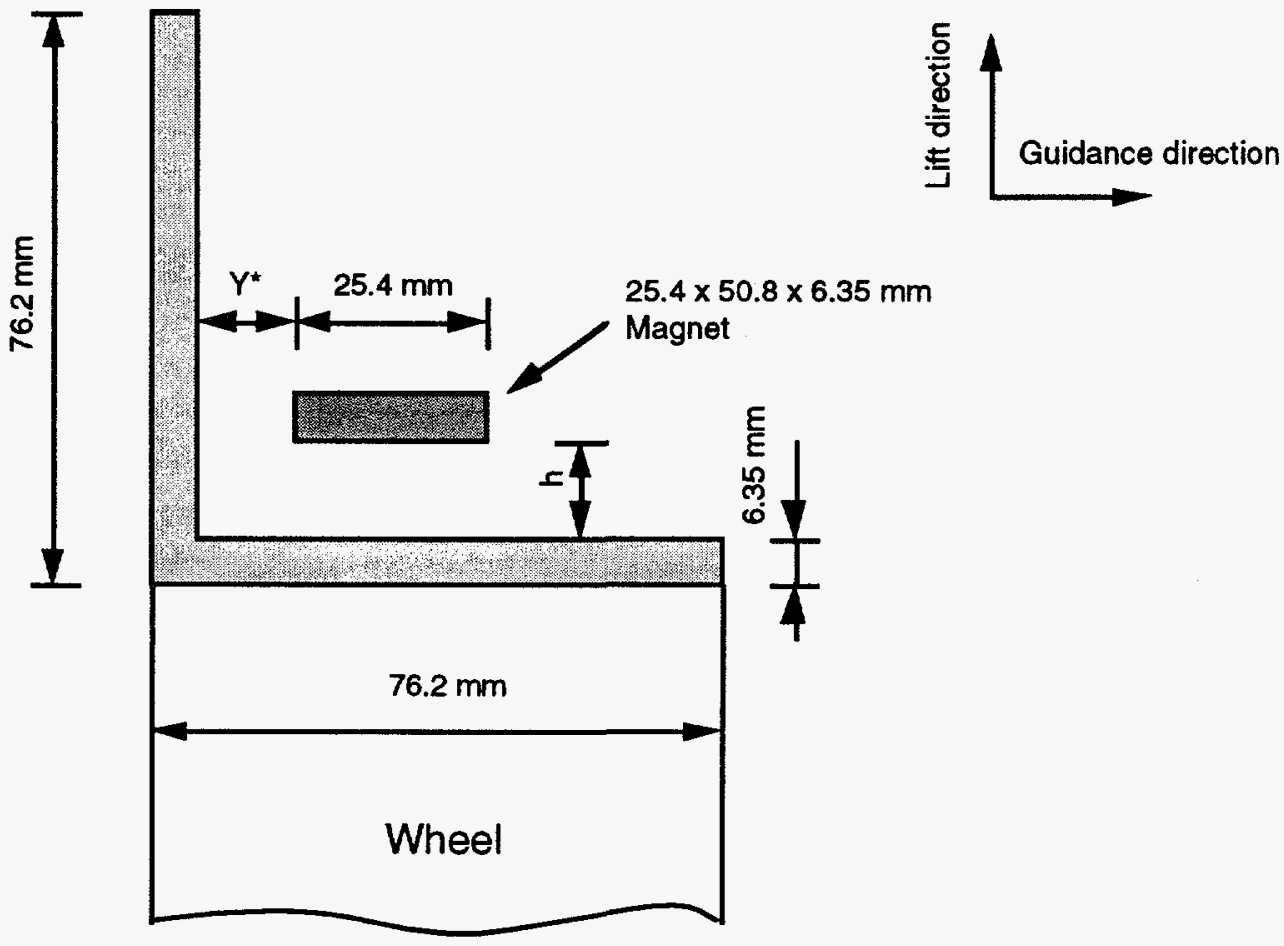

Fig. 3. Schematic diagram of apparatus used to measure magnetic forces on L-shaped aluminum sheet guideway 
the wheel (ranging from 0 to $600 \mathrm{rpm}$, or 0 to $37.7 \mathrm{~m} / \mathrm{s}$ ), the lift, guidance, and drag magnetic forces were measured while the guidance gap $\mathrm{Y}^{*}$ and lift height $h$ were varied. A schematic diagram of the measurement approach is shown in Fig. 3 (Cai et al., 1992).

During testing, the long side of the $25.4 \times 50.8 \times 6.35-\mathrm{mm}$ rectangular magnet was oriented parallel to the direction of motion of the L-shaped guideway and was held stationary by a two-component force transducer that comprised two BLH C2G1 load cells connected in series to measure lift and guidance forces simultaneously. Laboratory weights were used to calibrate the transducer and to assess crosstalk (which was found to be $<2 \%$ ). The base of the load cell assembly was mounted on motorized stages that provided accurate positioning $( \pm 0.05 \mathrm{~mm})$. Out-of-roundness of the L-shaped guideway ring varied, but was always $< \pm 0.15$ $\mathrm{mm}$ for the lateral leg and $\pm 0.35 \mathrm{~mm}$ for the vertical leg. Ability to exactly position the magnet with respect to the guideway dominated our experimental error, which was estimated as $\pm 5 \%$.

Lift, guidance and drag forces were measured as a function of $h$, with $\mathrm{Y}^{*}$ fixed at 5 and $12.7 \mathrm{~mm}$, or as a function of $\mathrm{Y}^{*}$ with $\mathrm{h}$ fixed at 7 and $12.7 \mathrm{~mm}$ while the surface velocity of the lateral leg of the guideway varied from $4.55 \mathrm{~m} / \mathrm{s}$ to $36.1 \mathrm{~m} / \mathrm{s}$.

\subsection{Results and Discussion of Measured Magnetic Forces}

Measured lift, guidance, and drag forces are plotted in Figs. 4, 5, and 6, respectively, as a function of $h$, with $\mathrm{Y}^{*}$ fixed, or as a function of $\mathrm{Y}^{*}$, with $\mathrm{h}$ fixed, and with the wheel surface velocity $=4.55,7.89,10.62,13.32,18.20,24.15,30.10$, and $36.10 \mathrm{~m} / \mathrm{s}$.

The following characteristics of measured lift, guidance, and drag forces were noted from Figs. 4, 5, and 6.

- The qualitative trends in the lift, guidance, and drag force data for the L-shaped guideway are the same for all tested velocities. 


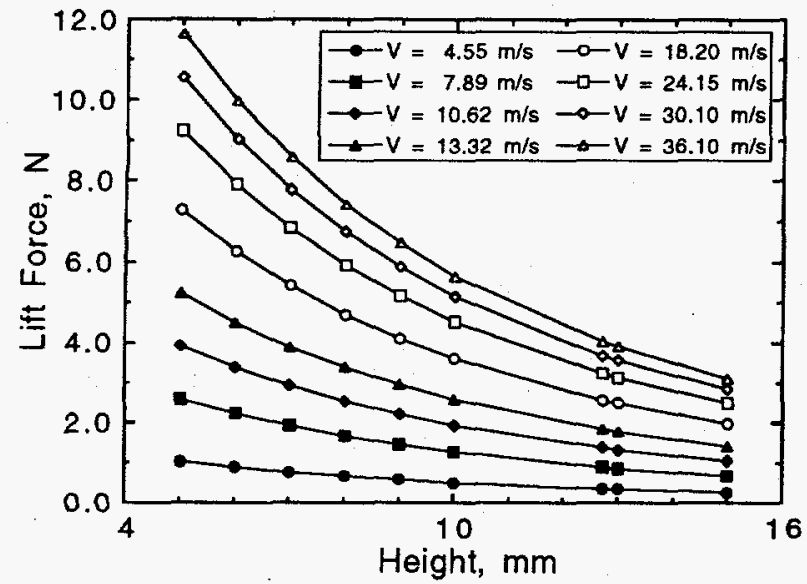

(a)

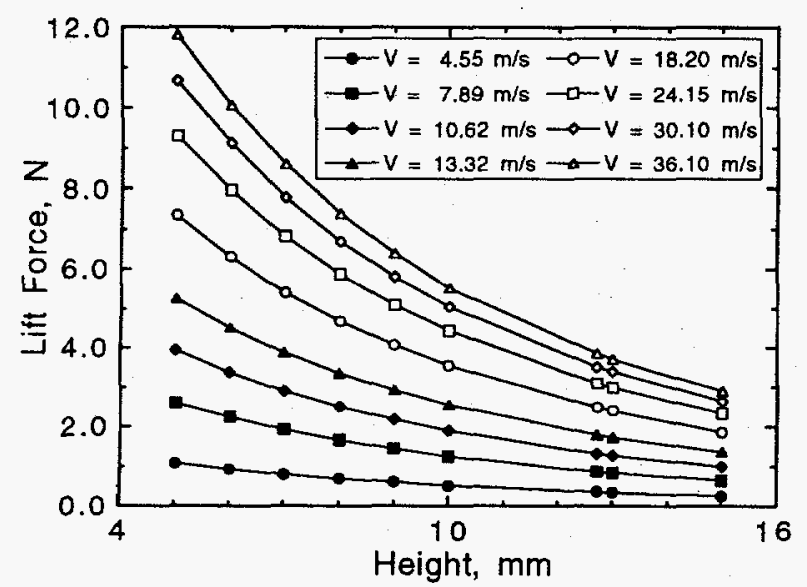

(b)

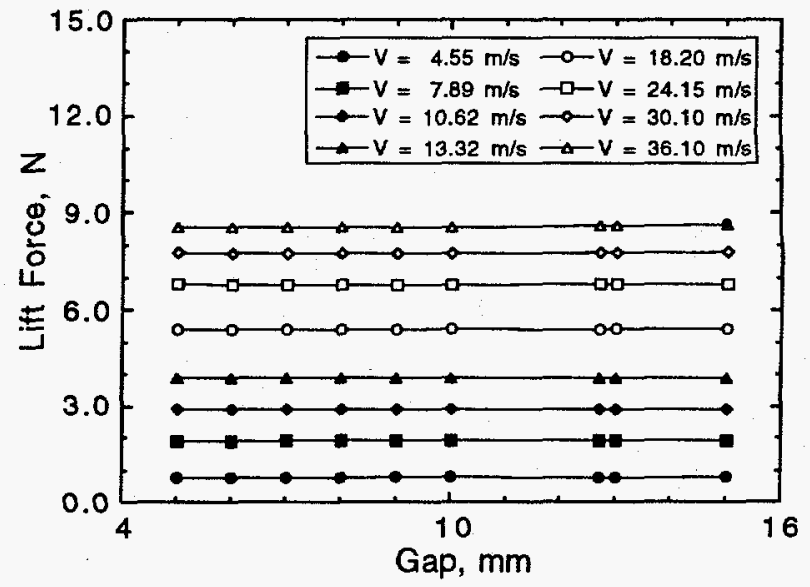

(c)

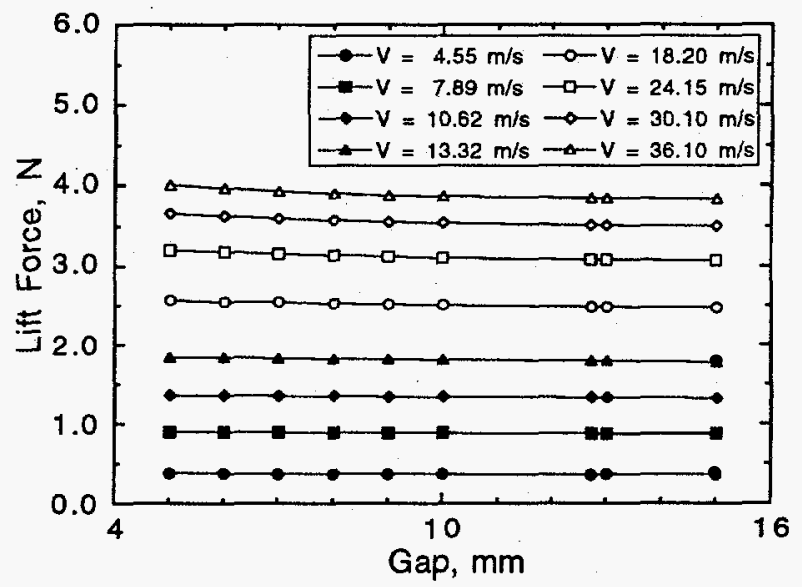

(d)

Fig. 4. Measured lift magnetic force, for various wheel surface velocities $V$, as a function of lift height when (a) $Y^{*}=5.0 \mathrm{~mm}$ and (b) $Y^{*}=12.7 \mathrm{~mm}$, and as a function of gap $Y^{*}$ when (c) $h=7.0 \mathrm{~mm}$ and $(d) h=12.7 \mathrm{~mm}$

- With fixed gap, the lift force decreases as height increases (Figs. 4a and $4 \mathrm{~b}$ ); with fixed height, the lift force remains almost the same when gap varies (Figs. $4 c$ and $4 d$ ). With fixed gap, the guidance force remains the same (Figs. $5 a$ and $5 b$ ), whereas with fixed height, the guidance force decreases as the gap increases (Figs. 5c and $5 \mathrm{~d}$ ). The drag force decreases as either gap or height increases (Fig 6).

- Compared with the lift and drag forces, the value of the guidance force is much smaller than that of the lift and drag forces. Without additional guidance magnets, the guidance force of a magnet could not maintain the vehicle in stable motion. 


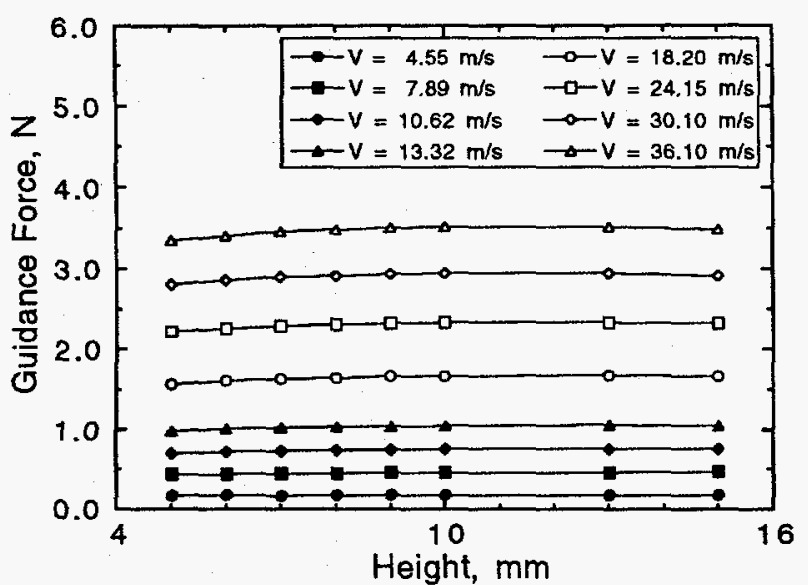

(a)

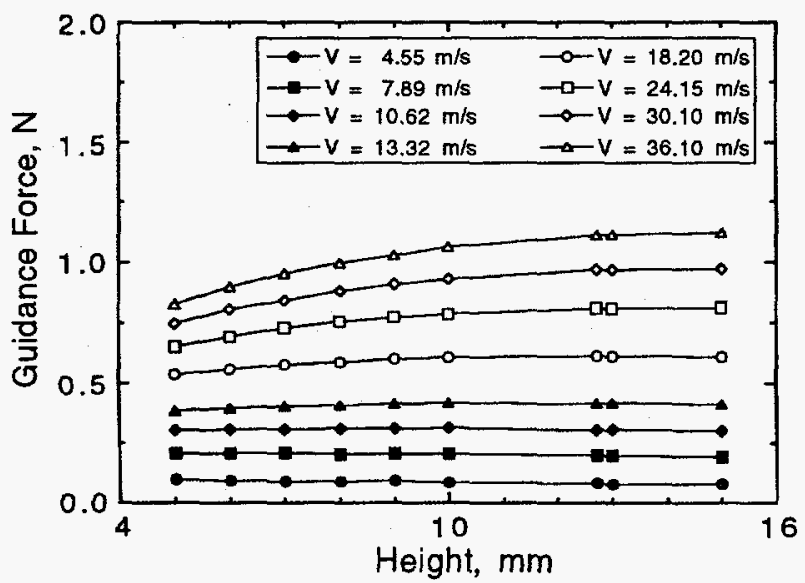

(b)

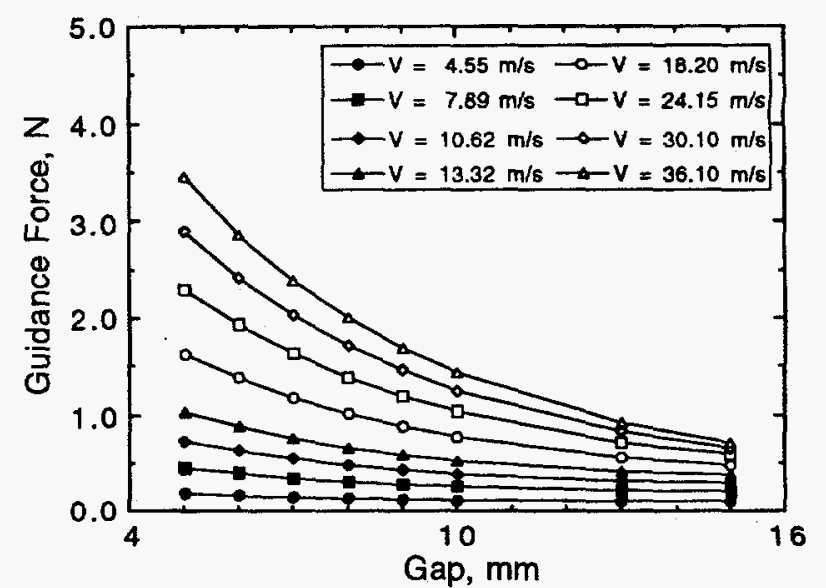

(c)

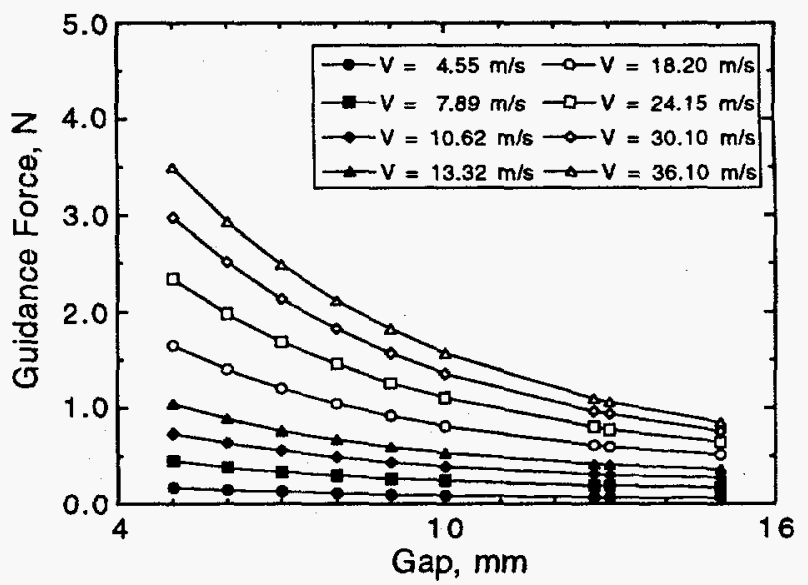

(d)

Fig. 5. Measured guidance magnetic force, for various wheel surface velocities $V$, as a function of lift height when (a) $Y^{*}=5.0 \mathrm{~mm}$ and (b) $Y^{*}=12.7 \mathrm{~mm}$, and as a function of gap $Y^{*}$ when (c) $h=7.0 \mathrm{~mm}$ and (d) $h=12.7 \mathrm{~mm}$

- Two features of guidance force are evident. First, a maximum occurs in the guidance force variation with respect to height variations at a fixed gap (as shown in Figs. 5a and 5b), a phenomenon that is caused by the corner region of the guideway. Second, a minimum occurs in the guidance force variation with respect to gap variations at a fixed height (as shown in Figs. 5c and $5 d$ ). This minimum is caused by the edge of the lateral leg of the guideway. As shown in the authors' previous publications, the first feature is associated with a flutter and the second with a divergence instability of a maglev vehicle model with three DOF (Cai et al., 1992a and 1992b). 


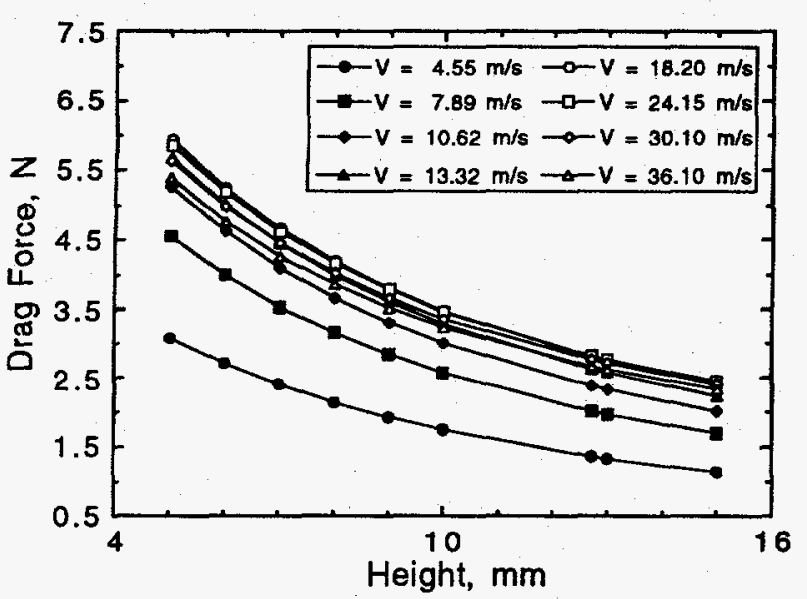

(a)

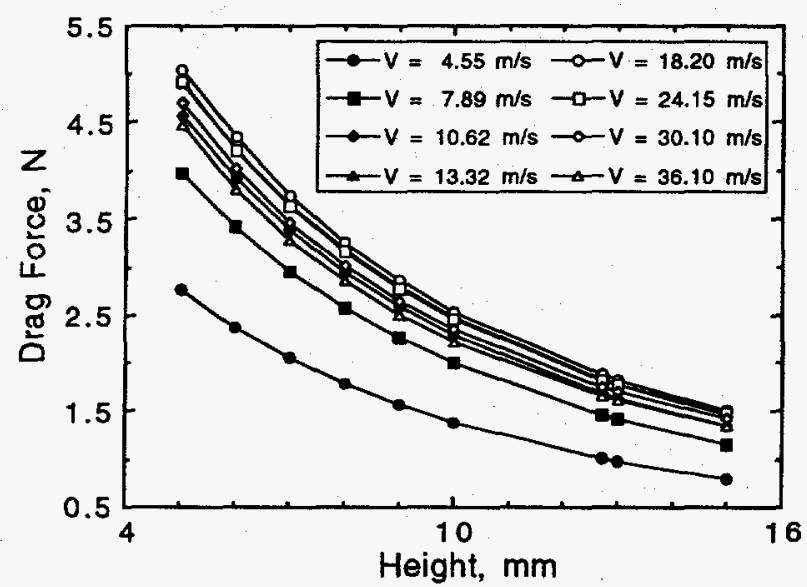

(b)

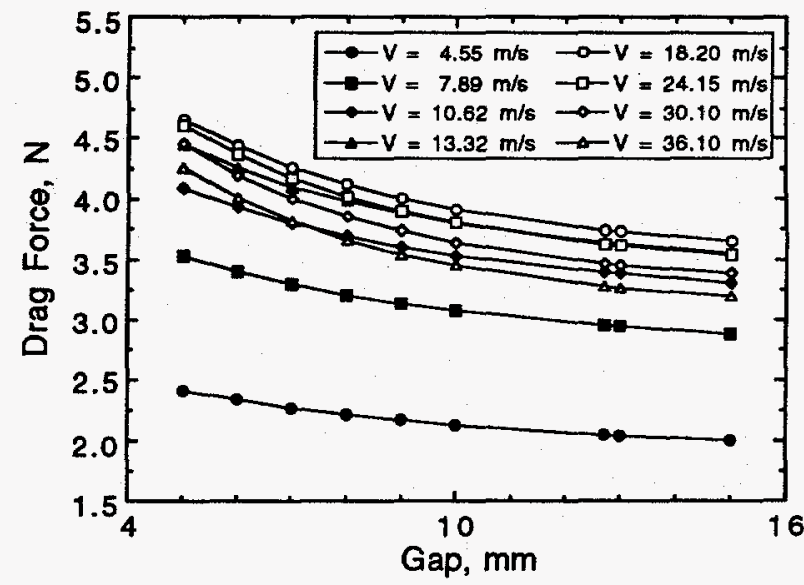

(c)

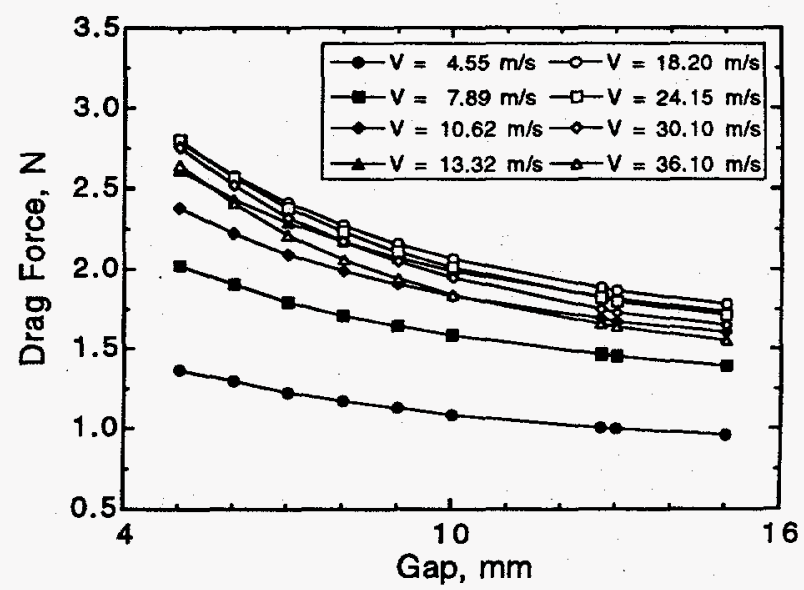

(d)

Fig. 6. Measured drag magnetic force, for various wheel surface velocities $V$, as a function of lift height when (a) $Y^{*}=5.0 \mathrm{~mm}$ and (b) $Y^{*}=12.7 \mathrm{~mm}$, and as a function of gap $Y^{*}$ when (c) $h=7.0 \mathrm{~mm}$ and (d) $h=12.7 \mathrm{~mm}$

The measured lift, guidance, and drag forces are replotted in Figs. 7, 8, and 9 , respectively, as a function of velocity, with $\mathrm{Y}^{*}$ or $\mathrm{h}$ fixed. Characteristics of the lift, guidance, and drag forces from Figs 7,8, and 9 can be summarized as follows:

- When velocity increases, the lift and guidance forces overall increase (Figs. 7 and 8); whereas drag force increases in the lower velocity range and decreases in the higher velocity range (Fig. 9).

- In the lower velocity range, the drag force is quite large when compared with lift and guidance forces; therefore, the drag force may introduce instability into a maglev vehicle in a low speed range. 


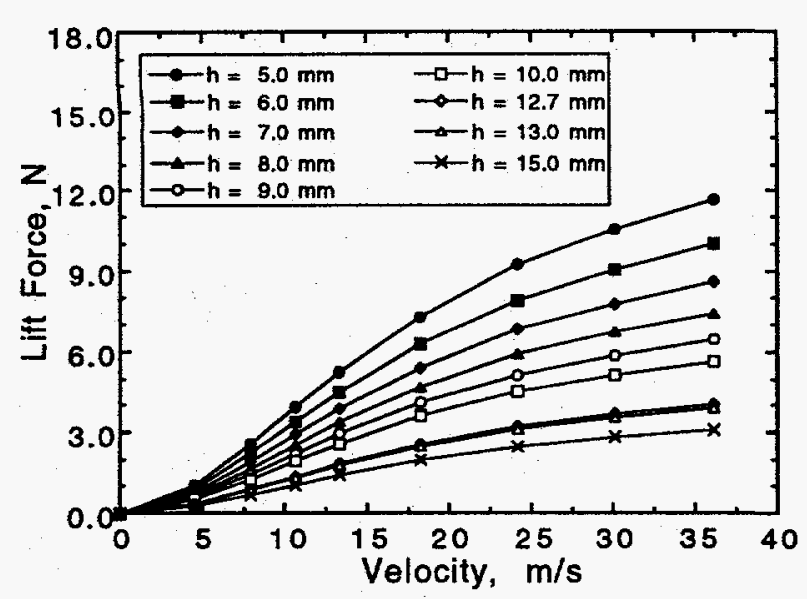

(a)

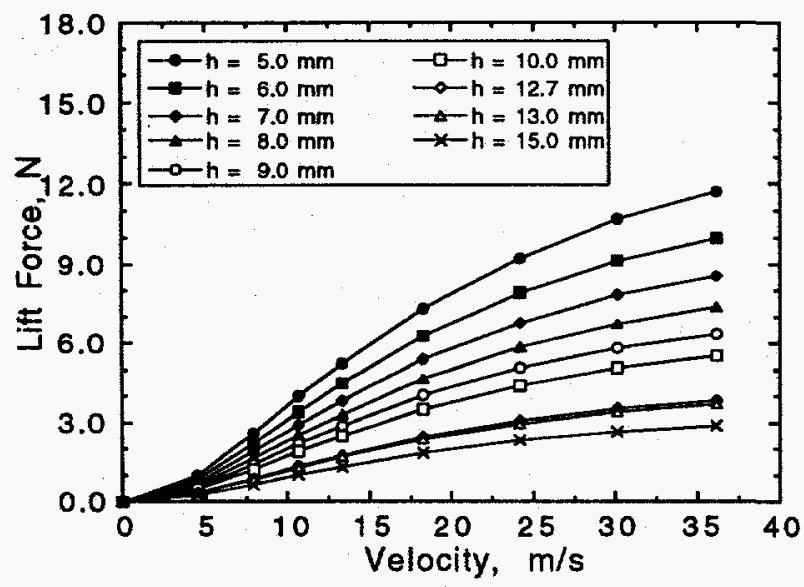

(b)

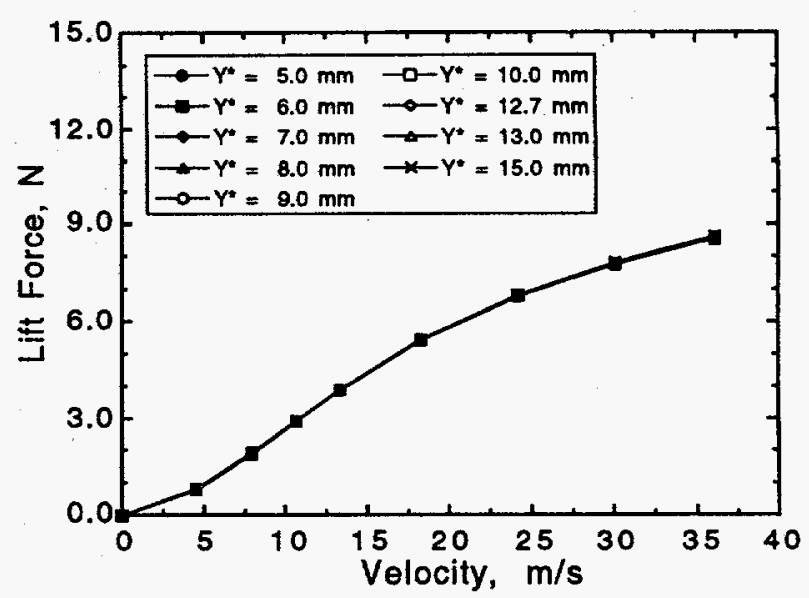

(c)

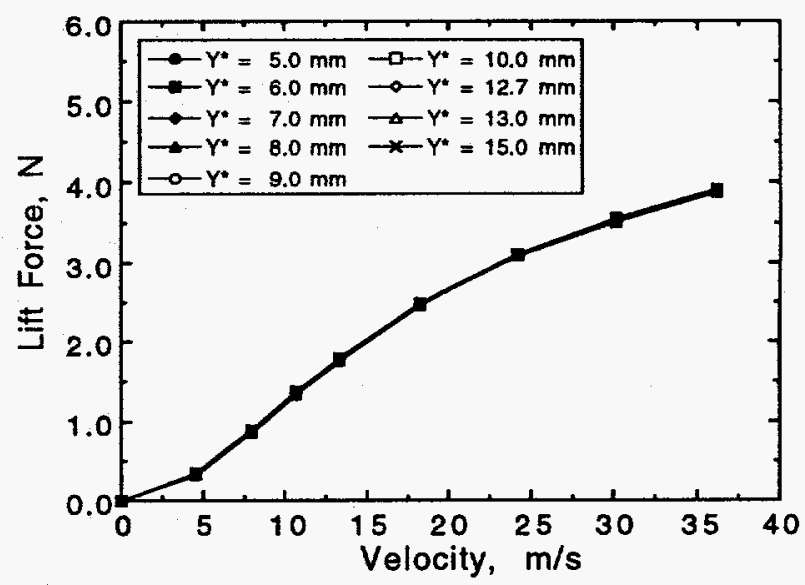

(d)

Fig. 7. Measured lift magnetic force, for various values of $h$ and $Y^{*}$, as a function of velocity when (a) $Y^{*}=5.0 \mathrm{~mm}$, (b) $Y^{*}=12.7 \mathrm{~mm}$, (c) $h=7.0 \mathrm{~mm}$, and (d) $h=12.7 \mathrm{~mm}$

The magnetic force data from experimental measurements are included in the Appendix of this report. The curve fits to magnetic forces in Figs. 4-9 were derived with polynomial expressions and input into a computer code to simulate the dynamic response of a maglev vehicle.

\subsection{Magnetic Force Computations}

A series of computations on a permanent magnet moving over an L-shaped guideway were carried out, and compared with experimental magnetic force data. The reason for conducting force computations is not only to verify experimental force data but also to provide potential theoretical support when magnetic forces cannot be obtained from experiments. Therefore, force calculations can 


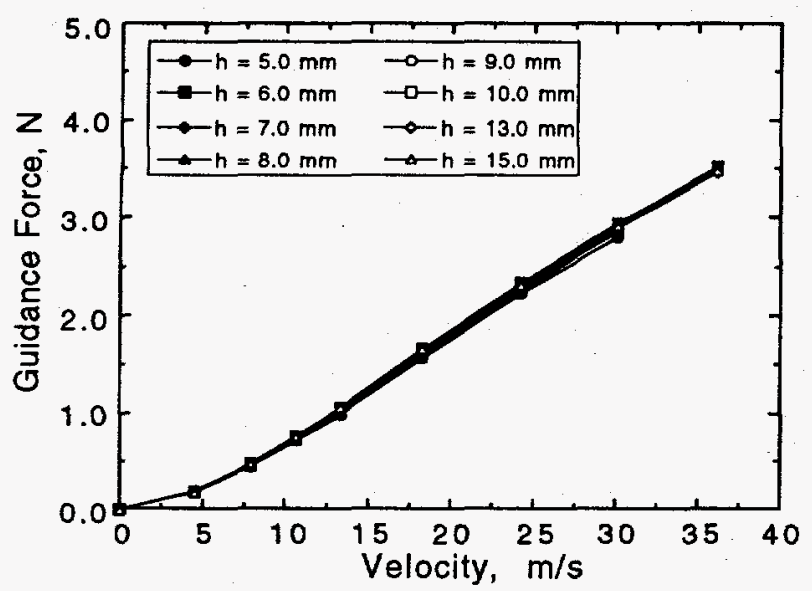

(a)

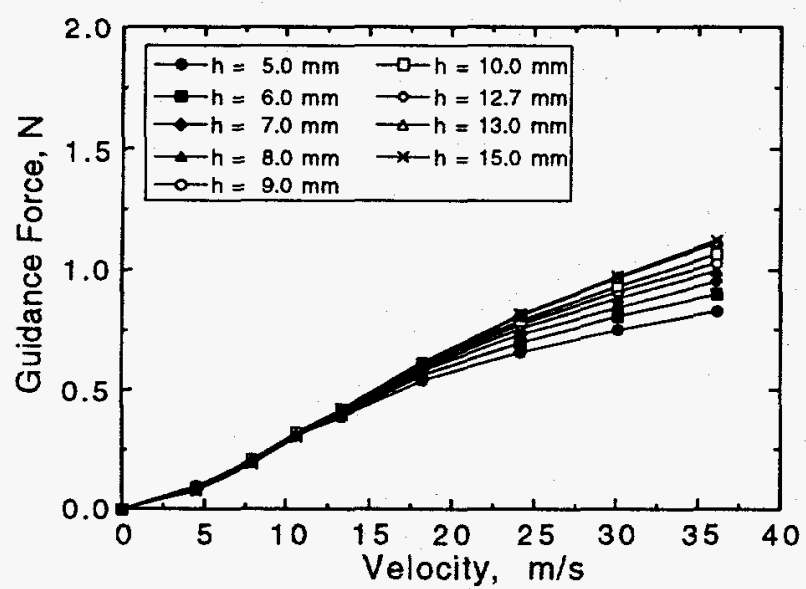

(b)

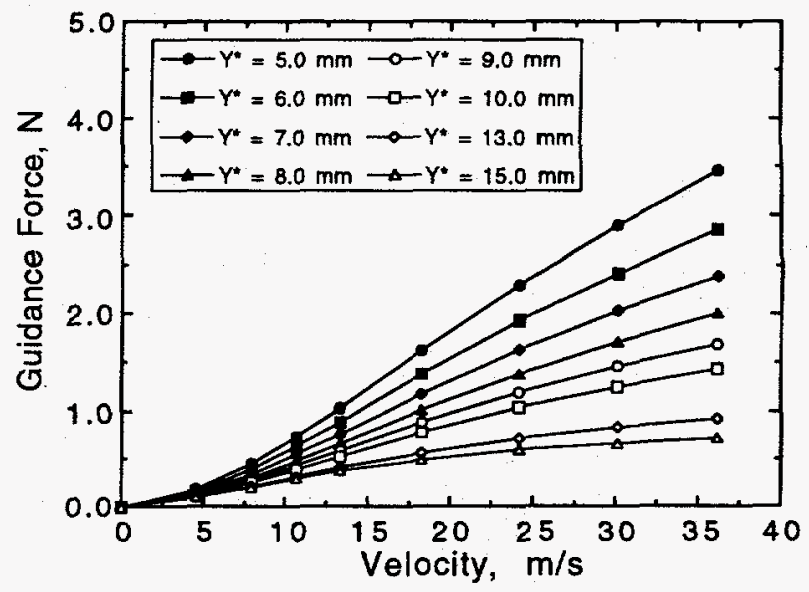

(c)

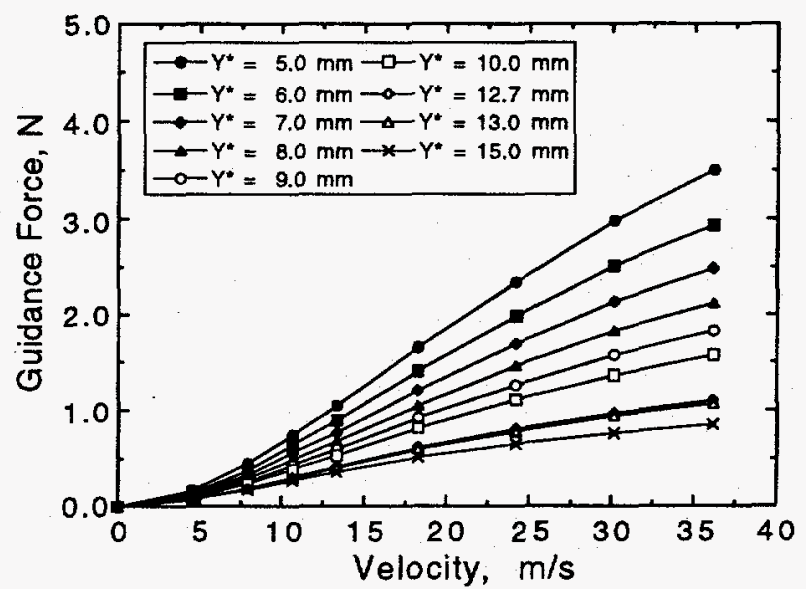

(d)

Fig. 8. Measured guidance magnetic force, for various values of $h$ and $Y^{*}$, as a function of velocity when (a) $Y^{*}=5.0 \mathrm{~mm}$, (b) $Y^{*}=12.7 \mathrm{~mm}$, (c) $h=$ $7.0 \mathrm{~mm}$, and (d) $h=12.7 \mathrm{~mm}$

be employed on the computer program of the maglev system to analyze vehicle dynamics. The force computations were conducted with different computer codes, including MAGFORCE and ELEKTRA, with the configuration and dimensions of the magnet and L-shaped guideway as shown in Fig. 3.

\subsubsection{MAGFORCE}

For a flat-plate guideway without considering transverse edge effects, MAGFORCE works very well. However, for an L-shaped guideway, MAGFORCE produces relatively large discrepancies due to modeling approximations: a finite thick rectangular permanent magnet is represented by a single-turn coil and the transverse edge of the guideway is ignored. 


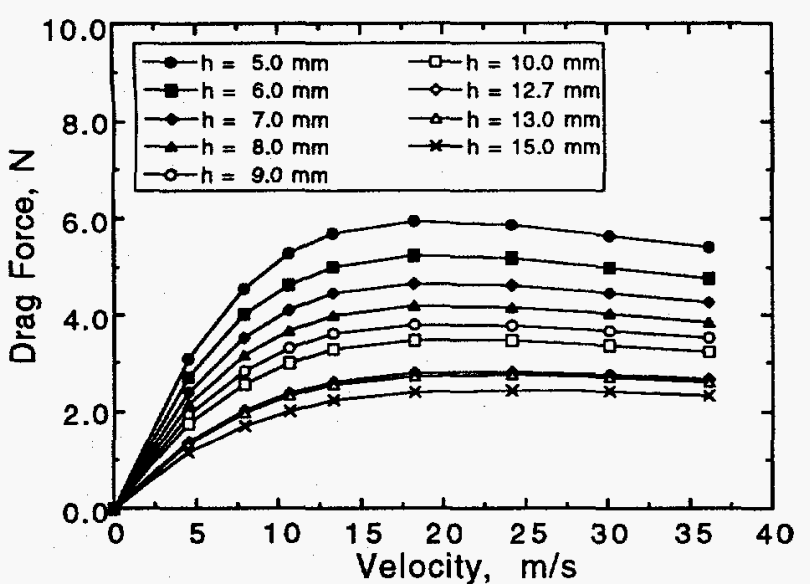

(a)

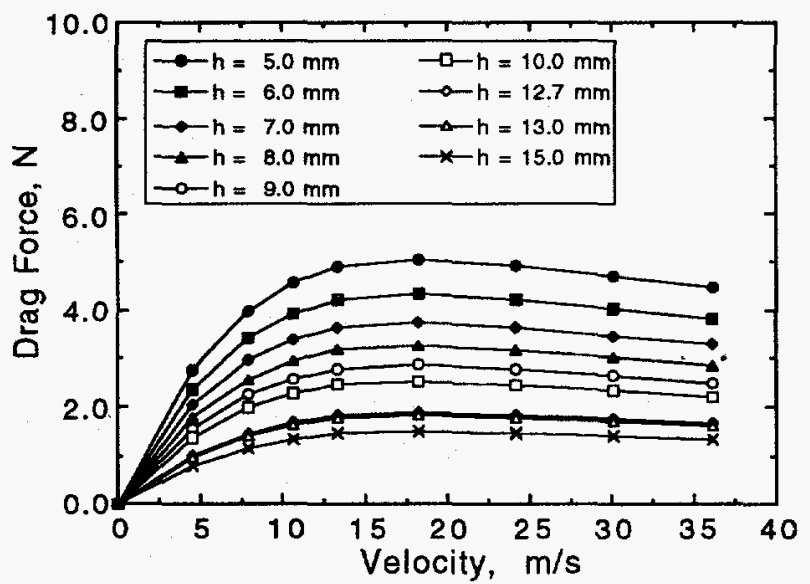

(b)

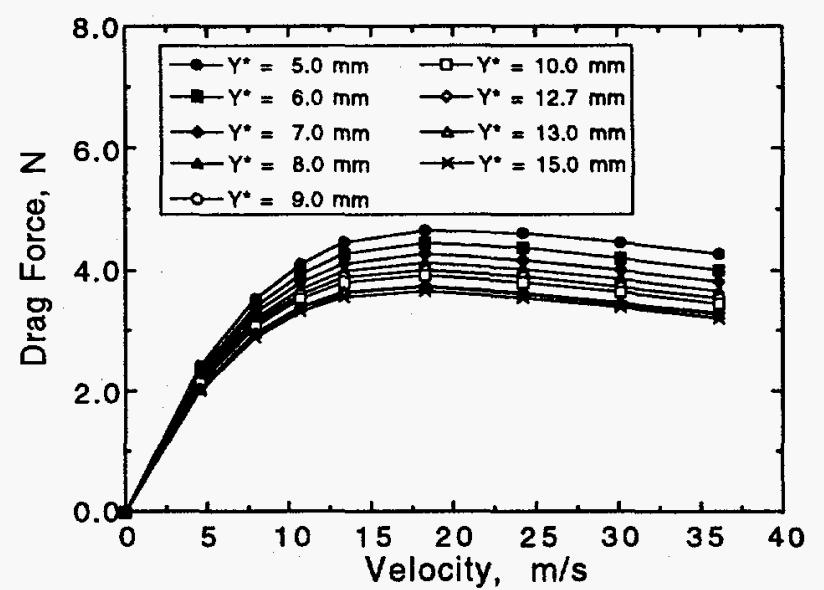

(c)

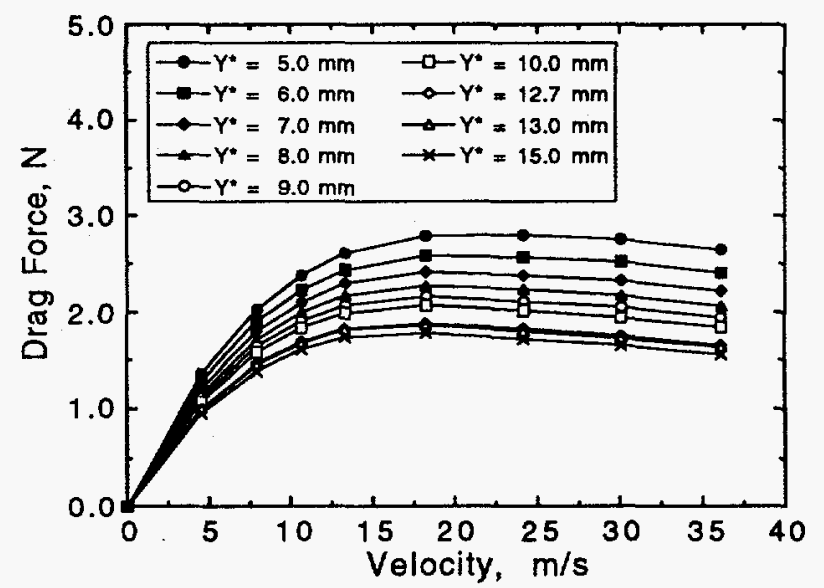

(d)

Fig. 9. Measured drag magnetic force, for various values of $h$ and $Y^{*}$, as a function of velocity when (a) $Y^{*}=5.0 \mathrm{~mm}$, (b) $Y^{*}=12.7 \mathrm{~mm}$, (c) $h=7.0$ $m m$, and $(d) h=12.7 \mathrm{~mm}$

In our experiments, we suspended a permanent magnet over an L-shaped guideway. Because MAGFORCE does not simulate a permanent magnet directly, an equivalent coil must be used to simulate the permanent magnet. We assumed that the dimensions of the coil are the same as those of the magnet (5.08 $\times$ $2.54 \mathrm{~cm}$ ), and located the coil in the middle of the magnet, as shown in Fig. 10 . This kind of coil model was used in flat-plate guideway problems, and it worked very well. However, for L-shaped guideway problems, large errors were produced, especially for drag and guidance forces. Figures 11-15 show the force results, which show that lift forces match experimental data reasonably well. But discrepancies up to $50 \%$ were noted for drag and guidance forces. 
Equivalent Coil

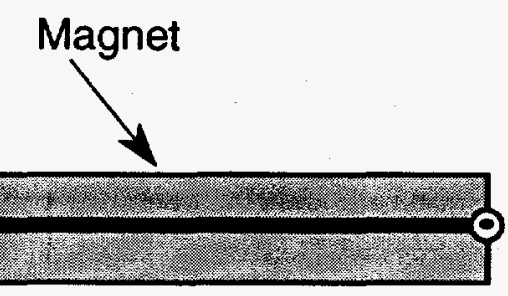

Fig. 10. Magnet and equivalent coil

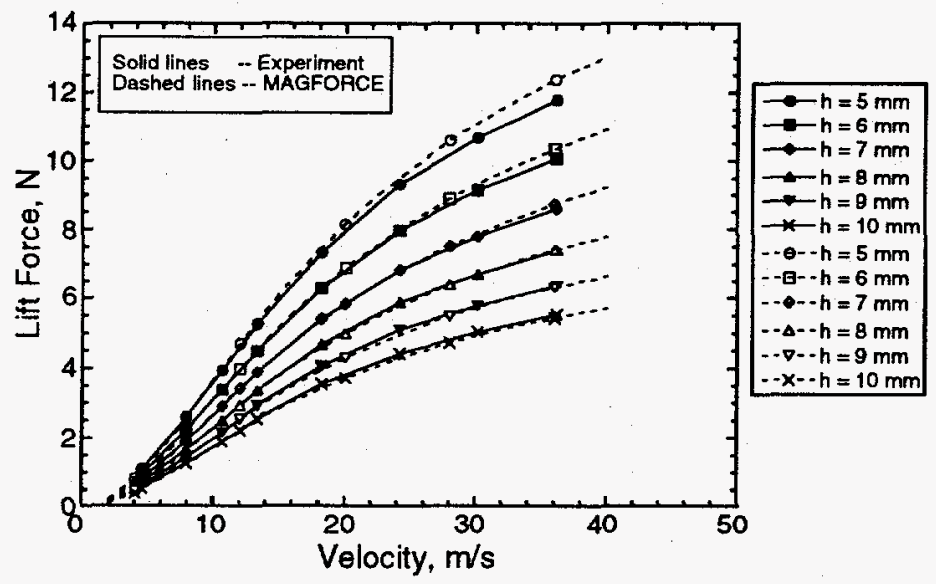

Fig. 11. Measured and MAGFORCE-calculated lift forces when $Y^{*}=12.7 \mathrm{~mm}$

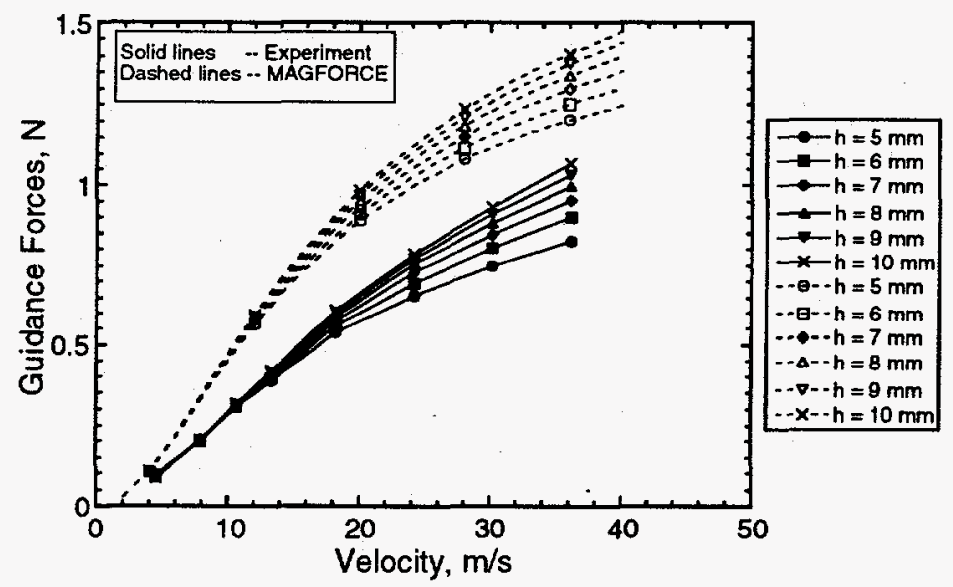

Fig. 12. Measured and MAGFORCE-calculated guidance forces when $Y^{*}=12.7 \mathrm{~mm}$ 


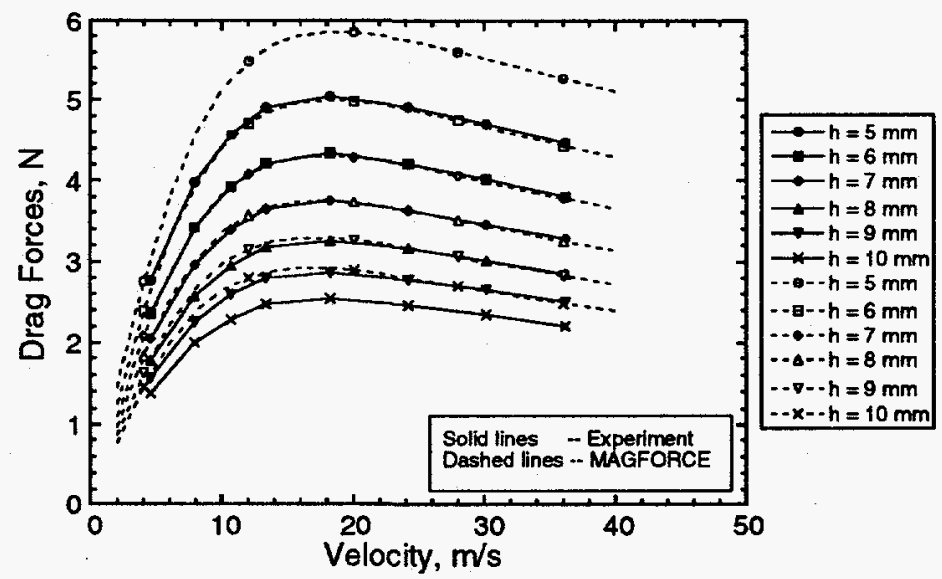

Fig. 13. Measured and MAGFORCE-calculated drag forces when $Y^{*}=12.7 \mathrm{~mm}$

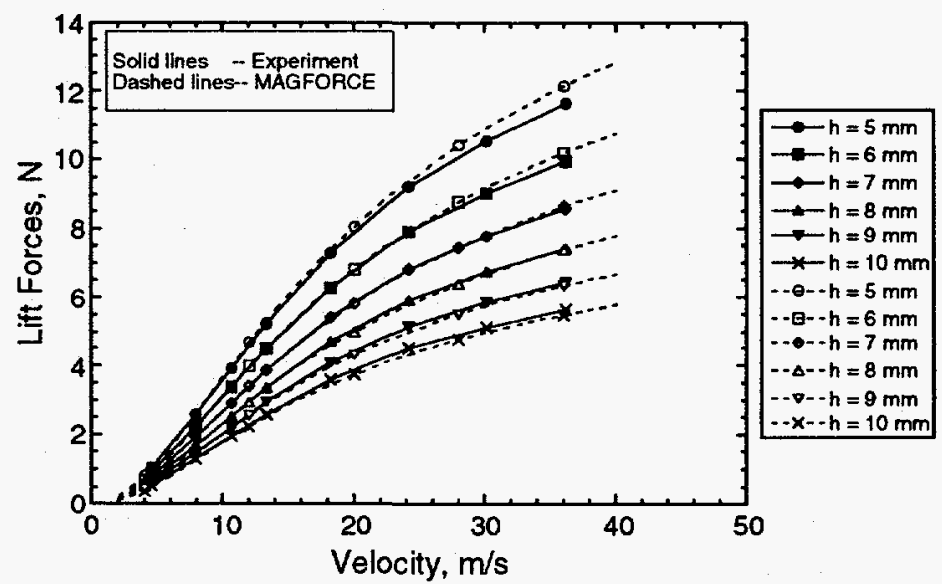

Fig. 14. Measured and MAGFORCE-calculated lift forces when $Y^{*}=5 \mathrm{~mm}$

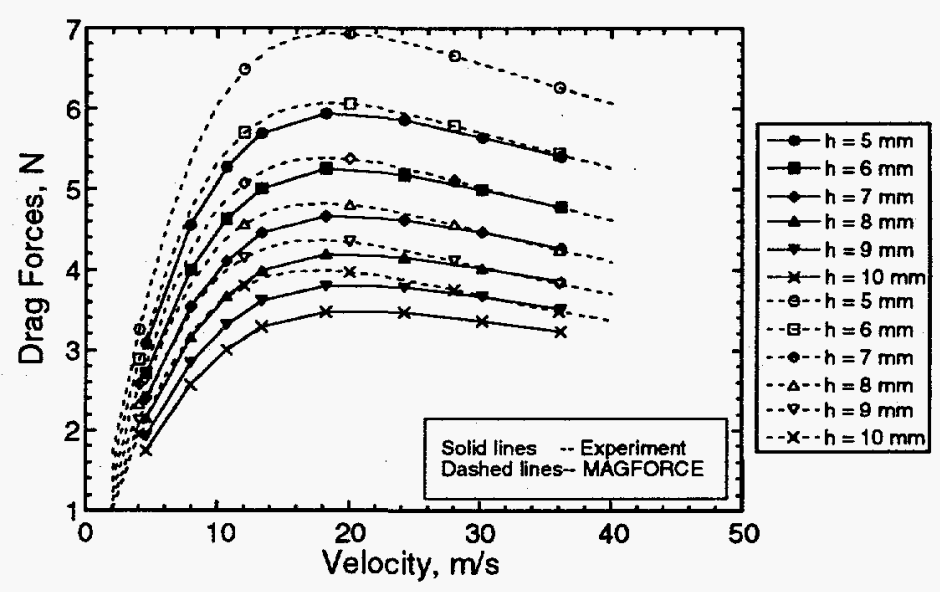

Fig. 15. Measured and MAGFORCE-calculated drag forces when $Y^{*}=5 \mathrm{~mm}$ 
A possible reason for the discrepancies is that the coil was located in the middle plane of the magnet instead of on the bottom surface of the magnet. An alternative was proposed that it should also be located elsewhere but not on the surface facing the guidance plate. Because the thickness of the magnet is $6.35 \mathrm{~mm}$, the dimensions of equivalent coils are assumed to be $4.45 \times 1.91 \mathrm{~cm}$, as shown in Fig. 16. MAGFORCE results obtained with this alternative coil are shown in Figs. 17-19. Discrepancies are smaller than those of the previous model, but the shapes of the guidance force curves obtained from MAGFORCE are different from those that were obtained from experiments.

MAGFORCE was developed at ANL by $\mathrm{H}$. Coffey and is based on a published Fourier transformation formulation (Coffey et al., 1972).

For design purposes, MAGFORCE is useful because it will give us an approximation of the steady-state capabilities for levitation, guidance, and propulsion. However, it does not model a permanent magnet and L-shaped guideway accurately enough to predict dynamic effects, which also depend on force gradients. However, it is not accurate enough for theoretical analysis.

\subsubsection{ELEKTRA}

The velocity version of ELEKTRA is a finite-element computer code, developed by Vector Fields, Ltd.; it is capable of solving three-dimensional eddycurrent problems with a moving conductor.

Theoretically, ELEKTRA can be used to analyze any kind of eddy current problems with complex geometries. It has been successfully used to analyze flat plate guideway and edge effect problems. Here, we use it to analyze the L-shaped guideway problem.

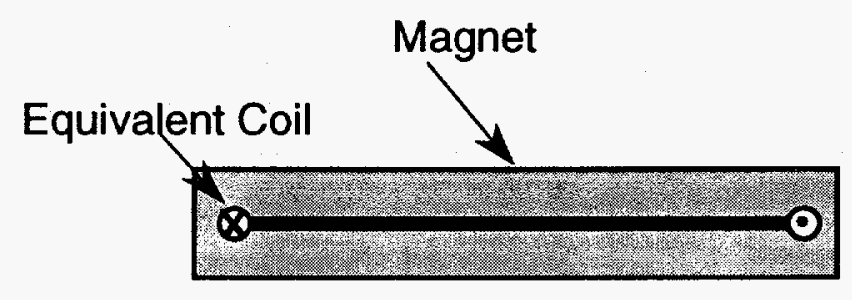

Fig. 16. Alternative magnet and equivalent coil 


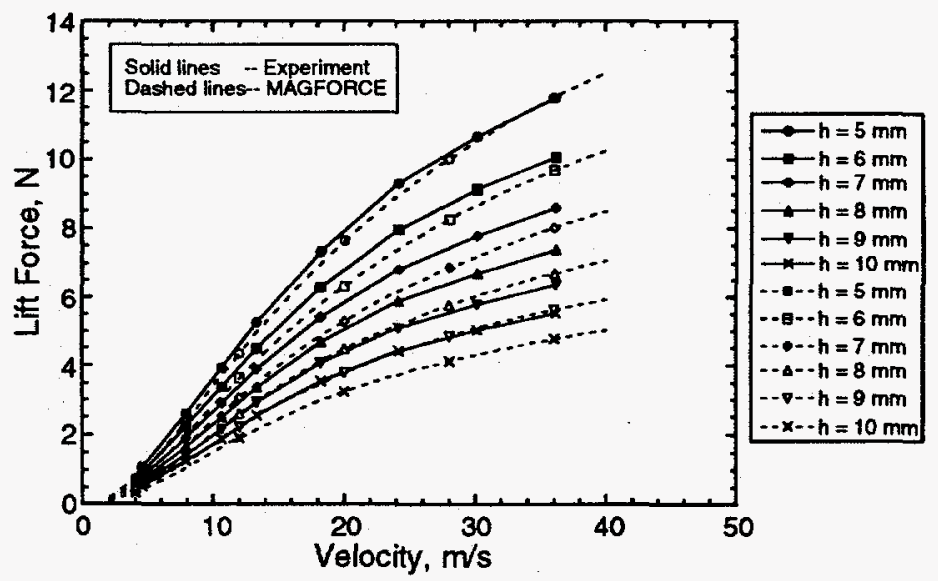

Fig. 17. Measured and MAGFORCE-calculated lift forces when $Y^{*}=12.7 \mathrm{~mm}$

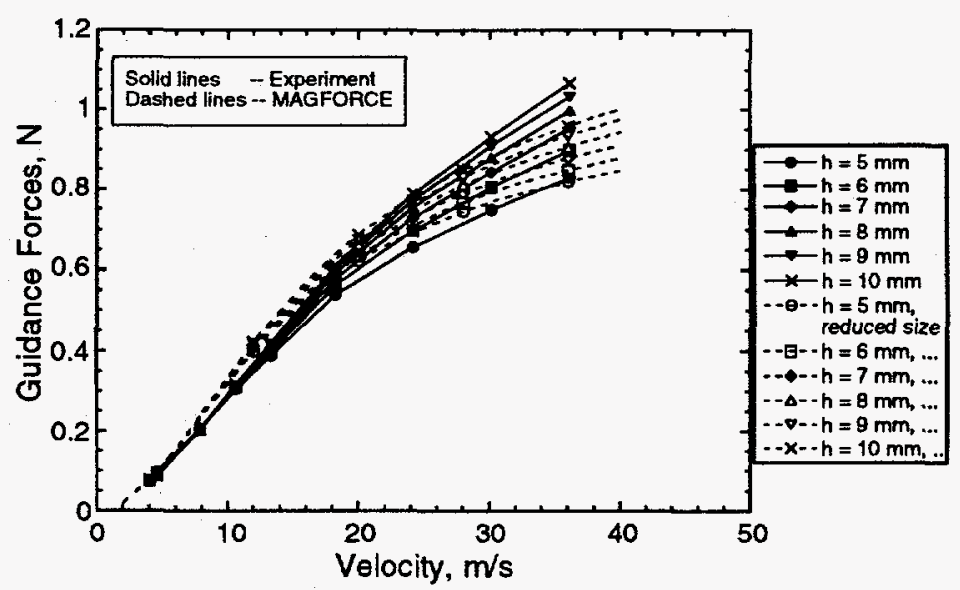

Fig. 18. Measured and MAGFORCE-calculated guidance forces when $Y^{*}=12.7 \mathrm{~mm}$

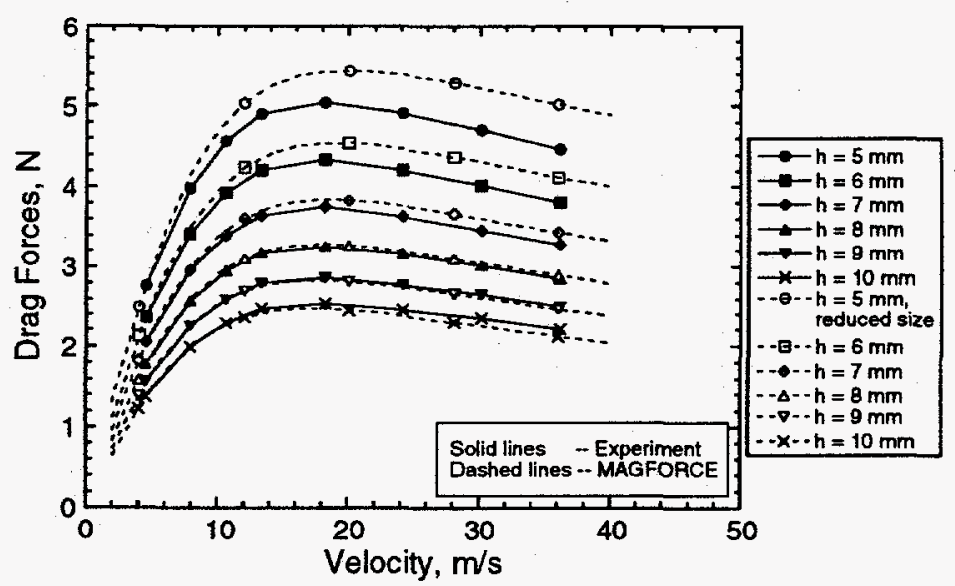

Fig. 19. Measured and MAGFORCE-calculated drag forces when $Y^{*}=12.7 \mathrm{~mm}$ 
Since ELEKTRA does not simulate a permanent magnet directly, an equivalent coil must be used to simulate the permanent magnet. Therefore, equivalent ampere turns (A-T) of the coil must be determined. One way to determine the ampere turns is to compare the amplitude and shape of the magnetic field in the gap between the magnet (coil) and the conductor sheet. When this technique is used, a coil equivalent to the magnet used in the experiments would have 5,994 A-T. The outer dimensions of the coil used in ELEKTRA correspond exactly to the outer dimensions of the permanent magnet used in the experiment, and the coil cross section is $1 \mathrm{~mm}$ wide by $6.35 \mathrm{~mm}$ high.

During construction of the mesh, one should make the mesh distribution around and inside the coil as fine as possible to obtain more accurate force computations. The total number of nodes for our case is $\approx 13,000-16,000$, and computational time for one velocity is $\approx 2-8 \mathrm{~h}$, depending upon the velocity.

Figure 20 shows lift, drag, and guidance forces vs. velocity calculated for $\mathrm{h}=$ $12.7 \mathrm{~mm}$ and $\mathrm{L}=12.7 \mathrm{~mm}$. ELEKTRA results agree well with experimental data. However, ELEKTRA is too time consuming. It sometimes required 6-8 $\mathrm{h}$ (20003000 iterations) at a SUN work station to obtain converged solutions.

Figures 21-23 illustrate forces vs. velocity for $\mathrm{L}=5 \mathrm{~mm}$. Figures 24-26 show forces vs. velocity for $\mathrm{h}=7 \mathrm{~mm}$. All ELEKTRA results are in good agreement with experimental data. However, ELEKTRA has two shortcomings: it is too time consuming, as mentioned above, and it sometimes has difficulty in achieving convergence, even though the velocity is not high, e.g., $25 \mathrm{~m} / \mathrm{s}$. In addition,

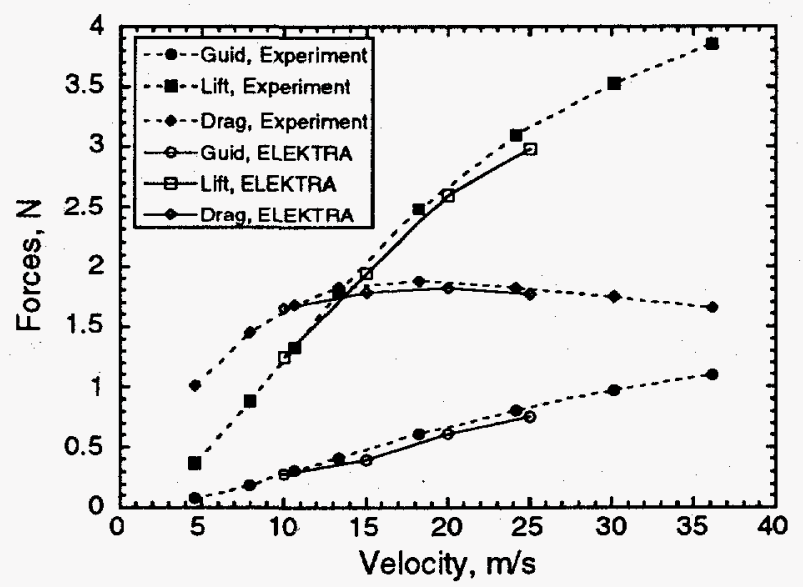

Fig. 20. Measured and ELEKTRA-calculated lift, guidance, and drag forces when $Y^{*}=$ $12.7 \mathrm{~mm}$ 


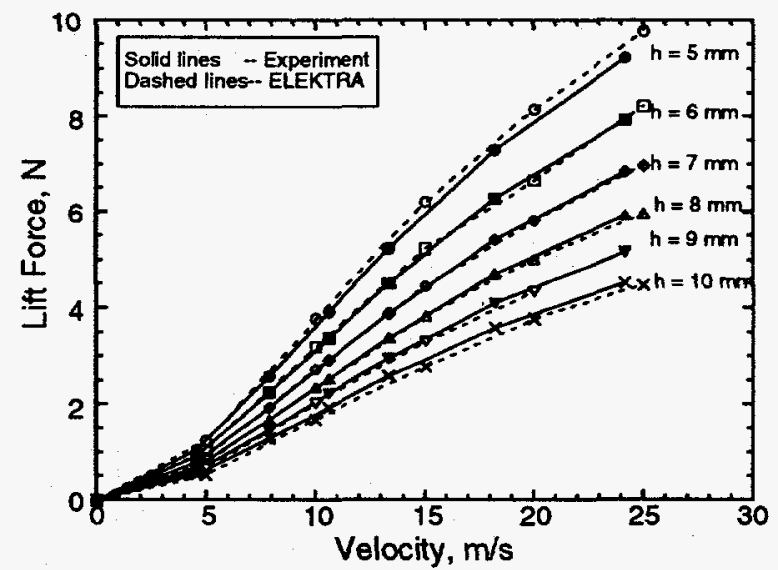

Fig. 21. Measured and ELEKTRA-calculated lift forces when $Y^{*}=5 \mathrm{~mm}$

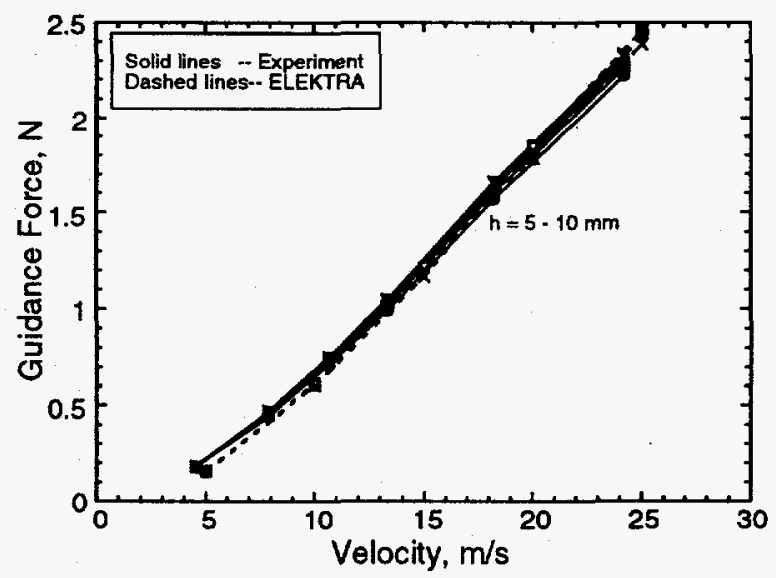

Fig. 22. Measured and ELEKTRA-calculated guidance forces when $Y^{*}=5 \mathrm{~mm}$

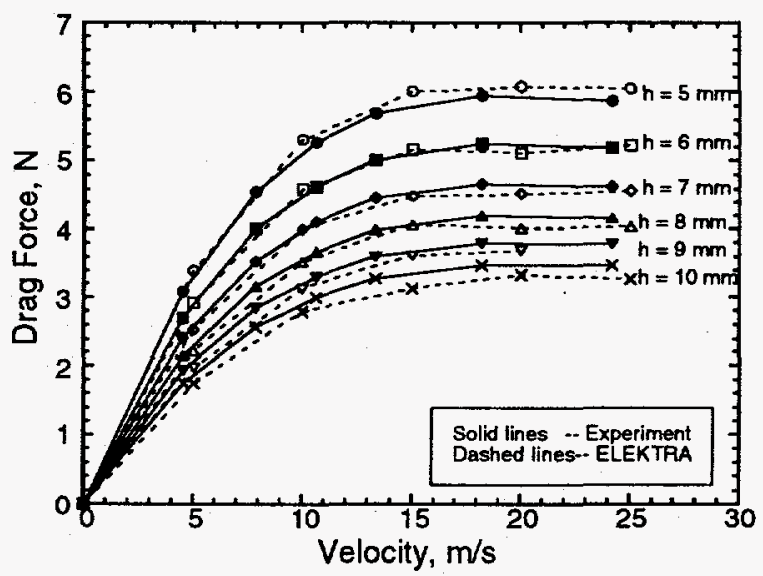

Fig. 23. Measured and ELEKTRA-calculated drag forces when $Y^{*}=5 \mathrm{~mm}$ 


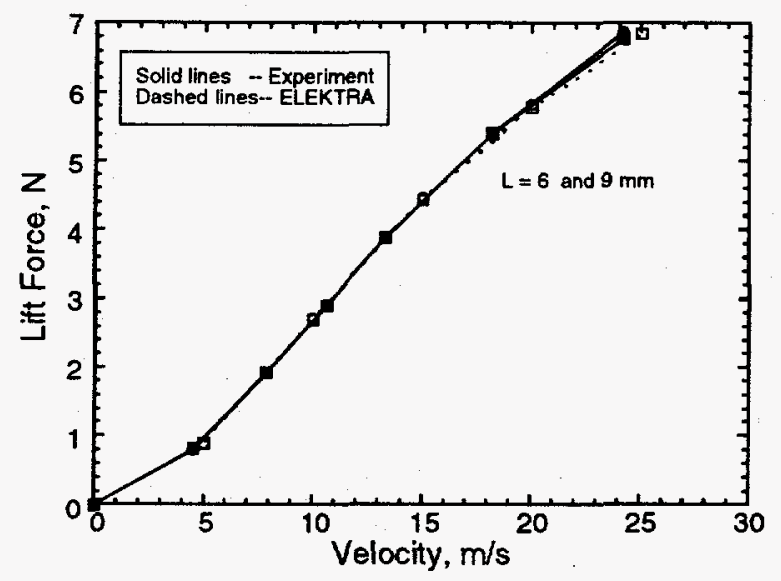

Fig. 24. Measured and ELEKTRA-calculated lift forces when $h=7 \mathrm{~mm}$

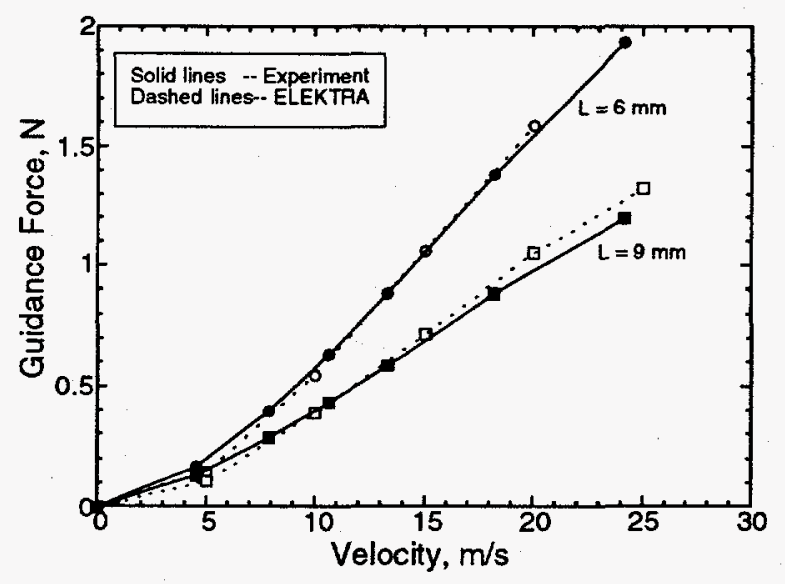

Fig. 25. Measured and ELEKTRA-calculated guidance forces when $h=7 \mathrm{~mm}$

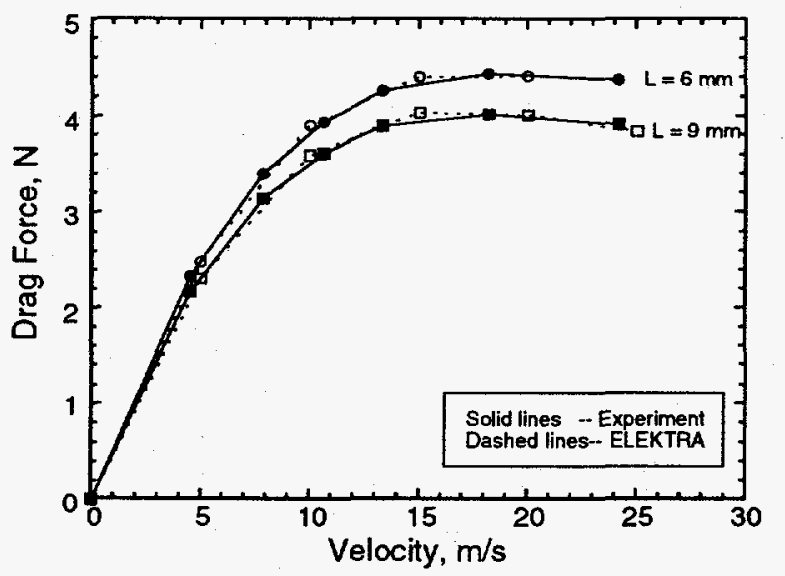

Fig. 26. Measured and ELEKTRA-calculated drag forces when $h=7 \mathrm{~mm}$ 
ELEKTRA has been verified as a means of calculating steady-state magnetic forces, but dynamic forces (of damping) must still be measured.

\subsection{Measuring Magnetic Forces of Guidance Magnets}

Because the $25.4 \times 50.8 \times 6.35-\mathrm{mm}$ rectangular magnet shown in Fig. 3 cannot provide sufficient guidance force for a maglev vehicle moving on an L-shaped aluminum guideway, additional guidance magnets are needed to increase guidance force and vehicle stability. A rectangular $12.7 \times 50.8 \times 6.35-\mathrm{mm}$ magnet was selected as a guidance magnet. The measurement of lift and drag forces was conducted by setting the magnet on a rotating drum covered with a $14.61-\mathrm{cm}$-wide, $6.35-\mathrm{mm}$-thick aluminum sheet rolled to a diameter of $26.99 \mathrm{~cm}$. The rotating speed can be varied from 0 to $3500 \mathrm{rpm}$; therefore, the speed of the wheel is $0-50 \mathrm{~m} / \mathrm{s}$ (the detailed experimental setup can be found in Chen et al., 1993). The configuration of the guidance magnet is shown in Fig. 27, where the distance between the magnet and the aluminum sheet is $h$.

The measured lift and drag forces of the guidance magnet as a function of velocity are plotted in Fig. 28, with h fixed at $8.5,13.5$, and $18.5 \mathrm{~mm}$. Lift and drag force data are included in the Appendix. The curve fits to magnetic forces in Fig. 28 were derived with polynomial expressions and incorporated into a computer code for dynamic simulation of a maglev vehicle.

magnet

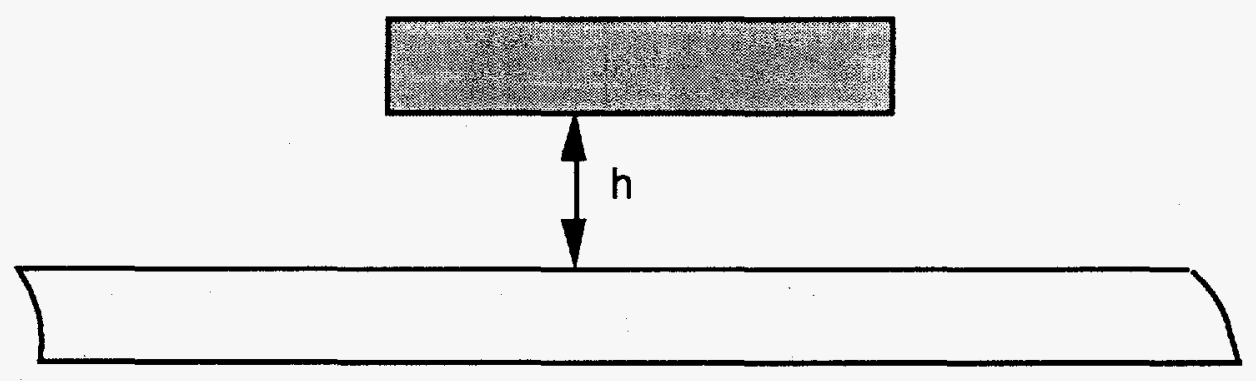

Fig. 27. Guidance magnet on aluminum sheet guideway 


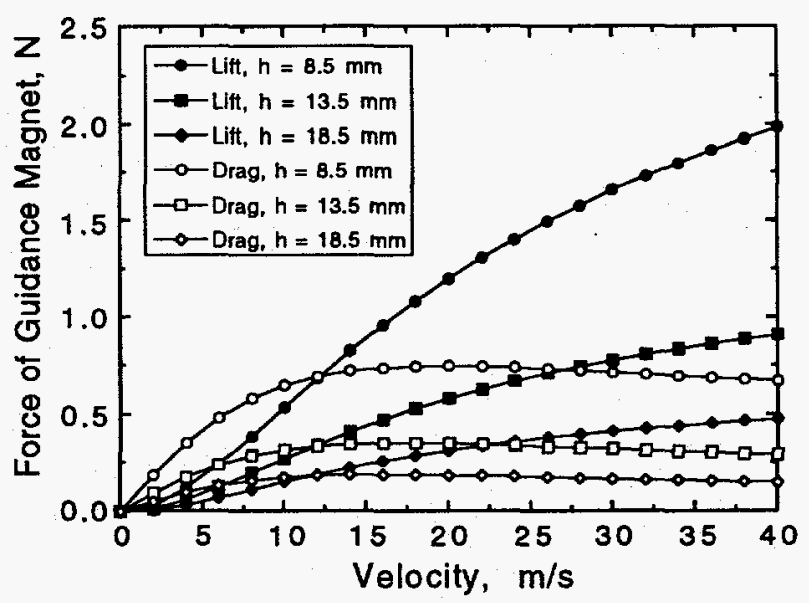

Fig. 28. Measured lift and drag magnetic forces of guidance magnet as a function of velocity

\section{Dynamic Stability Experiments}

The experimental apparatus for maglev dynamic stability investigation is shown in Fig. 29. Two L-shaped aluminum tracks, like an inverted T, are mounted over a rotating wheel. The maglev vehicle is magnetically levitated over the aluminum track when the wheel rotates with constant but adjustable speed. The vehicle, constrained in its longitudinal direction by a metal tether attached to its front, is free to move in up to five modes (vertical heave, lateral slip, pitch, yaw, and roll). The wheel diameter is $1.2 \mathrm{~m}$. The wheel rotating speed can be adjusted from 0 to $600 \mathrm{rpm}$ (or 0 to $37.7 \mathrm{~m} / \mathrm{s}$ on the surface of the wheel).

A force transducer is attached between the tether and support frame; therefore, the drag force applied to the vehicle can be measured. Several small accelerometers are installed on the vehicle body to measure vehicle motion by double analog integration. Displacement and force signals are first filtered by band-pass filters to eliminate low- and high-frequency noises and then digitized and stored in the analyzer. These signals are then analyzed to obtain frequencies and displacements of vehicle motion as a function of wheel speed. 


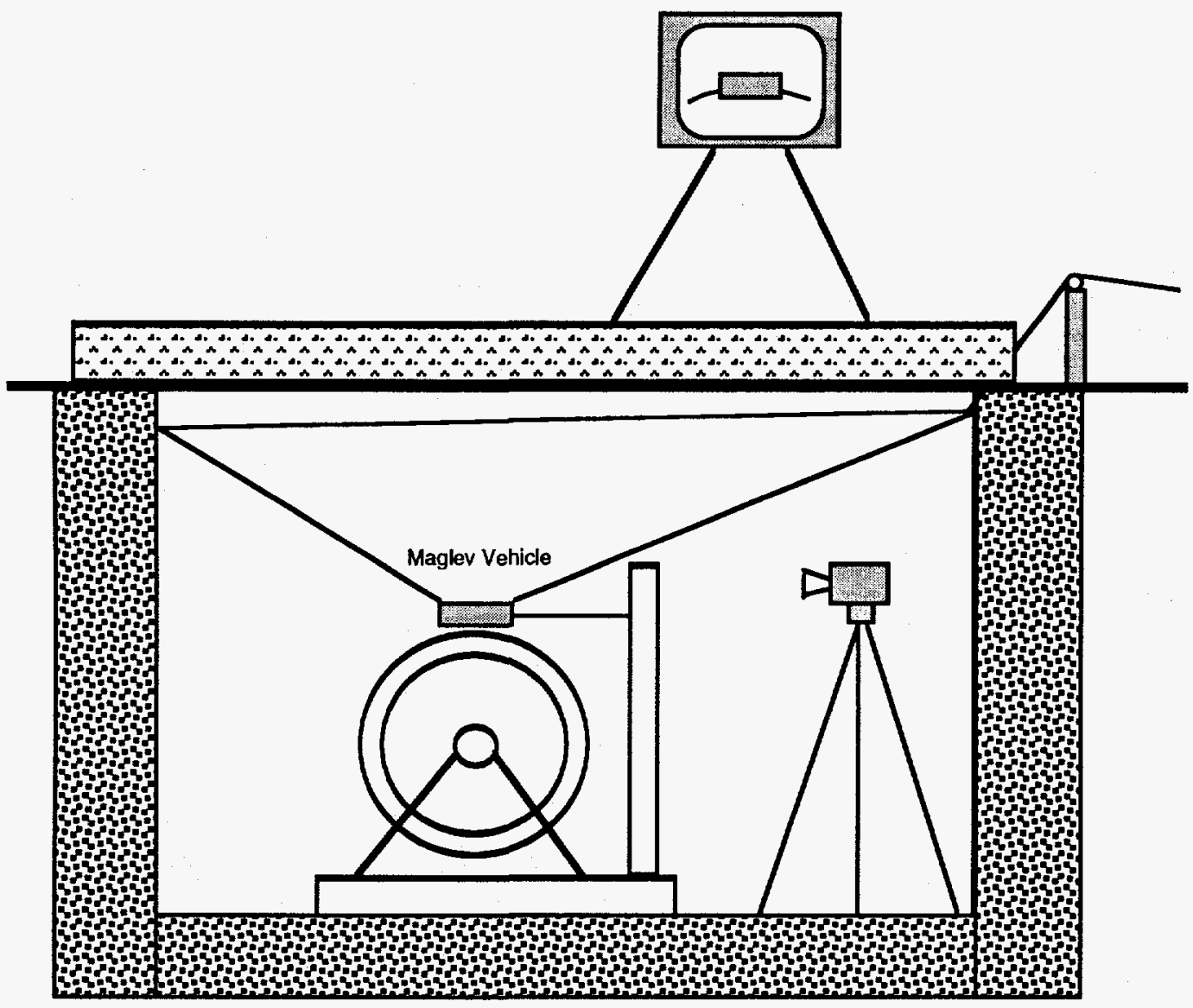

Fig. 29. Schematic diagram of experimental apparatus for testing maglev dynamic stability

For safety, the experimental apparatus is placed in an underground room with heavy concrete covers. A video camera is set beside the wheel. The test runs can be observed from a TV set and recorded in a VCR aboveground.

A fishing line is attached to each of the vehicle's four corners to control the position of the vehicle, like moving a puppet. When the vehicle is levitated, the fishing lines are loose; if instability occurs, the vehicle must be pulled out of the track to prevent damage to the vehicle and magnets; when the experiments are over, the vehicle is hung over the wheel.

The object of this experiment was to investigate the existence of instability in maglev systems. The term instability refers to motions that depart from equilibrium state and are distinguished from random oscillations due to track 
irregularities and from resonance-driven oscillations associated with the circular nature of the rotating guideway (Chu and Moon, 1983).

Two series of tests (A and B) were performed with a free vehicle moving on a double L-shaped aluminum guideway mounted on the top of the rotating wheel. In Test $A$, a vehicle model was supported by four permanent magnets on four corners, whereas in Test B, four magnets for levitation and four magnets for guidance were attached to the vehicle. The vehicle's motion in five directions was measured by double analog integration. When the rotating speed of the wheel was varied, stable and unstable motions of the maglev vehicle were observed and recorded.

\subsection{Test A}

A vehicle model with four $25.4 \times 50.8 \times 6.35-\mathrm{mm}$ rectangular levitation magnets is shown in Fig. 30. The vehicle body was made of fiberglass/epoxy (GIO) sheet. Dimensions of the vehicle are indicated in Fig. 30. A shaft, which is attached to the tether and placed in the lateral center, can move back and forth in the longitudinal direction, which constrains the DOF of the vehicle. Two accelerometers are installed on the vehicle to measure vertical and lateral motion.

To identify the regions of stability of the vehicle model, several runs were performed with various vehicle conditions, such as, changing lateral gaps to vary guidance forces, adding mass to vary vertical gaps and lift forces, and centering or offsetting the shaft. Dynamic instability was observed in most of vehicle conditions.

Figure 31 shows typical experimental results. In this test, the total mass of the vehicle was $2.12 \mathrm{~kg}$. The lateral gap was set at $155.6 \mathrm{~mm}$ (see Fig. 30). The test was run from a high speed of $595 \mathrm{rpm}$ to a low speed of $128 \mathrm{rpm}$ (if the speed is too low, the lift forces cannot levitate the vehicle). Vertical and lateral displacements were measured with accelerometers by analog integration. Drag force was measured by a force transducer between the tether and the frame. Three cases, with various shaft positions (in the center, and offset 50.8 and $76.2 \mathrm{~mm}$ ) were plotted in Fig. 31, in terms of RMS vertical and lateral displacements and RMS force as function of wheel speed. At least four speed regions were found by both 

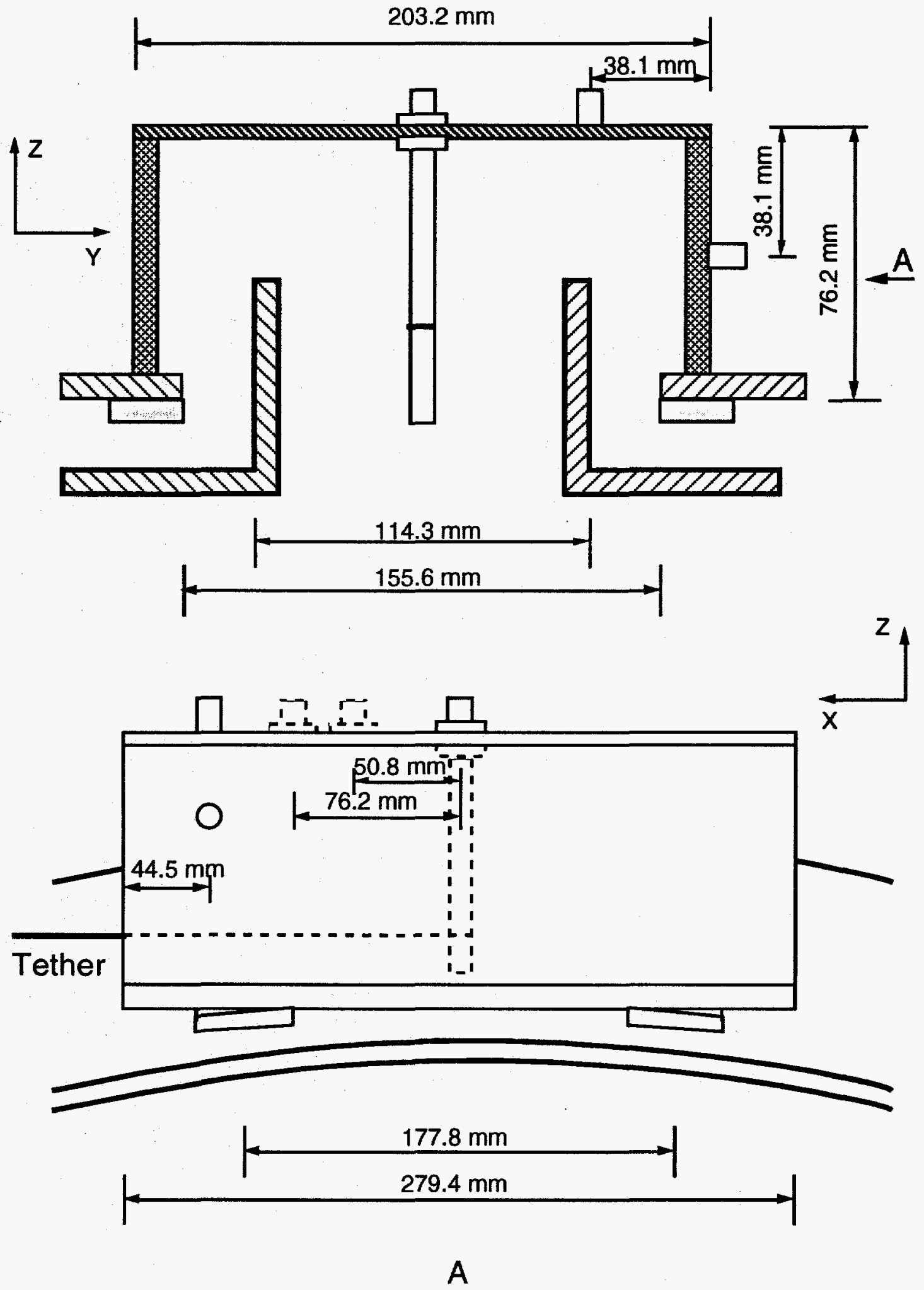

Fig. 30. Vehicle model with four levitation magnets in Test A 

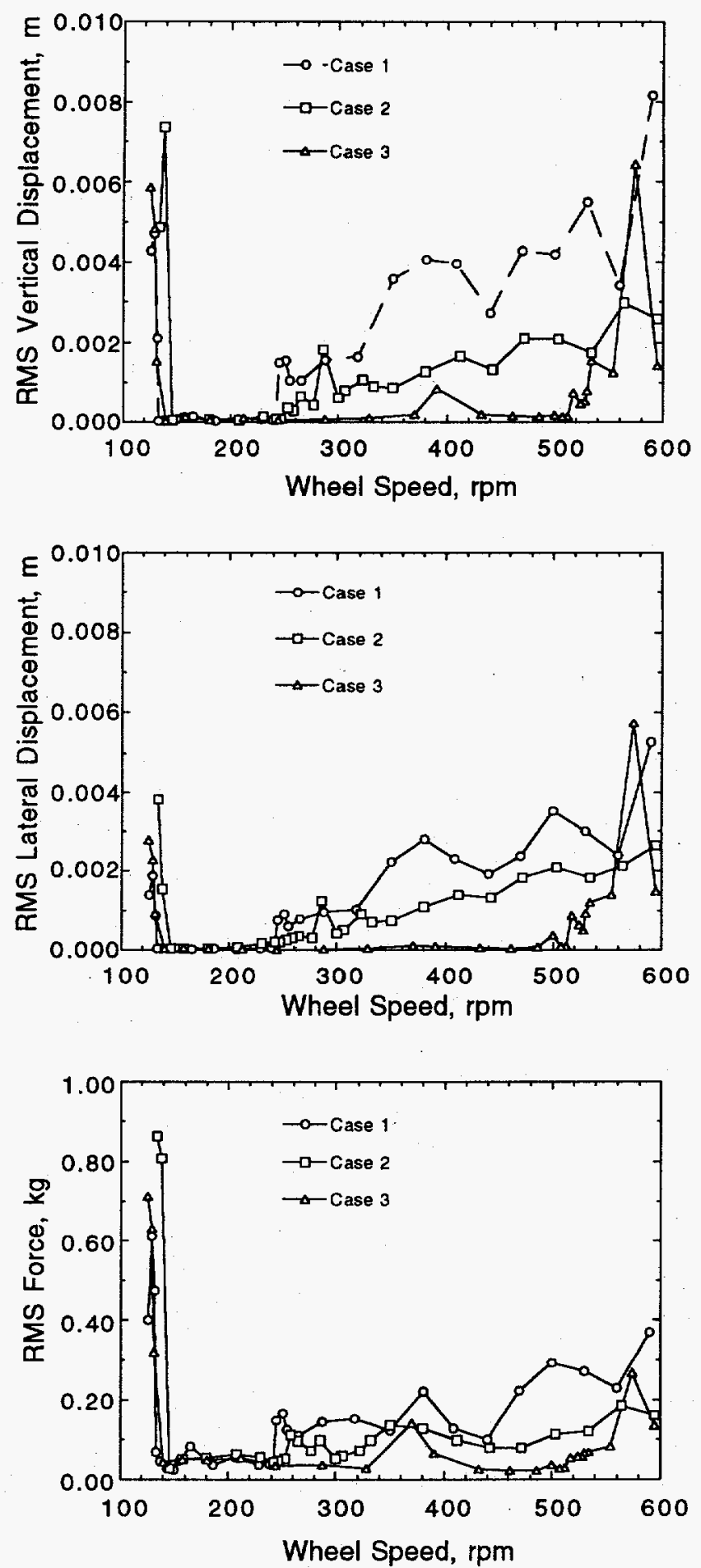

Fig. 31. Experimental results from Test A; Case 1 = shaft centered, Case 2 = shaft offset $50.8 \mathrm{~mm}$, Case $3=$ shaft offset $76.2 \mathrm{~mm}$ 
measurement and observation. For example, consider the case with the shaft in the center (Case 1). (1) When the speed is lower than $132 \mathrm{rpm}$, the vehicle is unstable, with high frequency flutter due to a large drag force. (2) When the speed is between 132 and $245 \mathrm{rpm}$, the vehicle is stable, amplitudes of displacement and force are relatively small, and the power spectral densities (PSD) show clear harmonic peaks. (3) When the speed is between 245 and $471 \mathrm{rpm}$, the vehicle is unstable and dominated by slide and yaw instability (divergence), and the oscillating frequency is quite low. (4) When the speed is over $471 \mathrm{rpm}$, the vehicle is unstable in almost every direction and the oscillation amplitudes in five directions increase significantly. Cases 2 and 3 show the same trends for four speed regions.

From observation and analysis, the vehicle model with four magnets (see Fig. 30) is likely to develop a divergence instability because the guidance force provided by the magnet on the L-shaped guideway is quite small when compared with lift and drag forces (see Section 2). Therefore, a new vehicle with additional guidance magnets was assembled and tested in Test $B$.

\subsection{Test B}

A vehicle model with four $25.4 \times 50.8 \times 6.35$-mm levitation magnets and four $12.7 \times 50.8 \times 6.35-\mathrm{mm}$ guidance magnets is schematically shown in Fig. 32. The clearances between the sheet guideway and guidance and levitation magnets can be set at several values. Four small wheels are attached to the vehicle to prevent damage from dynamic instability. The vehicle weight is $2.502 \mathrm{~kg}$ or $24.52 \mathrm{~N}$. Moments of inertia from measurement are $0.4389,0.2840$, and $0.1920 \mathrm{kgm}^{2}$ for $\mathrm{x}$, $\mathrm{y}$, and $\mathrm{z}$ axes, respectively.

In addition to the force transducer, six accelerometers were placed on the vehicle (Fig. 33): four ( $\mathrm{Z1}, \mathrm{Z2}, \mathrm{Z3}$, and $\mathrm{Z4}$ ) at the four corners of the vehicle in the vertical direction and two ( $\mathrm{Y} 1$ and $\mathrm{Y} 2$ ) at two corners of one side of the vehicle, in the lateral direction. Accelerations were doubly integrated to obtain displacement. Therefore, vehicle motion, including vertical heave, lateral slide, pitch, yaw, and roll can be calculated from measured displacements as follows: 


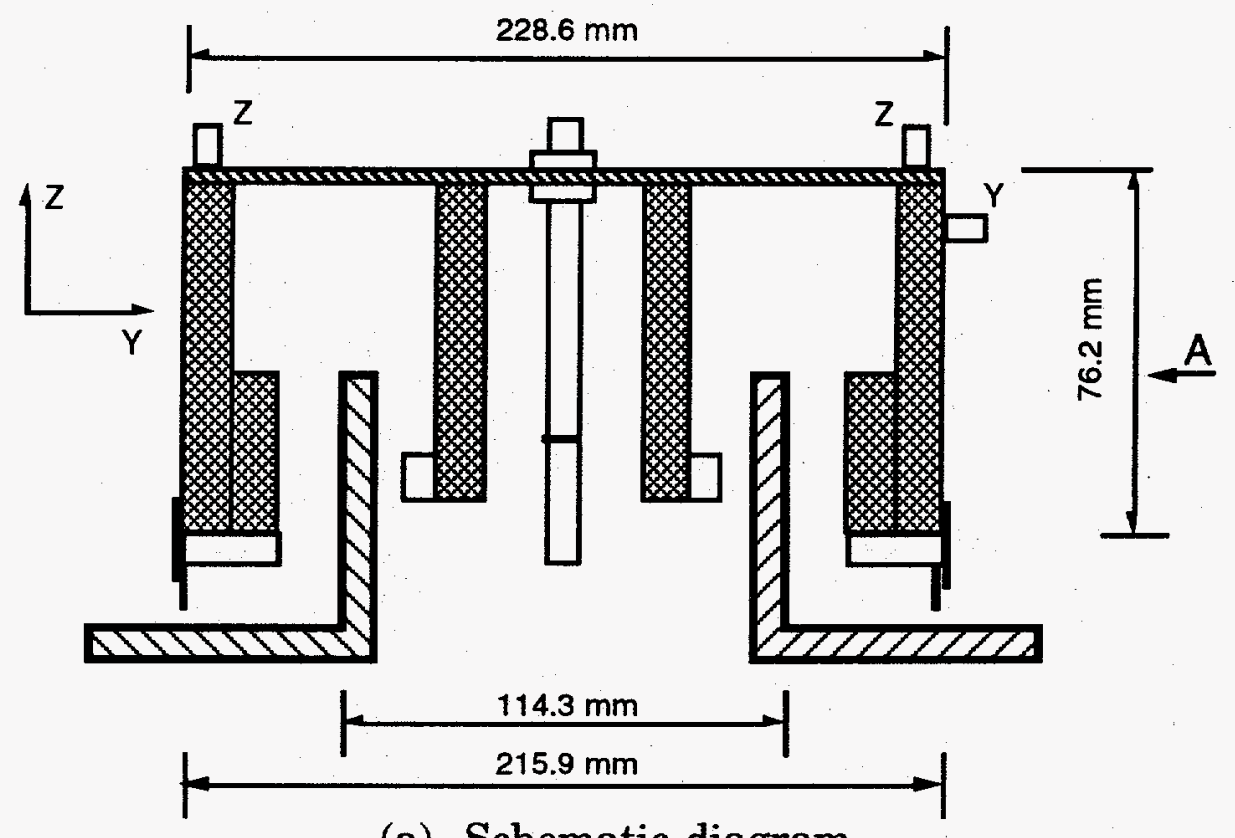

(a) Schematic diagram
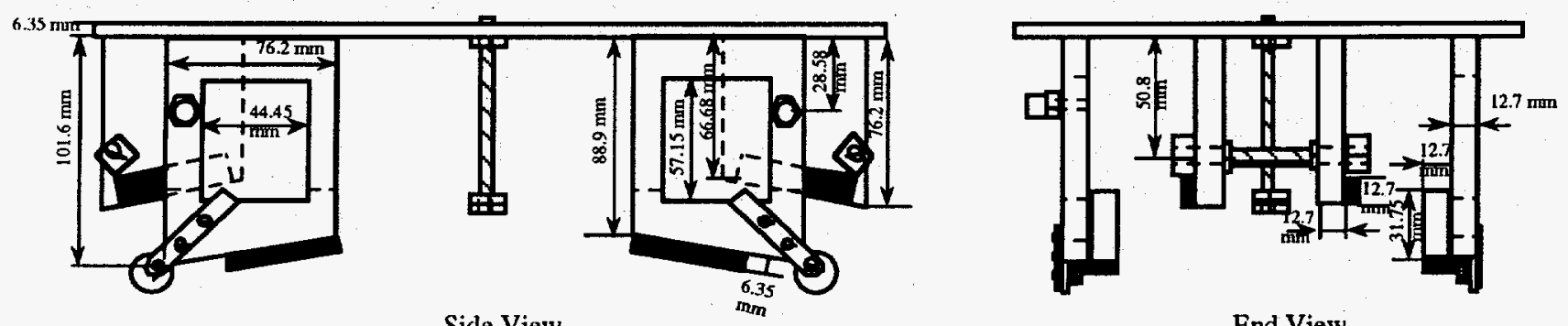

End View

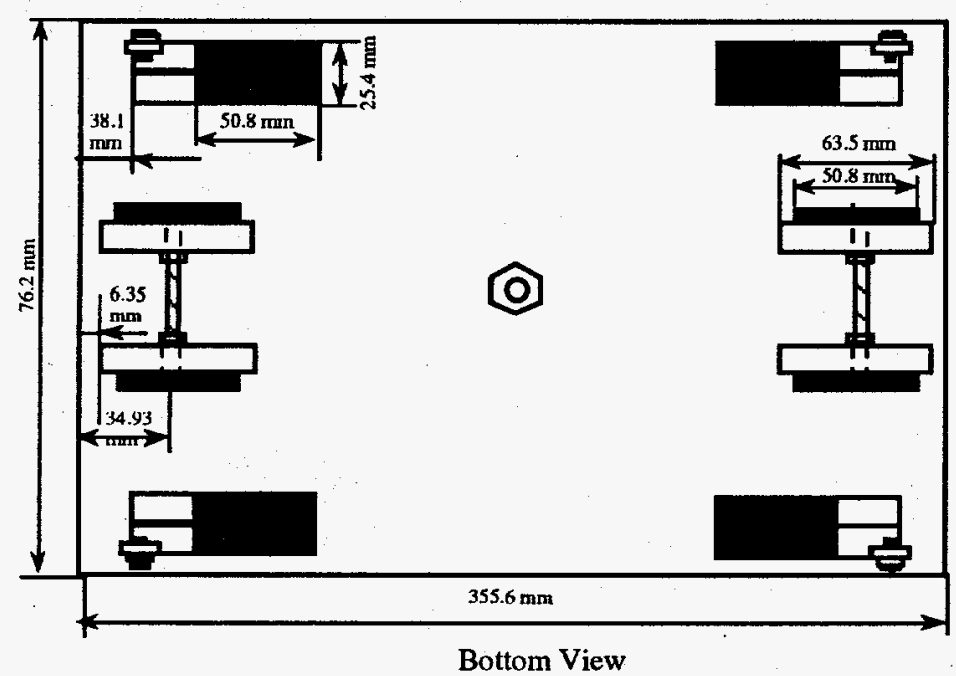

(b) Detailed vehicle drawing

Fig. 32. Vehicle model with four levitation and four guidance magnets in Test B 


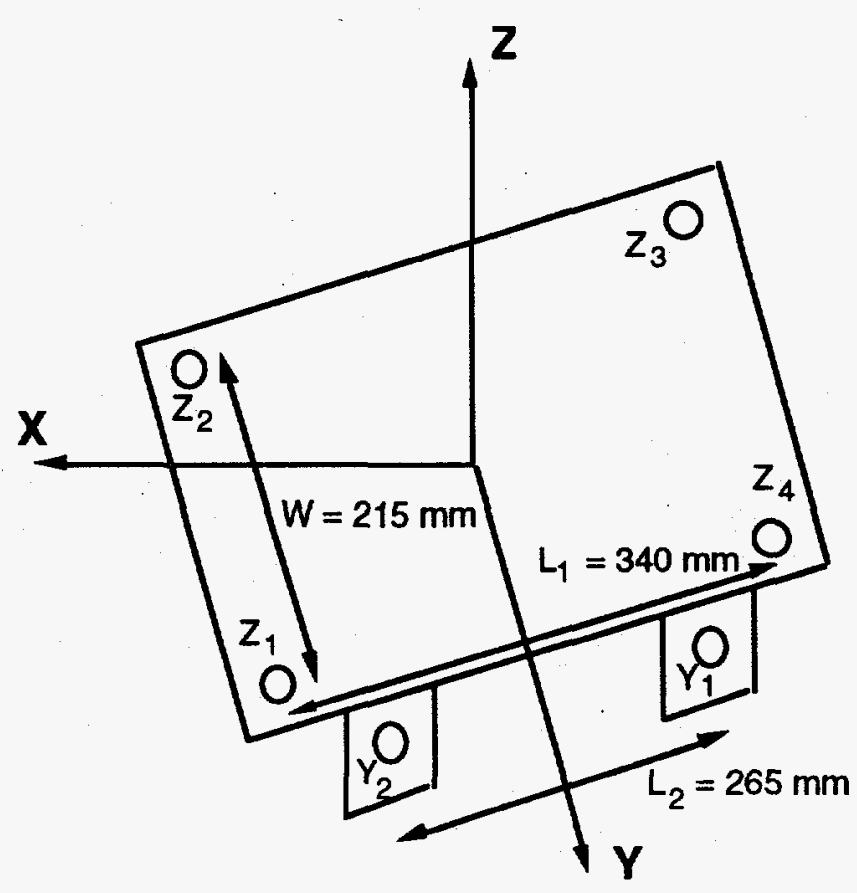

Fig. 33. Accelerometer arrangement for vehicle model in Test $B$

Heave $(\mathrm{t})=\left[\mathrm{Z}_{1}(\mathrm{t})+\mathrm{Z}_{2}(\mathrm{t})+\mathrm{Z}_{3}(\mathrm{t})+\mathrm{Z}_{4}(\mathrm{t})\right] / 4$

Slide $(t)=\left[\mathrm{Y}_{1}(\mathrm{t})+\mathrm{Y}_{2}(\mathrm{t})\right] / 2$

$\operatorname{Pitch}(\mathrm{t})=\left[\mathrm{Z}_{3}(\mathrm{t})+\mathrm{Z}_{4}(\mathrm{t})-\mathrm{Z}_{1}(\mathrm{t})-\mathrm{Z}_{2}(\mathrm{t})\right] /\left(2 \mathrm{~L}_{1}\right)$

$\operatorname{Yaw}(\mathrm{t})=\left[\mathrm{Y}_{2}(\mathrm{t})-\mathrm{Y}_{1}(\mathrm{t})\right] / \mathrm{L}_{2}$

$\operatorname{Roll}(\mathrm{t})=\left[\mathrm{Z}_{1}(\mathrm{t})+\mathrm{Z}_{4}(\mathrm{t})-\mathrm{Z}_{2}(\mathrm{t})-\mathrm{Z}_{3}(\mathrm{t})\right] /(2 \mathrm{~W})$

Vehicle response and stability were tested as a function of speed for a specific configuration of levitation and guidance magnets. When the flywheel was running from 300 to $600 \mathrm{rpm}$, two dynamic instability regions were noted. Two video tapes showing the dynamic response of the vehicle at different speeds are available.

A test was conducted to see if the vehicle can be operated in a stable position without the four guidance magnets. The result showed that, in this setup, the vehicle was always unstable. 
Several series of tests were performed to investigate the effect of the clearance between the sheet guideway and the magnets. The gap between the sheet guideway and the levitation magnets was set at 1.27 and $2.54 \mathrm{~mm}$, while the gap between the sheet guideway and the guidance magnets was set at 8.5, 13.5, $18.5 \mathrm{~mm}$. The response characteristics depend on the gaps between the guideway and levitation or guidance magnets. However, some general characteristics were noted.

- For speeds over $\mathbf{4 5 0} \mathrm{rpm}$, the motions of the vehicle were small.

- For speeds between 350 and $450 \mathrm{rpm}$, the motions of the vehicle were fairly large, with one of its wheels frequently touching the guideway.

- For speeds between 300 and $350 \mathrm{rpm}$, the motions of the vehicle were again relatively small.

- For speeds lower than $300 \mathrm{rpm}$, the vehicle was not yet completely levitated.

Figure 34 shows results of a detailed test performed for the following gaps: $2.54 \mathrm{~cm}$ between the vertical part of the guideway $\mathrm{L}$ and the edge of the levitation magnets; $1.35 \mathrm{~cm}$ between the vertical part of the guideway $L$ and guidance magnets (see Fig. 32). Figure 34a shows RMS longitudinal force as a function of the rotating speed of the wheel; Fig. 34b shows RMS displacements at six measurement positions as a function of speed; pitch, roll, yaw, heave, and slide motions calculated from displacements are given in Fig. 34c and 34d. The motion of the vehicle at various rotating speeds was recorded on a video tape from $\approx 600$ to $290 \mathrm{rpm}$. At each of the following speeds, the motions were recorded for about 30 s: $596,455,440,390,380,370,330,320,310$, and $290 \mathrm{rpm}$.

From Fig. 34 and recorded video tape playback, dynamic instability for this vehicle model indeed exists and large motion occurs at between 350 and $450 \mathrm{rpm}$. From the video, it was noted that the vehicle touched the guideway intermittently from 380 to $440 \mathrm{rpm}$; while at 370 and $455 \mathrm{rpm}$, no impact was noted. The response characteristics depend on the rotating speed of the flywheel. At $440 \mathrm{rpm}$, the motion was fairly steady with regular and sometimes intermittent impacts. At $390 \mathrm{rpm}$, the motion was more irregular; it appeared to be chaotic vibration. At $380 \mathrm{rpm}$, the motion was fairly steady but, in each cycle, there were several impacts. 


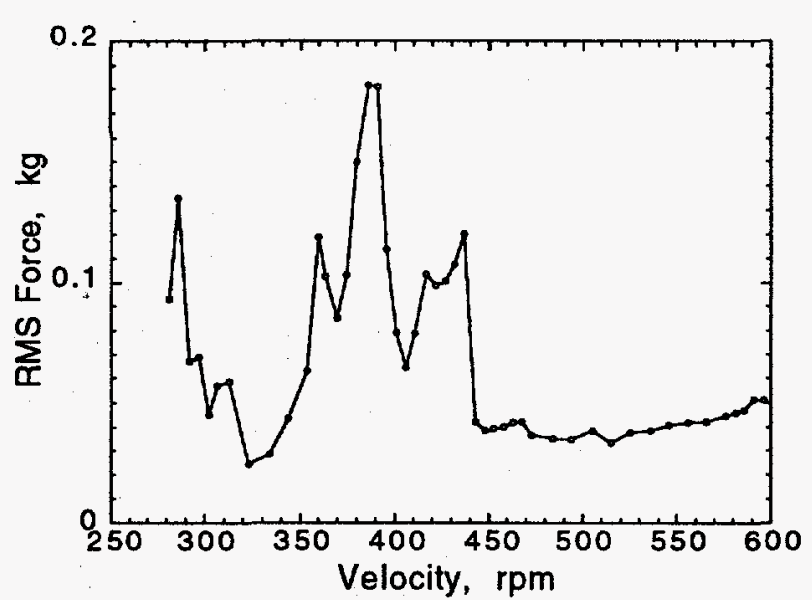

(a)

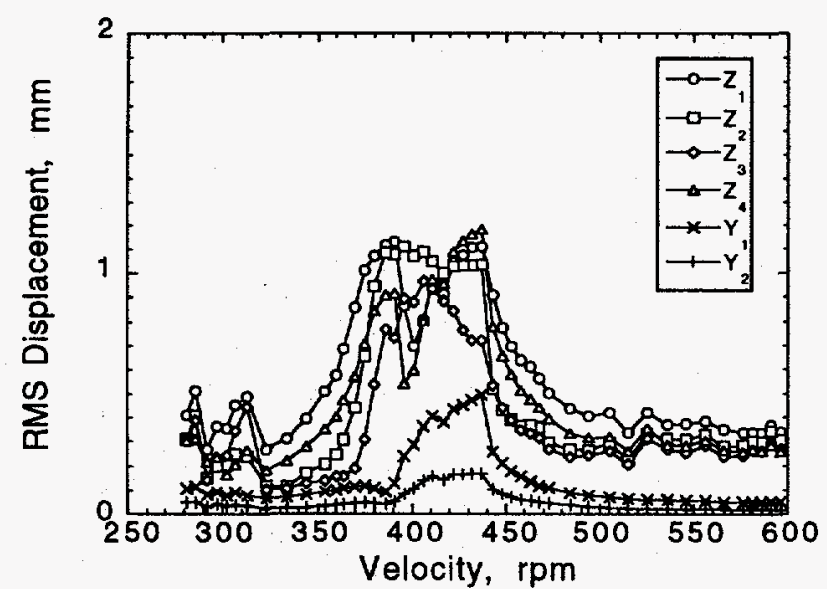

(b)

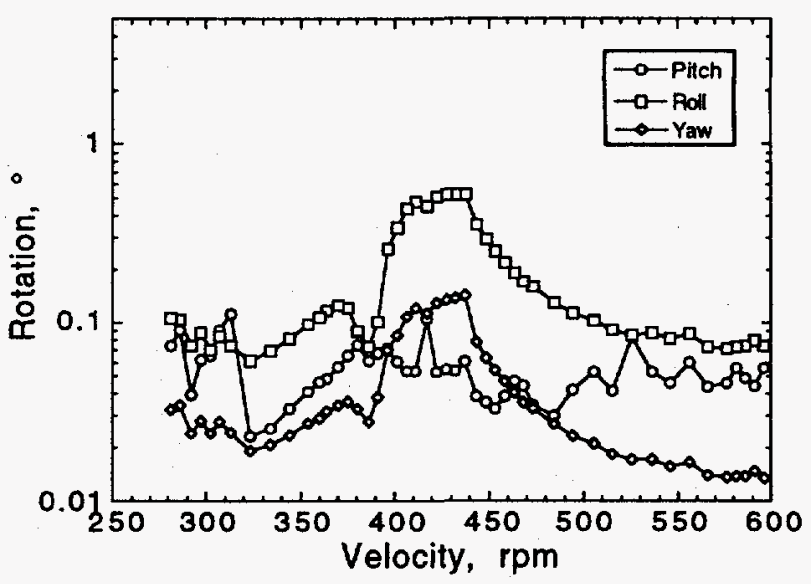

(c)

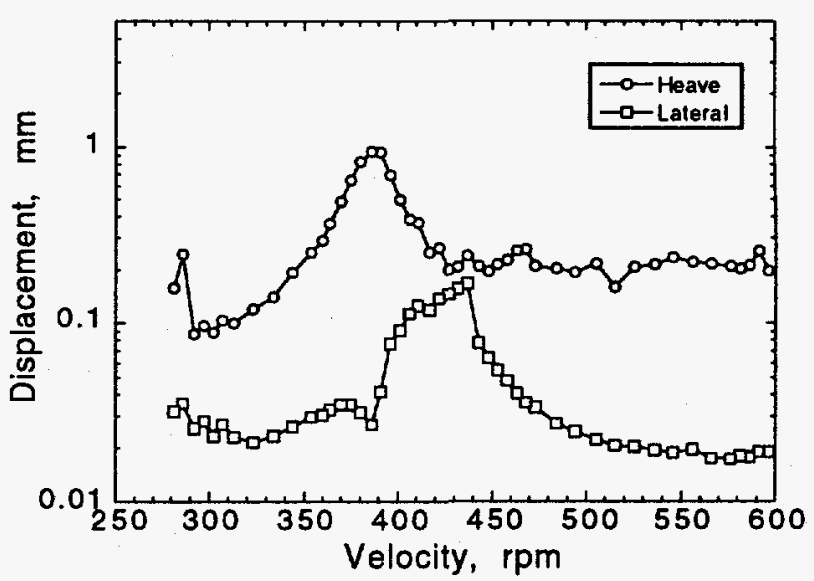

(d)

Fig. 34. Experimental results from Test B. (a) RMS force; (b) RMS displacement; (c) degree of pitch, roll, and yaw; and (d) heave and lateral displacement, all as a function of velocity

Significantly, it was noted that slide motion was much smaller in Test B than in Test $A$ because the guidance magnets in Test B provided sufficient guidance force. From experimental data and observation, oscillations of the vehicle were dominated by heave and roll motions.

Based on the experimental data, it is difficult to identify precisely the cause of large-amplitude oscillations. Several mechanisms may be involved: periodic excitation because of imperfections in the flywheel; motion-dependent magnetic forces; aerodynamic forces. The results from the experiment illustrate future research needs in the area of vehicle dynamics of maglev systems. To predict vehicle response confidently, magnetic and aerodynamic forces, and guideway characteristics must be quantified. The most critical elements in predicting 
vehicle response are magnetic forces; these include steady and unsteady magnetic forces. At this time, only limited steady magnetic forces are available. Future research should be extended to the prediction and measurement of unsteady magnetic forces.

\section{Numerical Simulation of Maglev Vehicles with Five DOF}

A computer code for simulating the dynamic response of maglev systems was developed. The code, which incorporated all of the quasistatic magnetic forces that were measured experimentally, can simulate the nonlinear dynamic response of maglev systems with six DOF when the user inputs vehicle and track configurations. It was employed in this study to calculate dynamic response and the onset of instability in a maglev vehicle model with five DOF. The simulations and predictions were compared with results obtained from dynamic stability experiments.

\subsection{Theoretical Aspects}

Consider a maglev vehicle system with six DOF, i.e., three translations, $\mathbf{u}_{x}$, $u_{y}$, and $u_{z}$, and three rotations, $\omega_{x}, \omega_{y}$, and $\omega_{z}$, as illustrated in Fig. 35 .

Governing equations of motion of this six-DOF maglev system are derived from Newton's and Euler's equations, and the transform between the vehicle and guideway coordinate systems is based on Euler angles (Cai and Chen, 1993a and 1995; Coffey et al., 1991).

Consider a rigid body vehicle with six DOF (three translations, $u_{x}, u_{y}$, and $u_{z}$, and three rotations, $\omega_{x}, \omega_{y}$, and $\omega_{z}$. Let $U$ be the translation vector and $\Omega$ the rotation vector, i.e.,

$$
\mathrm{U}=\left\{\begin{array}{l}
\mathrm{u}_{\mathrm{x}} \\
\mathrm{u}_{\mathrm{y}} \\
\mathrm{u}_{\mathrm{z}}
\end{array}\right\}, \quad \Omega=\left\{\begin{array}{c}
\omega_{\mathrm{x}} \\
\omega_{\mathrm{y}} \\
\omega_{\mathrm{z}}
\end{array}\right\} .
$$



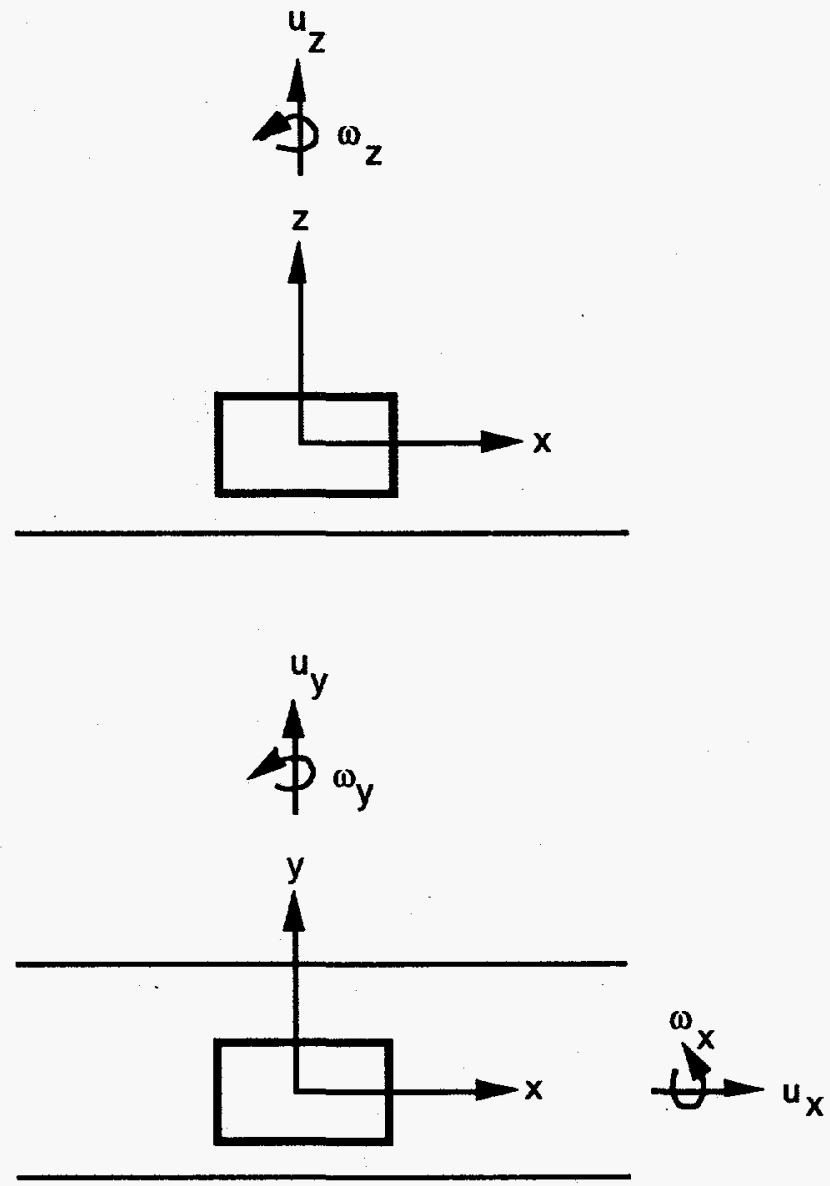

Fig. 35. Displacement components of a maglev system

To transform from the vehicle to the guideway coordinate system (Coffey et al., 1991), the Euler angles $\psi$ (heading), $\theta$ (attack), and $\phi$ (roll) are introduced. A vector $\vec{R}_{g}$ in the guideway coordinates transforms from a vector $\vec{R}_{v}$ in the vehicle coordinates as

$$
\overline{\mathrm{R}}_{\mathrm{g}}=[\ell] \overline{\mathrm{R}}_{\mathrm{v}},
$$

with the transformation matrix given by

$$
[\ell]=\left[\begin{array}{ccc}
\cos \theta \cos \psi & -\sin \psi \cos \phi+\cos \psi \sin \theta \sin \phi & \sin \psi \sin \phi+\cos \psi \sin \theta \cos \phi \\
\cos \theta \sin \psi & \cos \psi \cos \phi+\sin \psi \sin \theta \sin \phi & -\cos \psi \sin \phi+\sin \psi \sin \theta \cos \phi \\
-\sin \theta & \cos \theta \sin \phi & \cos \theta \cos \phi
\end{array}\right] .
$$

Equations of motion expressed in the vehicle coordinate system can be described as 


$$
\left.\begin{array}{l}
\mathrm{M} \dot{U}+\mathrm{C} \dot{\dot{U}}=M \bar{G}+M(\bar{U} \times \dot{\hat{\Omega}})+\vec{F}_{m} \\
I \bar{U}+D \bar{U}=I \vec{\Gamma}+R \cdot \bar{F}_{m}
\end{array}\right\},
$$

where $M$ and $I$ are the mass of the vehicle and the moment of inertia about the center of the mass inertia moment of the vehicle, and are defined by

$$
\mathrm{M}=\left[\begin{array}{ccc}
\mathrm{m} & 0 & 0 \\
0 & \mathrm{~m} & 0 \\
0 & 0 & \mathrm{~m}
\end{array}\right], \quad \mathrm{I}=\left[\begin{array}{ccc}
\mathrm{I}_{\mathrm{x}} & 0 & 0 \\
0 & \mathrm{I}_{\mathrm{y}} & 0 \\
0 & 0 & \mathrm{I}_{\mathrm{z}}
\end{array}\right]
$$

and $\mathrm{C}$ and $\mathrm{D}$ are damping coefficient matrices

$$
\mathrm{C}=\left[\begin{array}{lll}
c_{11} & c_{12} & c_{13} \\
c_{21} & c_{22} & c_{23} \\
c_{31} & c_{32} & c_{33}
\end{array}\right], \quad \mathrm{D}=\left[\begin{array}{lll}
\mathrm{d}_{11} & \mathrm{~d}_{12} & \mathrm{~d}_{13} \\
\mathrm{~d}_{21} & \mathrm{~d}_{22} & \mathrm{~d}_{23} \\
\mathrm{~d}_{31} & \mathrm{~d}_{32} & \mathrm{~d}_{33}
\end{array}\right]
$$

The damping coefficient in Eq. 6 should be determined from experimental data. Before these experimental data are available, assumed damping ratios can be utilized in the simulations. The elements of $\bar{G}$ and $\vec{\Gamma}$ are defined by

$$
\overline{\mathrm{G}}=\left\{\begin{array}{c}
-\mathrm{g} \sin \theta \\
\mathrm{g} \cos \theta \sin \phi \\
\mathrm{g} \cos \theta \cos \phi
\end{array}\right\}
$$

and

$$
\vec{\Gamma}=\left\{\begin{array}{c}
\frac{I_{y}-I_{z}}{I_{x}} \dot{\omega}_{y} \dot{\omega}_{z} \\
\frac{I_{z}-I_{x}}{I_{y}} \dot{\omega}_{z} \dot{\omega}_{x} \\
\frac{I_{x}-I_{y}}{I_{z}} \dot{\omega}_{x} \dot{\omega}_{y}
\end{array}\right\}
$$


$\overline{\mathrm{F}}_{\mathrm{m}}$ is the magnetic force applied on the center of the mass, and $\mathrm{R}$ is the moment arm matrix. Because the applied forces depend on the distances between the vehicle and the guideway surfaces, but all components of the forces and moments in the equations of motion are to be expressed along the axes of the vehicle, the transformation must convert forces from one coordinate to the other.

Because the time derivatives of the Euler angles $\psi, \theta$, and $\phi$ are related to the rotational velocities,

$$
\left.\begin{array}{l}
\dot{\psi}=\sec \theta\left(\dot{\omega}_{\mathrm{z}} \cos \phi+\dot{\omega}_{\mathrm{y}} \sin \phi\right) \\
\dot{\theta}=\dot{\omega}_{\mathrm{y}} \cos \phi-\dot{\omega}_{\mathrm{z}} \sin \phi \\
\dot{\phi}=\dot{\omega}_{\mathrm{x}}+\tan \theta\left(\dot{\omega}_{\mathrm{z}} \cos \phi+\dot{\omega}_{\mathrm{y}} \sin \phi\right)
\end{array}\right\}
$$

Because only a five-DOF vehicle model is considered in the dynamic simulation and experiments with the ANL rotating-wheel facility, the longitudinal motion of the vehicle $u_{x}$ is restricted and can be assumed to be zero in the equations of motion.

\subsection{Computer Code for Maglev Systems}

A computer code, based on governing Eqs. 4 to 9, was developed for nonlinear dynamic simulation of maglev systems. The program uses the fourth-order Runge-Kutta method to numerically integrate nonlinear differential equations that characterize the dynamics of maglev vehicles.

The objective of the computer code is to predict the dynamic behavior of the five-DOF maglev systems described in Section 3, even though the code can be extended to cover a wider range of vehicle and guideway designs. The different system descriptions in Test $A$ and Test $B$, such as design of vehicle and track geometry, number and size of magnets, and vehicle traveling speed, can easily be included in a user-friendly input package of the code. Then, a specific subroutine of the code will automatically calculate essential parameters of vehicle/track systems for later numerical simulation. 
Magnetic-force data from experimental measurements are incorporated in force subroutines of the code. Once the distances between the magnets and the sheet guideway are calculated out during each time step, lift, guidance, and drag forces on each magnet are determined from prestored magnetic-force data curves by a multidimensional interpolation method. Then, total magnetic forces and moments acting on the vehicle body are calculated and inserted into differential equations. The coordinate transformation (Eq. 2) is required to convert forces from one coordinate to the other, because the applied forces are dependent on the distance between the vehicle and the guideway surfaces, but all components of the forces and moments in the equations of motion are to be expressed along the axes of the vehicle body.

One difficulty with describing the system is how to determine system damping in the differential equation. The system damping is very important in the dynamic and stability analysis. However, so far, an actual system damping ratio cannot be obtained by either experimental or analytical methods. Therefore, we assumed the reasonable value of $+2.5 \%$ for the damping ratio in most of the simulations. Here, the reasonable value means that, with this value, simulation results would be closest to those obtained from experiments. Also, different damping values are considered in the simulation. Usually, if the damping ratio is increasing to a certain value, the vehicle motion would be stable in the whole speed range; if less damping is assumed, the instability region broadens. The system damping affects motions in all directions.

\subsection{Numerical Simulation and Comparison with Test $A$}

Typical experimental results from Case 1 of Test A (see Fig. 31) are replotted in Fig. 36, with RMS force and displacements as a function of wheel surface velocity $(\mathrm{m} / \mathrm{s})$. Several speed regions were found by measurement and observation. (1) When the wheel speed was lower than $6 \mathrm{~m} / \mathrm{s}$, the vehicle was unstable, with high-frequency (flutter) due to a large drag force. (2) When the speed was between 6 and $13 \mathrm{~m} / \mathrm{s}$, the vehicle was stable and amplitudes of displacement and force were relatively small. (3) When the speed was between 13 and $30 \mathrm{~m} / \mathrm{s}$, the vehicle was unstable and dominated by slide and yaw instability. (4) When the speed was over $30 \mathrm{~m} / \mathrm{s}$, the vehicle was unstable in almost every direction and the oscillation amplitudes in five directions increased significantly. 


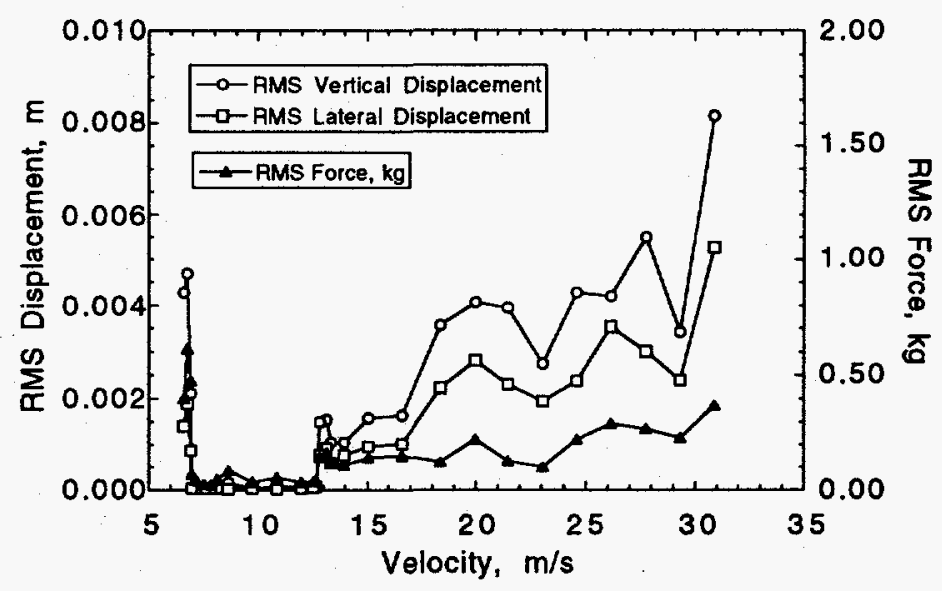

Fig. 36. Experimental results from Case 1 in Test $A$

Numerical simulation of the dynamic response of a five-DOF maglev vehicle was carried out by using vehicle dimension input as described in Fig. 30 and Section 3. Figure 37 shows the simulation results of lateral and vertical displacements of vehicle mass center for various wheel speeds, with initial perturbations of $\mathrm{z}_{0}$ and $\mathrm{y}_{0}$ equal to $0.1 \mathrm{~mm}$. The system damping ratio in the simulation was assumed to be $2.5 \%$. For vertical displacement, the positive value means the vehicle is moving toward the guideway. The following conclusions can be drawn. (1) When vehicle velocity is $15 \mathrm{~m} / \mathrm{s}$, the vehicle is stable. Its amplitudes of vertical and lateral motion decrease as time increases. (2) For vehicle velocities of 20,25 , and $30 \mathrm{~m} / \mathrm{s}$, both lateral and vertical oscillation amplitudes increase until the vehicle hits the guideway. (3) With defined vehicle parameters, vehicle motion is dominated by slide and yaw instabilities, even though heave instability is still present. This is caused by weak guidance force. (4) Oscillation frequency varies with the vehicle velocity because of lift and drag forces. In stable regions, frequency is quite low. (5) The current computer program is unable to deal with nonlinearity when the vehicle hits the guideway. For all calculations of time history, the program automatically stops once any side of a vehicle hits the guideway; therefore, it cannot be used to calculate RMS values of displacement and power spectral density (PSD) for comparison with the experimental data shown in Fig. 36.

Figure 38 shows time histories of both lateral and vertical motion of a vehicle with a velocity of $30.0 \mathrm{~m} / \mathrm{s}$. Lateral motion is rapidly developed and finally the vehicle hits the guideway. Notice that the oscillation period changes when the amplitude of lateral motion increases. After the vehicle contacts the side wall of an L-shaped guideway ( $\mathrm{t}>1.0 \mathrm{~s}$ ), the lateral motion of vehicle mass center increases significantly and period is reduced. 


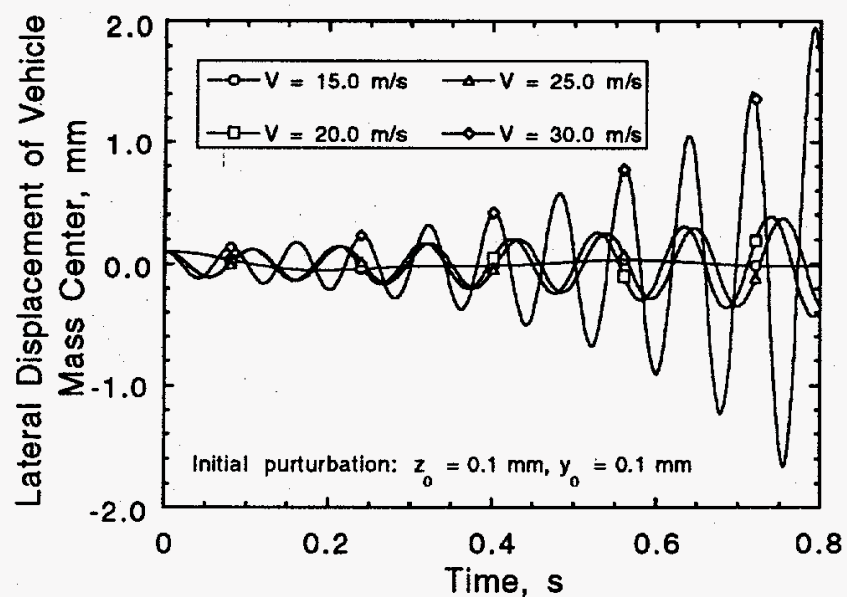

(a)

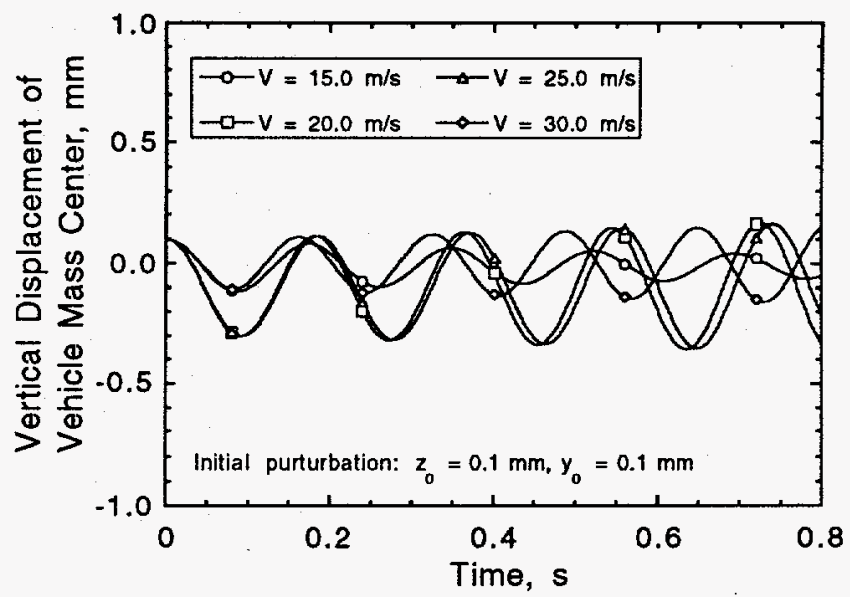

(b)

Fig. 37. Simulation results of (a) lateral and (b) mass center displacements in Test $A$ at various vehicle speeds

Figure 39 shows five vehicle motions, slip, heave, yaw, pitch, and roll, when vehicle velocity $=20.0 \mathrm{~m} / \mathrm{s}$ and initial perturbation is $0.1 \mathrm{~mm}$ in slip and heave motion and $0.1^{\circ}$ in pitch and roll motions. In this particular case, pitch and roll motion is stable, while slip, heave, and yaw motion is unstable. The frequency and phase of the five motions are different, which may be attributed to weak coupling of motion in different directions. The slip and yaw motions are strongly coupled, but only weakly coupled to the vertical modes. 


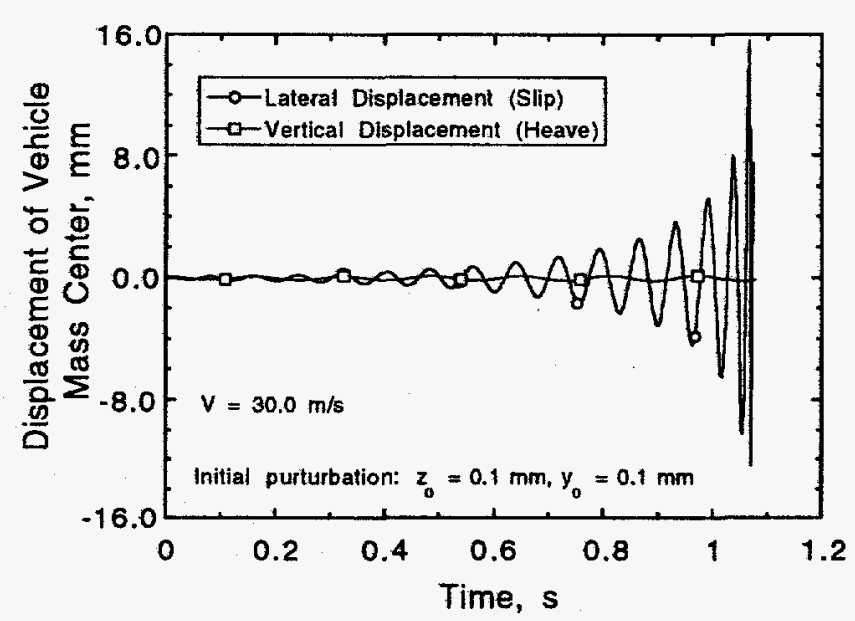

Fig. 38. Simulated time histories of lateral and vertical displacement of vehicle that contacts side wall of guideway

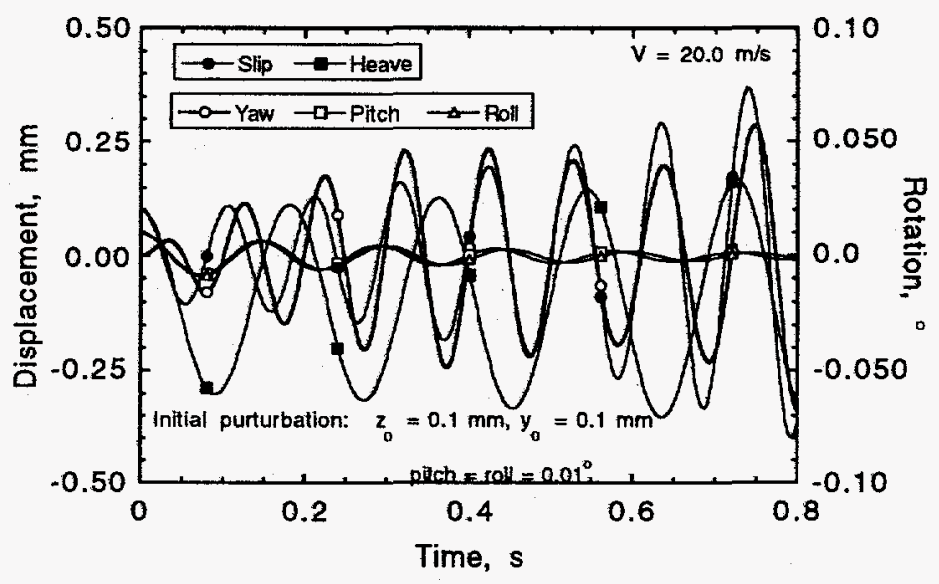

Fig. 39. Simulation results of displacements and rotations in Test $A$ with vehicle speed $=20 \mathrm{~m} / \mathrm{s}$

\subsection{Numerical Simulation and Comparison with Test B}

Typical results from Test B (see Fig. 34) are replotted in Fig. 40, with RMS values of heave, slide, yaw, pitch, and roll motion of the vehicle as a function of wheel surface velocity ranging from 15 to $31 \mathrm{~m} / \mathrm{s}$, with the lateral gap between guidance magnets and the vertical part of the guideway $\mathrm{L}$ equal to $13.5 \mathrm{~mm}$. Large motion occurs between 19 and $23 \mathrm{~m} / \mathrm{s}$. When the velocity is lower than $18 \mathrm{~m} / \mathrm{s}$ or higher than $24 \mathrm{~m} / \mathrm{s}$, the vehicle was very stable (Fig. 40 ). 

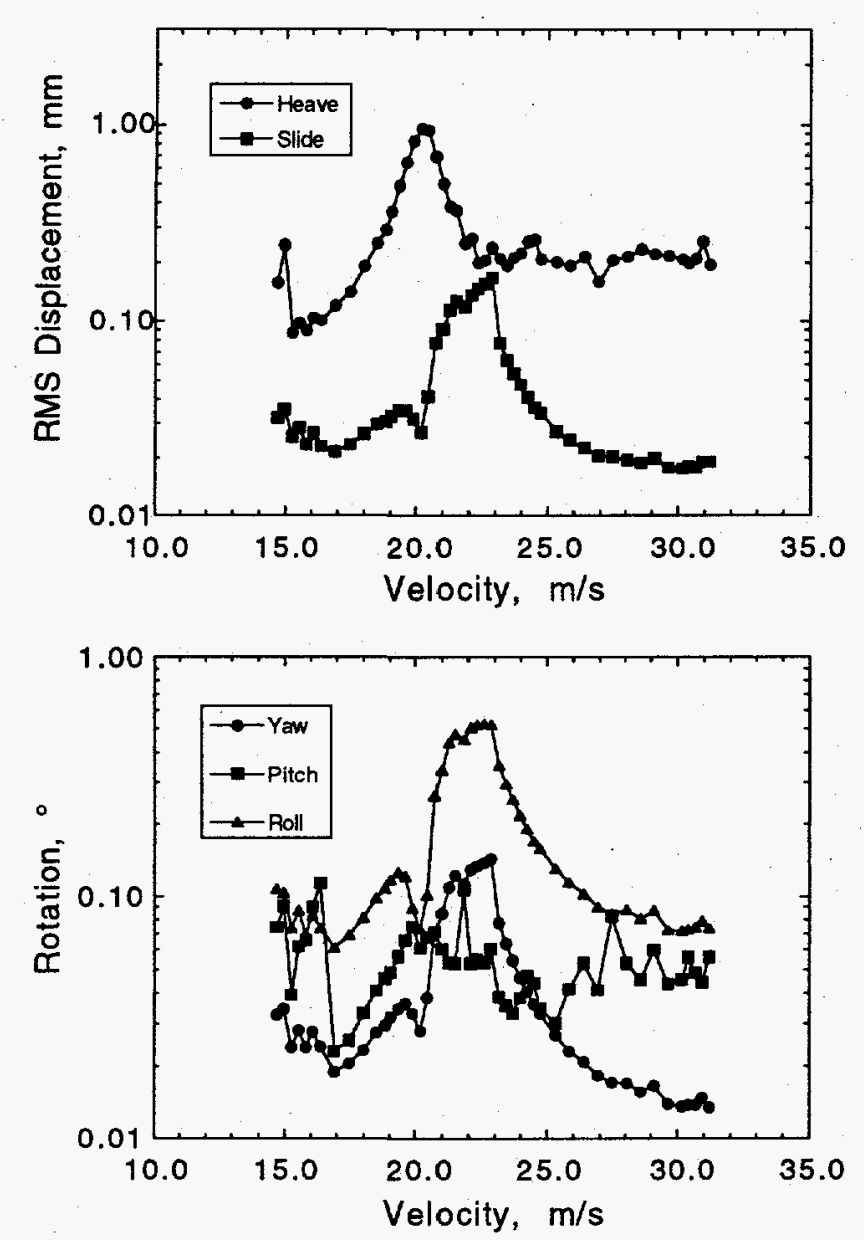

Fig. 40. Experimental results with guidance magnet gap $=13.5 \mathrm{~mm}$ in Test $B$

Numerical simulation was carried out for the vehicle in Test B. The vehicle configuration and magnet's position were measured and input into the program. Detailed vehicle dimensions and other parameters have been described in Section 3.2. In the simulation, the initial gaps between magnets and the guideway $\mathrm{L}$ were set as follows: lateral gap, $13.5 \mathrm{~mm}$; vertical gap, equal to the value at which the lift forces of four lift magnets were sufficient to balance the vehicle weight at given wheel speeds; initial perturbations $\mathrm{z}_{0}$ and $\mathrm{y}_{0}$ at vertical and lateral directions, $0.1 \mathrm{~mm}$; and system damping ratio, $2.5 \%$. Note that for vertical displacement, the positive value means the vehicle is moving toward the guideway.

Figures 41-44 show the time histories of simulation results with vehicle velocities of $15,20,25$, and $30 \mathrm{~m} / \mathrm{s}$, respectively. The following conclusions can be drawn. (1) With strong guidance forces provided by four guidance magnets, slide 

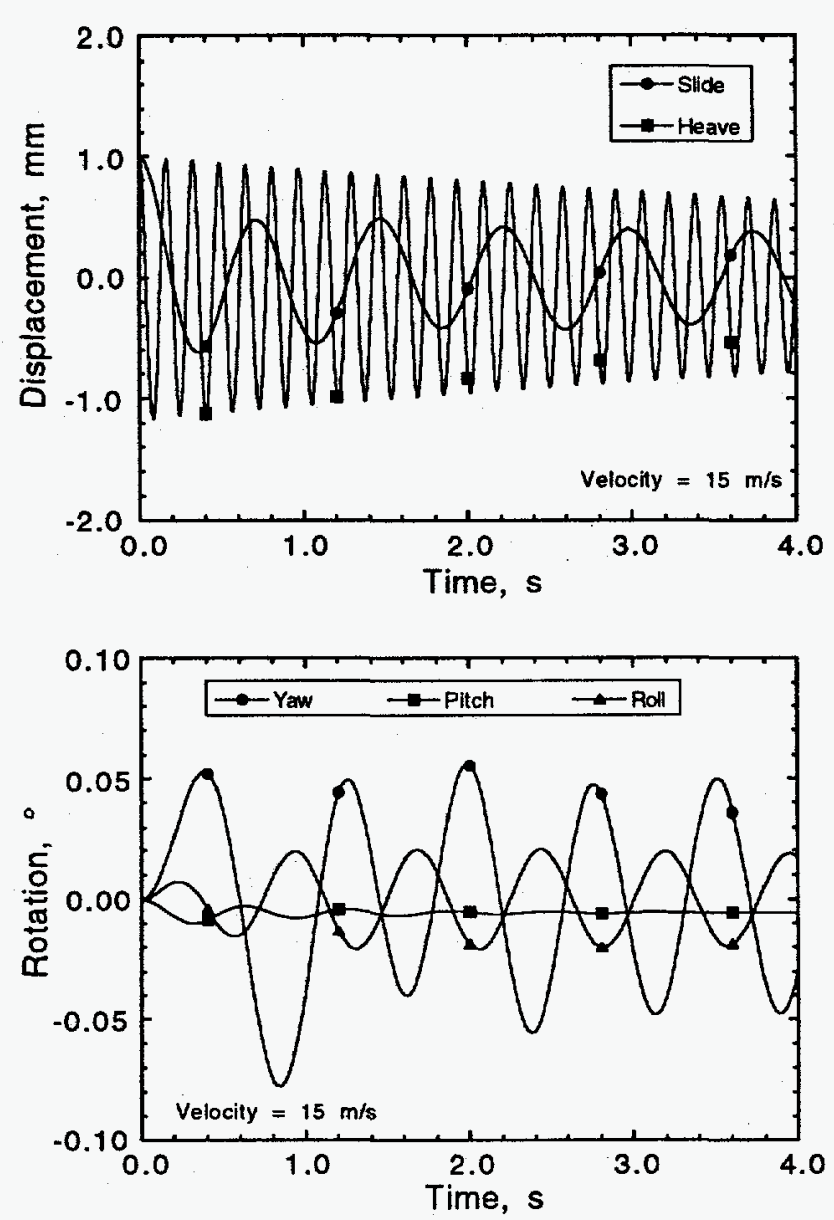

Fig. 41. Simulation results of displacement and rotation in Test $B$ with vehicle speed $=15 \mathrm{~m} / \mathrm{s}$

motion decays very quickly ( $<4 \mathrm{~s}$, which seems to agree well with experimental observations), and no slide or yaw instabilities are present in whole speed range. When the vehicle velocity increases, the period for slide motion to die out decreases because guidance forces increase with wheel velocity. This conclusion can also be applied to all of the rotation motions. (2) Pitch oscillations are quite small because, in the calculation, drag force moments are balanced mostly by the moment of the tether. However, because of the rest of the unbalanced drag moment, some pitch angle offset is still present when oscillation disappears. (3) Oscillating frequencies of various motions are quite different for this configuration. (4) The vehicle motion is dominated by heave motion, and heave instability occurs when vehicle velocity is $20 \mathrm{~m} / \mathrm{s}$, which is in a good agreement with the experimental result shown in Fig. 40. 

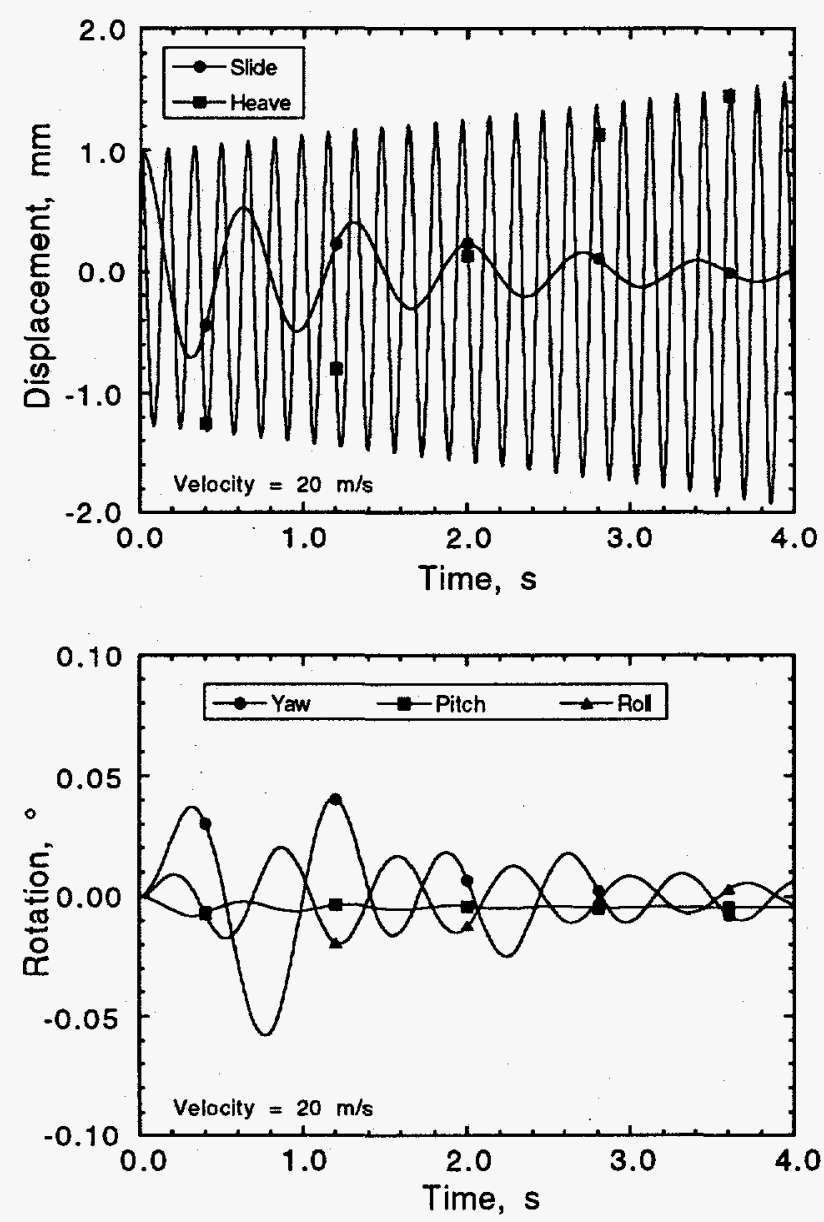

Fig. 42. Simulation results of displacement and rotation in Test $B$ with vehicle speed $=20 \mathrm{~m} / \mathrm{s}$

The drag force produced by four lift magnets may play an important role in these experiments. Figure 45 shows the guidance force (actually, lift force to this magnet, see Section 2.3, but guidance force to the vehicle) and drag force of the guidance magnet as a function of vehicle speed. Drag force is small and remains almost constant in the test speed region. Thus, the influence of the drag force of the guidance magnet on vehicle motion could be ignored. Figure 46 gives the initial vertical gap at which magnets support the vehicle, and the drag force that is produced by the lift magnet at various speeds. As the velocity increases, the vertical gap between the magnet and sheet guideway increases because the lift force needed to balance the vehicle weight remains the same; while in this same situation, drag force decreases. This property may affect not only slide, yaw, roll, and pitch motions as their time to die out is reduced with increased velocity, but also heave motion, as seen in Figs. 41-44. 

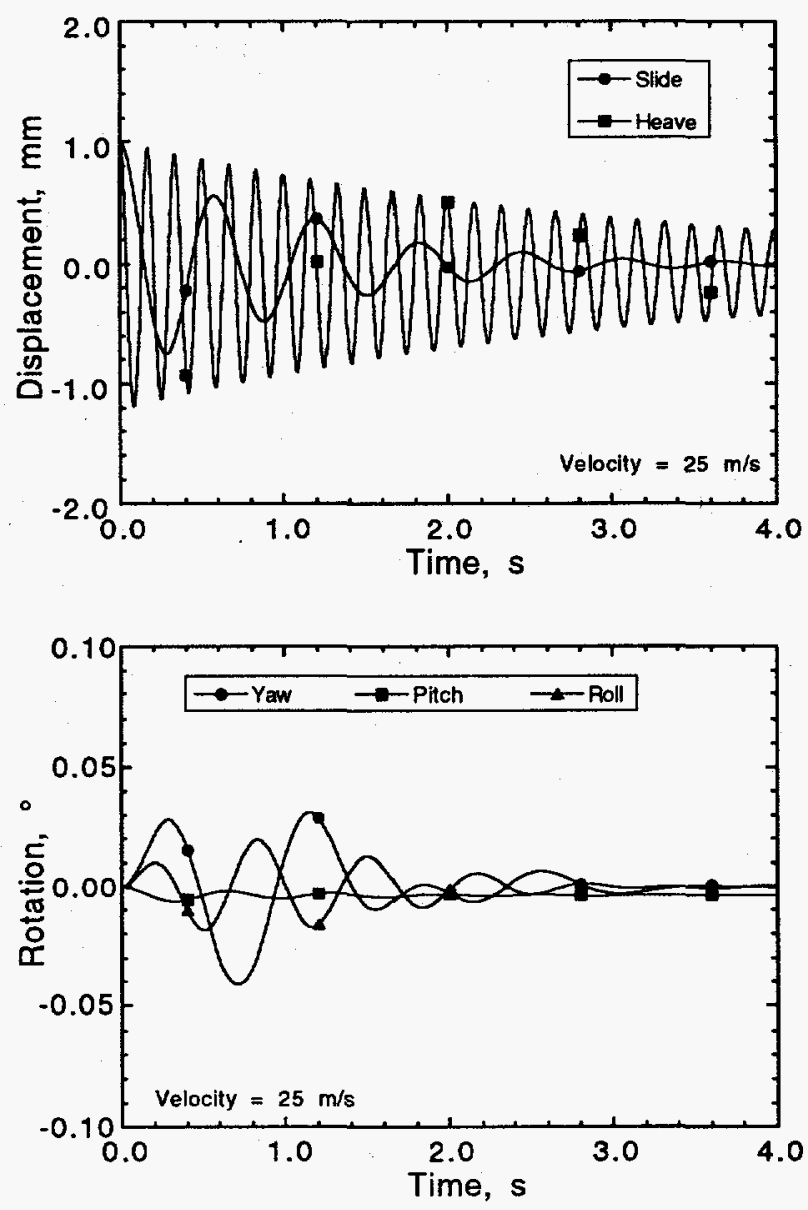

Fig. 43. Simulation results of displacement and rotation in Test $B$ with vehicle speed $=25 \mathrm{~m} / \mathrm{s}$

\section{Conclusions}

Magnetic forces are critically important to the analysis of any vehicle dynamics, design of guideway structures and fastening, and prediction of ride quality. These force components are considered from the standpoint of vehicle stability. This report documents magnetic-force data obtained from both experiments and calculations for a permanent magnet moving over a sheet guideway. All of the experimental data have been incorporated into an existing computer program for simulation of nonlinear dynamics of maglev vehicles. The magnetic force data, which have never been published, will provide potential references for future maglev programs. 

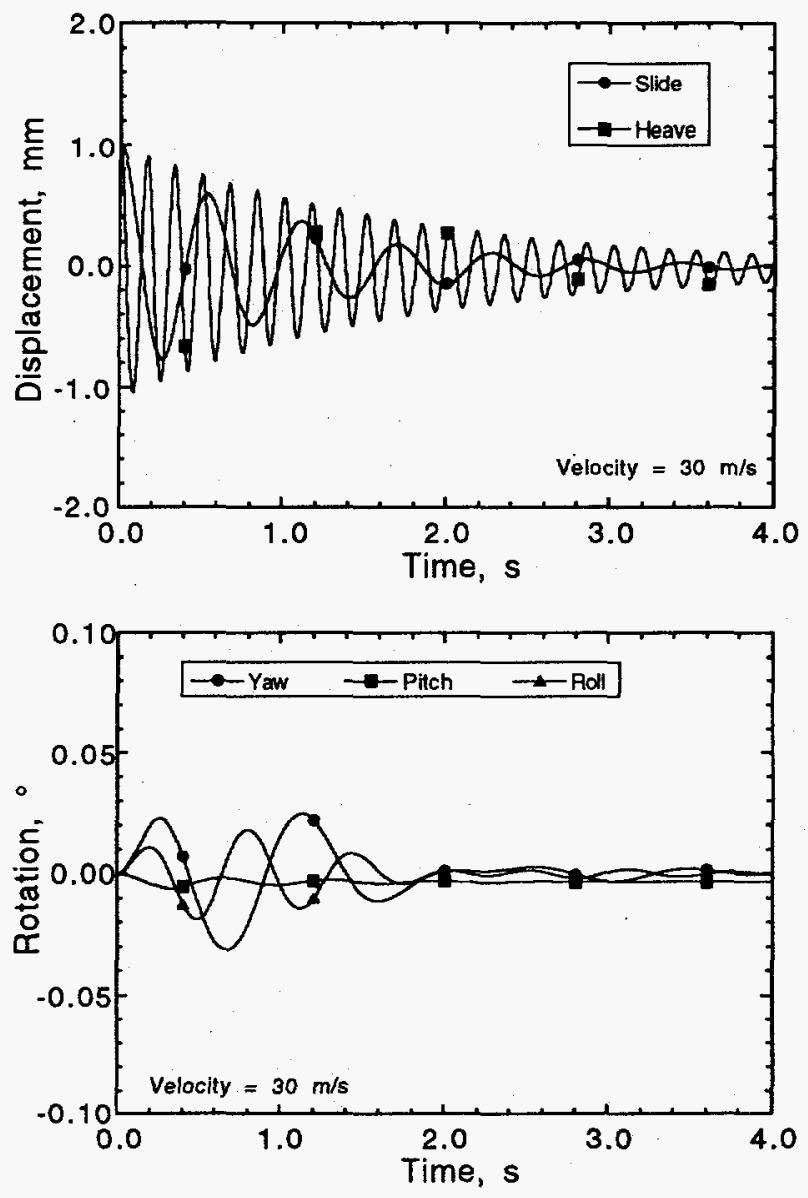

Fig. 44. Simulation results of displacement and rotation in Test $B$ with vehicle speed $=30 \mathrm{~m} / \mathrm{s}$

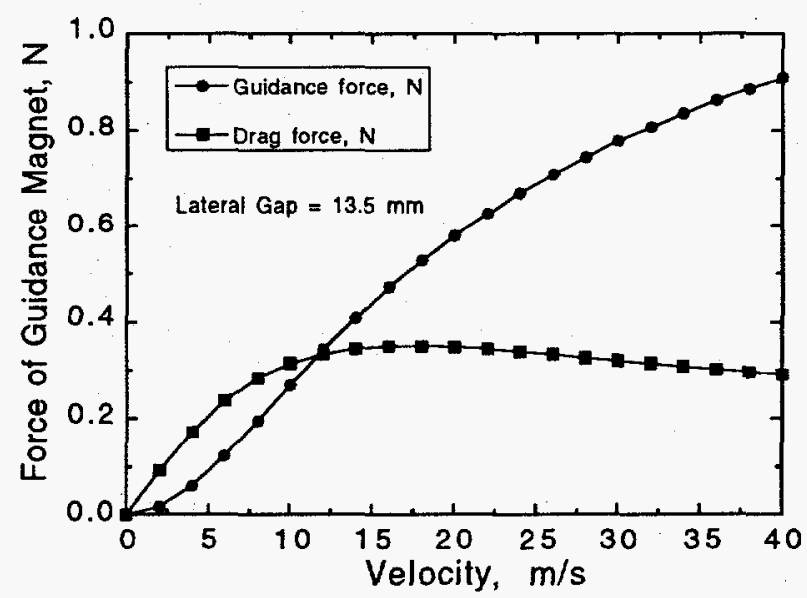

Fig. 45. Comparison of vehicle guidance and drag forces as a function of velocity 


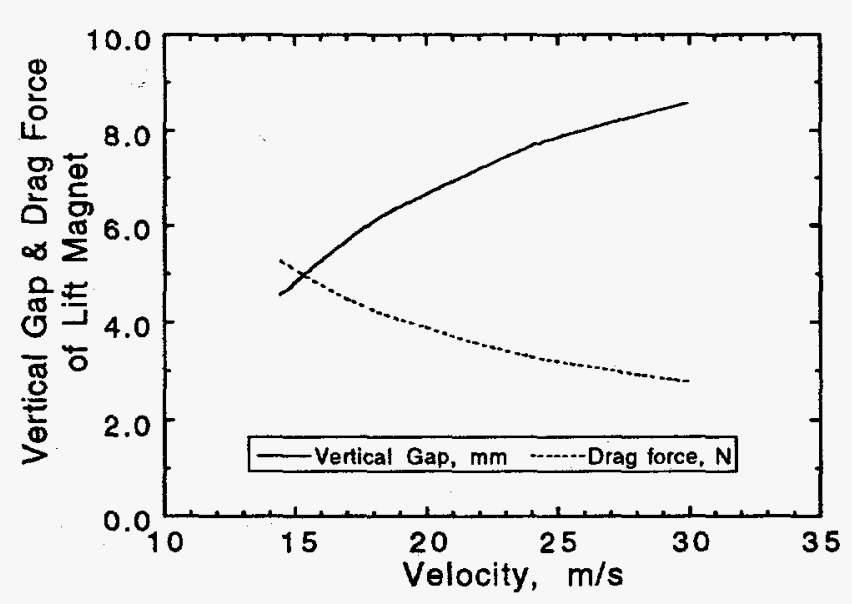

Fig. 46. Comparison of vertical gap and drag force as a function of velocity when vehicle is at equilibrium

Motion-dependent magnetic forces are the key elements in modeling and understanding dynamic instabilities of maglev systems. At this time, it appears that very limited data are available for motion-dependent magnetic forces. Efforts will be made to compile analytical results and experimental data for motiondependent magnetic forces. When this work is completed, recommendations will be presented on the needs of research on magnetic forces. In addition, specific methods to obtain motion-dependent magnetic forces will be described in detail.

Two series of extensive experimental investigations on dynamic stability of maglev systems were conducted with a free vehicle moving on a double L-shaped aluminum guideway mounted on the top of a rotating wheel. Five modes (vertical heave, lateral slip, pitch, yaw, and roll) of the vehicle motion were measured in experiments when the rotating speed of the wheel was varied. Instabilities of an EDS-type maglev system have been observed through the experiments. Stable and unstable motion of the maglev vehicle was observed and recorded. An integrated experimental/analytical study of stability characteristics is definitely an important aspect of maglev research and must be considered in the development of all maglev systems.

Various methods can be used to stabilize a maglev system: passive electrodynamic primary suspension damping, active electrodynamic primary suspension damping, passive mechanical secondary suspension, and active mechanical secondary suspension. With a better understanding of vehicle stability characteristics, a better control law can be adopted to ensure a high level of ride comfort and safety. 
Computer programs are needed to screen new system concepts, evaluate various designs, and predict vehicle response. A computer code for nonlinear dynamic simulation of maglev systems was extensively developed in this study. It can simulate nonlinear dynamic response of maglev systems with six DOF when the user inputs vehicle and track configurations. It provides more functionality for broad vehicle/guideway designs than any previous codes. Numerical simulations presented in this study for a five-DOF maglev system are in good agreement with experimental results. However, it appears that the stability characteristics of maglev vehicles under different conditions have not been studied in detail. When information on motion-dependent magnetic forces becomes available, the computer codes can be improved significantly.

The experimental and theoretical analyses developed in this study identify basic stability characteristics and future research needs of maglev systems.

\section{Acknowledgments}

This work was performed under the sponsorship of the U.S. Army Corps of Engineers and the Federal Railroad Administration through interagency agreements with the U.S. Department of Energy. The authors thank Drs. Jianliang He, Howard T. Coffey, and John Hull for their help in extensive discussions and constructive comments on this study.

\section{References}

Cai, Y., Chen, S. S., Mulcahy, T. M., and Rote, D. M., (1992a), Dynamic Stability of Maglev Systems, Proceedings 63rd Shock and Vibration Symposium, 27-29 Oct. 1992, Las Cruces, NM, pp. 533-543.

Cai, Y., Chen, S. S., Mulcahy, T. M., and Rote, D. M., (1992b), Dynamic Stability of Maglev Systems, Report ANL-92/21, Argonne National Laboratory, Argonne, IL.

Cai, Y., Chen, S. S., and Rote, D. M., (1992c), Dynamic and Controls in Maglev Systems, Report ANL-92/43, Argonne National Laboratory, Argonne, IL. 
Cai, Y. and Chen, S. S., (1993a), Instability of Electrodynamic Maglev Systems, Proceedings of the 64th Shock and Vibration Symposium, Ft. Walton Beach, FL, October 25-28, 1993, pp. 319-326.

Cai, Y., Chen, S. S., Zhu, S., Mulcahy, T. M., Rote, D. M., and Coffey, H. T., (1993b), Dynamics, Stability, and Control of Maglev Systems, Proceedings Maglev '93, 13th International Conf. on Magnetically Levitated Systems and Linear Drives, May 19-21, 1993, Argonne, IL, pp. 265-270.

Cai, Y., Zhu, S., Chen, S. S., and Rote, D. M., (1993c), Control of Maglev Suspension Systems, 1993 ASME Pressure Vessels and Piping Conf., ASME New York, PVP-Vol. 256-2, pp. 57-67.

Cai. Y., and Chen, S. S., (1995), Numerical Analysis for Dynamic Instability of Electrodynamic Maglev Systems, The Shock and Vibration Journal, 2(4), pp. 339349.

Chen, S. S., Rote, D. M., and Coffey, H. T., (1992), A Review of Vehicle/Guideway Interactions in Maglev Systems, Fluid-Structure Interaction, Transient ThermalHydraulics, and Structural Mechanics, ASME, New York, Vol. 231, pp. 81-95.

Chen, S. S., Zhu, S., and Cai, Y., (1993), On the Unsteady-Motion Theory of Magnetic Forces for Maglev, Report ANL-93/39, Argonne National Laboratory, Argonne, IL.

Chu, D., and Moon, F. C., (1983), Dynamic Instabilities in Magnetically Levitated Models, J. Appl. Phys. 54(3), pp. 1619-1625.

Coffey, H. T., et al., (1991), Preliminary Design for a Maglev Development Facility, Report ANL/ESD-14, Argonne National Laboratory, Argonne, IL.

Coffey, H. T., (1993), Status and Review of the U. S. Maglev Program, Proceedings of the International Conference on Speedup Technology for Railway and Maglev Vehicles, November 22-26, 1993, Yokohama, Japan, p. 6.

Coffey, H. T., Chilton, F., and Hoppie, L. O., (1972), The Feasibility of Magnetically Levitating High Speed Ground Vehicle, National Technical Information Service Publication 210505. 
Davis, L. C., and Wilkie, D. F., (1971), Analysis of Motion of Magnetic Levitation Systems: Implications, J. Appl. Phys. 42(12), pp. 4779-4793.

He, J. L., Rote, D. M., and Chen, S. S., (1994), Characteristics and Computer Model Simulation of Magnetic Damping Forces in Maglev System, Report ANL/ESD/TM-66, Argonne National Laboratory, Argonne, IL.

Kim, I. K., Yoo, M. W., Park, C., Chung, H. K., and Kim, K. H., (1993), Maglev Programs in Korea, Proceedings Maglev '93, 13th International Conf. on Magnetically Levitated Systems and Linear Drives, May 19-21, 1993, Argonne, IL, pp. 41-45.

Lian, J. S., Zhou, J. W., Zhang, K. L., and Jiang; H., (1993), A General Survey of Chinese Maglev Train, Proceedings Maglev '93, 13th International Conf. on Magnetically Levitated Systems and Linear Drives, May 19-21, 1993, Argonne, IL, pp. 46-50.

Martinelli, G., and Morini, A., (1993), Present Status of Research for Maglev in Italy, Proceedings Maglev '93, 13th International Conf. on Magnetically Levitated Systems and Linear Drives, May 19-21, 1993, Argonne, IL, pp. 51-53.

Masada, E., (1993), Development of Maglev Transportation in Japan: Present State and Future Prospects, Proceedings Maglev '93, 13th International Conf. on Magnetically Levitated Systems and Linear Drives, May 19-21, 1993, Argonne, IL, pp. 1-6.

Moon, F. C., (1974), Laboratory Studies of Magnetic Levitation in the Thin Track Limit, IEEE Trans. on Magnetics MAG-10(3), pp. 439-442.

Moon, F. C., (1977), Vibration Problems in Magnetic Levitation and Propulsion, Transport Without Wheels, E. R. Laithwaite, ed., Elek Science, London, pp. 122-161.

Ohno, E., Iwamoto, M., and Yamada, T., (1973), Characteristic of Superconductive Magnetic Suspension and Propulsion for High-Speed Trains, Proc. IEEE 61(5), pp. 579-586. 
Ozeki, M., (1993), Current Status of Research and Development of Superconducting Maglev System in Japan, Proceedings of the International Conference on Speedup Technology for Railway and Maglev Vehicles, November 22-26, 1993, Yokohama, Japan, p. 7.

Wiescholek, U., Mayer, W. J., Rogg, D., (1993), High-Speed Magnetic Levitation Train Transrapid, Planning of the Development Program until 1995 and Prospects of Utilization in the Federal Republic of Germany, Proceedings Maglev '93, 13th International Conf. on Magnetically Levitated Systems and Linear Drives, May 19-21, 1993, Argonne, IL, pp. 22-28.

Wyczalek, F. A., (1993), Maglev Transit Technology in Russia, Proceedings Maglev '93, 13th International Conf. on Magnetically Levitated Systems and Linear Drives, May 19-21, 1993, Argonne, IL, pp. 88-93.

Zhu, S., Chen, S. S., Cai, Y., and Rote, D. M., (1994), Magnetic Damping for Maglev, 1994 Winter Annual Meeting, November 6-11, 1994, Chicago, IL. ASME, New York, PVP-Vol. 289, pp. 1-10. 


\section{Appendix}

Measured quasistatic magnetic-force data for the magnet $(50.8 \times 25.4 \times$ $6.35 \mathrm{~mm})$, corresponding to Figs. $4-9$, and the magnet $(50.8 \times 12.7 \times 6.35 \mathrm{~mm})$, corresponding to Fig. 28, are listed in Tables A.1-A.13. 
Table A.1. Measured lift magnetic force $(N)$ when $Y=5.0 \mathrm{~mm}$

\begin{tabular}{|c|c|c|c|c|c|c|c|c|}
\hline $\begin{array}{c}\text { Height, } \\
\text { m m }\end{array}$ & $\begin{array}{c}\mathrm{V}=4.55 \\
\mathrm{~m} / \mathrm{s}\end{array}$ & $\begin{array}{c}\mathrm{V}=7.89 \\
\mathrm{~m} / \mathrm{s}\end{array}$ & $\begin{array}{c}\mathrm{V}=10.62 \\
\mathrm{~m} / \mathrm{s}\end{array}$ & $\begin{array}{c}\mathrm{V}=13.32 \\
\mathrm{~m} / \mathrm{s}\end{array}$ & $\begin{array}{c}\mathrm{V}=18.20 \\
\mathrm{~m} / \mathrm{s}\end{array}$ & $\begin{array}{c}\mathrm{V}=24.15 \\
\mathrm{~m} / \mathrm{s}\end{array}$ & $\begin{array}{c}\mathrm{V}=30.10 \\
\mathrm{~m} / \mathrm{s}\end{array}$ & $\begin{array}{c}\mathrm{V}=36.10 \\
\mathrm{~m} / \mathrm{s}\end{array}$ \\
\hline 5.0000 & 1.0451 & 2.5957 & 3.9378 & 5.2324 & 7.2951 & 9.2438 & 10.562 & 11.651 \\
\hline 6.0000 & 0.91766 & 2.2373 & 3.3923 & 4.5002 & 6.2764 & 7.9298 & 9.0468 & 9.9822 \\
\hline 7.0000 & 0.79077 & 1.9308 & 2.9271 & 3.8891 & 5.4203 & 6.8365 & 7.7943 & 8.5869 \\
\hline 8.0000 & 0.69039 & 1.6812 & 2.5420 & 3.3842 & 4.7035 & 5.9278 & 6.7518 & 7.4294 \\
\hline 9.0000 & 0.61040 & 1.4675 & 2.2207 & 2.9615 & 4.1118 & 5.1641 & 5.8795 & 6.4625 \\
\hline 10.000 & 0.53812 & 1.2908 & 1.9460 & 2.5938 & 3.6103 & 4.5277 & 5.1504 & 5.6501 \\
\hline 12.700 & 0.38141 & 0.91256 & 1.3865 & 1.8570 & 2.5750 & 3.2354 & 3.6788 & 4.0371 \\
\hline 13.000 & 0.37110 & 0.88029 & 1.3383 & 1.7943 & 2.4931 & 3.1303 & 3.5554 & 3.9008 \\
\hline 15.000 & 0.28903 & 0.69668 & 1.0637 & 1.4284 & 1.9862 & 2.4957 & 2.8386 & 3.1147 \\
\hline 20.000 & & & & & & & & 1.8988 \\
\hline 25.000 & & & & & & & & 1.2636 \\
\hline 30.000 & & & & & & & & 0.90294 \\
\hline 35.000 & & & & & & & & 0.69926 \\
\hline 40.000 & & & & & & & & 0.57776 \\
\hline 45.000 & & & & & & & & 0.48013 \\
\hline 50.000 & & & & & & & & 0.36727 \\
\hline
\end{tabular}


Table A.2. Measured lift magnetic force $(N)$ when $Y=12.7 \mathrm{~mm}$

\begin{tabular}{|c|c|c|c|c|c|c|c|c|}
\hline $\begin{array}{l}\text { Height, } \\
\text { m m }\end{array}$ & $\begin{array}{c}\mathrm{V}=4.55 \\
\mathrm{~m} / \mathrm{s}\end{array}$ & $\begin{array}{c}\mathrm{V}=7.89 \\
\mathrm{~m} / \mathrm{s}\end{array}$ & $\begin{array}{c}\mathrm{V}=10.62 \\
\mathrm{~m} / \mathrm{s}\end{array}$ & $\begin{array}{c}\mathrm{V}=13.32 \\
\mathrm{~m} / \mathrm{s}\end{array}$ & $\begin{array}{c}\mathrm{V}=18.20 \\
\mathrm{~m} / \mathrm{s}\end{array}$ & $\begin{array}{c}\mathrm{V}=24.15 \\
\mathrm{~m} / \mathrm{s}\end{array}$ & $\begin{array}{c}\mathrm{V}=30.10 \\
\mathrm{~m} / \mathrm{s}\end{array}$ & $\begin{array}{c}\mathrm{V}=36.10 \\
\mathrm{~m} / \mathrm{s}\end{array}$ \\
\hline 5.0000 & 1.0955 & 2.6161 & 3.9605 & 5.2814 & 7.3515 & 9.3087 & 10.676 & 11.805 \\
\hline 6.0000 & 0.94664 & 2.2545 & 3.3970 & 4.5139 & 6.3151 & 7.9683 & 9.1351 & 10.080 \\
\hline 7.0000 & 0.81583 & 1.9367 & 2.9226 & 3.8977 & 5.4191 & 6.8397 & 7.8049 & 8.6117 \\
\hline 8.0000 & 0.70712 & 1.6686 & 2.5221 & 3.3668 & 4.6907 & 5.8954 & 6.7165 & 7.3991 \\
\hline 9.0000 & 0.61203 & 1.4513 & 2.1937 & 2.9296 & 4.0759 & 5.1076 & 5.8145 & 6.3945 \\
\hline 10.000 & 0.53374 & 1.2658 & 1.9114 & 2.5579 & 3.5538 & 4.4472 & 5.0512 & 5.5470 \\
\hline 12.700 & 0.36982 & 0.88409 & 1.3357 & 1.7984 & 2.4904 & 3.1052 & 3.5267 & 3.8584 \\
\hline 13.000 & 0.35219 & 0.84933 & 1.2875 & 1.7361 & 2.4037 & 2.9957 & 3.4014 & 3.7259 \\
\hline 15.000 & 0.27539 & 0.66572 & 1.0054 & 1.3636 & 1.8837 & 2.3421 & 2.6608 & 2.9041 \\
\hline 20.000 & & & & & & & & 1.6615 \\
\hline 25.000 & & & & & & & & 1.0252 \\
\hline 30.000 & & & & & & & & 0.66869 \\
\hline 35.000 & & & & & & & & 0.45884 \\
\hline 40.000 & & & & & & & & 0.32739 \\
\hline 45.000 & & & & & & & & 0.23401 \\
\hline 50.000 & & & & & & & & 0.16809 \\
\hline
\end{tabular}


Table A.3. Measured lift magnetic force (N) when $h=7.0 \mathrm{~mm}$

\begin{tabular}{|c|c|c|c|c|c|c|c|c|}
\hline $\begin{array}{l}\text { Gap, } \\
\mathrm{m} \mathrm{m}\end{array}$ & $\begin{array}{c}\mathrm{V}=4.55 \\
\mathrm{~m} / \mathrm{s}\end{array}$ & $\begin{array}{c}\mathrm{V}=7.89 \\
\mathrm{~m} / \mathrm{s}\end{array}$ & $\begin{array}{c}\mathrm{V}=10.62 \\
\mathrm{~m} / \mathrm{s}\end{array}$ & $\begin{array}{c}\mathrm{V}=13.32 \\
\mathrm{~m} / \mathrm{s}\end{array}$ & $\begin{array}{c}\mathrm{V}=18.20 \\
\mathrm{~m} / \mathrm{s}\end{array}$ & $\begin{array}{c}\mathrm{V}=24.15 \\
\mathrm{~m} / \mathrm{s}\end{array}$ & $\begin{array}{c}\mathrm{V}=30.10 \\
\mathrm{~m} / \mathrm{s}\end{array}$ & $\begin{array}{c}\mathrm{V}=36.10 \\
\mathrm{~m} / \mathrm{s}\end{array}$ \\
\hline 5.0000 & 0.80121 & 1.9141 & 2.9061 & 3.8765 & 5.4086 & 6.8017 & 7.7810 & 8.5608 \\
\hline 6.0000 & 0.80485 & 1.9186 & 2.9103 & 3.8865 & 5.4090 & 6.7890 & 7.7679 & 8.5471 \\
\hline 7.0000 & 0.80143 & 1.9207 & 2.9116 & 3.8811 & 5.4047 & 6.7887 & 7.7602 & 8.5383 \\
\hline 8.0000 & 0.80612 & 1.9224 & 2.9143 & 3.8877 & 5.4072 & 6.7844 & 7.7642 & 8.5411 \\
\hline 9.0000 & 0.80847 & 1.9266 & 2.9177 & 3.8896 & 5.4110 & 6.7777 & 7.7583 & 8.5448 \\
\hline 10.000 & 0.81084 & 1.9339 & 2.9212 & 3.8907 & 5.4181 & 6.7858 & 7.7670 & 8.5598 \\
\hline 12.700 & 0.80694 & 1.9314 & 2.9187 & 3.8878 & 5.4097 & 6.8048 & 7.7962 & 8.5949 \\
\hline 13.000 & 0.80654 & 1.9298 & 2.9218 & 3.8918 & 5.4166 & 6.8056 & 7.7969 & 8.6008 \\
\hline 15.000 & 0.80960 & 1.9306 & 2.9161 & 3.8883 & 5.4222 & 6.8127 & 7.8057 & 8.6321 \\
\hline 17.000 & & & & & & & 7.8208 & 8.6663 \\
\hline 20.000 & & & & & & & & 8.7054 \\
\hline 22.000 & & & & & & & & 8.7193 \\
\hline 25.000 & & & & & & & & 8.7220 \\
\hline 26.000 & & & & & & & & 8.7130 \\
\hline 27.000 & & & & & & & & 8.7019 \\
\hline 28.000 & & & & & & & & 8.6783 \\
\hline 29.000 & & & & & & & & 8.6503 \\
\hline 30.000 & & & & & & & & 8.6122 \\
\hline 31.000 & & & & & & & & 8.5553 \\
\hline 32.000 & & & & & & & & 8.4845 \\
\hline 35.000 & & & & & & & & 8.1381 \\
\hline 40.000 & & & & & & & & 6.9166 \\
\hline 45.000 & & & & & & & & 4.9871 \\
\hline 50.000 & & & & & & & & 2.7338 \\
\hline
\end{tabular}


Table A.4. Measured lift magnetic force $(N)$ when $h=12.7 \mathrm{~mm}$

\begin{tabular}{|c|c|c|c|c|c|c|c|c|}
\hline $\begin{array}{l}\text { Gap, } \\
\text { m m }\end{array}$ & $\begin{array}{c}\mathrm{V}=4.55 \\
\mathrm{~m} / \mathrm{s}\end{array}$ & $\begin{array}{c}\mathrm{V}=7.89 \\
\mathrm{~m} / \mathrm{s}\end{array}$ & $\begin{array}{c}\mathrm{V}=10.62 \\
\mathrm{~m} / \mathrm{s}\end{array}$ & $\begin{array}{c}\mathrm{V}=13.32 \\
\mathrm{~m} / \mathrm{s}\end{array}$ & $\begin{array}{c}\mathrm{V}=18.20 \\
\mathrm{~m} / \mathrm{s}\end{array}$ & $\begin{array}{c}\mathrm{V}=24.15 \\
\mathrm{~m} / \mathrm{s}\end{array}$ & $\begin{array}{c}\mathrm{V}=30.10 \\
\mathrm{~m} / \mathrm{s}\end{array}$ & $\begin{array}{c}\mathrm{V}=36.10 \\
\mathrm{~m} / \mathrm{s}\end{array}$ \\
\hline 5.0000 & 0.37788 & 0.90238 & 1.3718 & 1.8505 & 2.5732 & 3.2065 & 3.6706 & 4.0127 \\
\hline 6.0000 & 0.37967 & 0.90227 & 1.3676 & 1.8437 & 2.5494 & 3.1774 & 3.6340 & 3.9705 \\
\hline 7.0000 & 0.37603 & 0.90000 & 1.3620 & 1.8343 & 2.5468 & 3.1599 & 3.6043 & 3.9352 \\
\hline 8.0000 & 0.37182 & 0.89802 & 1.3575 & 1.8266 & 2.5321 & 3.1395 & 3.5848 & 3.9074 \\
\hline 9.0000 & 0.37459 & 0.89189 & 1.3531 & 1.8208 & 2.5151 & 3.1268 & 3.5595 & 3.8855 \\
\hline 10.000 & 0.37172 & 0.88857 & 1.3477 & 1.8163 & 2.5118 & 3.1097 & 3.5498 & 3.8729 \\
\hline 12.700 & 0.36636 & 0.88496 & 1.3382 & 1.7973 & 2.4896 & 3.0842 & 3.5213 & 3.8490 \\
\hline 13.000 & 0.36895 & 0.88526 & 1.3369 & 1.7979 & 2.4892 & 3.0826 & 3.5163 & 3.8488 \\
\hline 15.000 & 0.36174 & 0.87754 & 1.3247 & 1.7828 & 2.4769 & 3.0673 & 3.5092 & 3.8402 \\
\hline 20.000 & & & & & & & & 3.8250 \\
\hline 25.000 & & & & & & & & 3.7733 \\
\hline 30.000 & & & & & & & & 3.6226 \\
\hline 35.000 & & & & & & & & 3.2929 \\
\hline 40.000 & & & & & & & & 2.7036 \\
\hline 45.000 & & & & & & & & 1.8991 \\
\hline 50.000 & & & & & & & & 1.0999 \\
\hline
\end{tabular}


Table A.5. Measured guidance magnetic force $(N)$ when $Y=5.0 \mathrm{~mm}$

\begin{tabular}{|c|c|c|c|c|c|c|c|c|}
\hline $\begin{array}{c}\text { Height, } \\
\text { m m }\end{array}$ & $\begin{array}{c}\mathrm{V}=4.55 \\
\mathrm{~m} / \mathrm{s}\end{array}$ & $\begin{array}{c}\mathrm{V}=7.89 \\
\mathrm{~m} / \mathrm{s}\end{array}$ & $\begin{array}{c}\mathrm{V}=10.62 \\
\mathrm{~m} / \mathrm{s}\end{array}$ & $\begin{array}{c}\mathrm{V}=13.32 \\
\mathrm{~m} / \mathrm{s}\end{array}$ & $\begin{array}{c}\mathrm{V}=18.20 \\
\mathrm{~m} / \mathrm{s}\end{array}$ & $\begin{array}{c}\mathrm{V}=24.15 \\
\mathrm{~m} / \mathrm{s}\end{array}$ & $\begin{array}{c}\mathrm{V}=30.10 \\
\mathrm{~m} / \mathrm{s}\end{array}$ & $\begin{array}{c}\mathrm{V}=36.10 \\
\mathrm{~m} / \mathrm{s}\end{array}$ \\
\hline 5.0000 & 0.18065 & 0.44393 & 0.71410 & 0.98960 & 1.5682 & 2.2220 & 2.7983 & 3.3500 \\
\hline 6.0000 & 0.18417 & 0.45186 & 0.72744 & 1.0170 & 1.6034 & 2.2619 & 2.8586 & 3.4133 \\
\hline 7.0000 & 0.18068 & 0.46084 & 0.74301 & 1.0289 & 1.6325 & 2.2890 & 2.8935 & 3.4652 \\
\hline 8.0000 & 0.18766 & 0.46147 & 0.74814 & 1.0445 & 1.6458 & 2.3130 & 2.9141 & 3.4866 \\
\hline 9.0000 & 0.18833 & 0.47170 & 0.75691 & 1.0496 & 1.6620 & 2.3285 & 2.9345 & 3.5110 \\
\hline 10.000 & 0.18729 & 0.47215 & 0.75790 & 1.0510 & 1.6666 & 2.3385 & 2.9420 & 3.5156 \\
\hline 13.000 & 0.19191 & 0.47090 & 0.76569 & 1.0615 & 1.6699 & 2.3323 & 2.9421 & 3.5116 \\
\hline 15.000 & 0.18777 & 0.47444 & 0.76355 & 1.0576 & 1.6677 & 2.3194 & 2.9147 & 3.4810 \\
\hline 20.000 & & & & & & & & 3.3748 \\
\hline 25.000 & & & 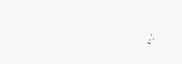 & & & & & 3.2648 \\
\hline 30.000 & & & & & & & & 3.1568 \\
\hline 35.000 & & & & & & & & 3.0531 \\
\hline 40.000 & & & & & & & & 2.9309 \\
\hline
\end{tabular}


Table A.6. Measured guidance magnetic force $(N)$ when $Y=12.7 \mathrm{~mm}$

\begin{tabular}{|c|c|c|c|c|c|c|c|c|}
\hline $\begin{array}{c}\text { Height, } \\
\text { m m } \\
\end{array}$ & $\begin{array}{c}\mathrm{V}=4.55 \\
\mathrm{~m} / \mathrm{s}\end{array}$ & $\begin{array}{c}\mathrm{V}=7.89 \\
\mathrm{~m} / \mathrm{s}\end{array}$ & $\begin{array}{c}\mathrm{V}=10.62 \\
\mathrm{~m} / \mathrm{s}\end{array}$ & $\begin{array}{c}\mathrm{V}=13.32 \\
\mathrm{~m} / \mathrm{s}\end{array}$ & $\begin{array}{c}\mathrm{V}=18.20 \\
\mathrm{~m} / \mathrm{s}\end{array}$ & $\begin{array}{c}\mathrm{V}=24.15 \\
\mathrm{~m} / \mathrm{s}\end{array}$ & $\begin{array}{c}\mathrm{V}=30.10 \\
\mathrm{~m} / \mathrm{s}\end{array}$ & $\begin{array}{c}\mathrm{V}=36.10 \\
\mathrm{~m} / \mathrm{s}\end{array}$ \\
\hline 5.0000 & 0.097706 & 0.20690 & 0.30712 & 0.38804 & 0.53884 & 0.65595 & 0.74890 & 0.82918 \\
\hline 6.0000 & 0.094964 & 0.20529 & 0.30992 & 0.39729 & 0.56286 & 0.69580 & 0.80601 & 0.90144 \\
\hline 7.0000 & 0.091036 & 0.20977 & 0.31310 & 0.40684 & 0.57802 & 0.73006 & 0.84524 & 0.95586 \\
\hline 8.0000 & 0.090508 & 0.20402 & 0.31586 & 0.41019 & 0.59173 & 0.75649 & 0.88238 & 0.99907 \\
\hline 9.0000 & 0.093734 & 0.20588 & 0.31544 & 0.41667 & 0.60427 & 0.77338 & 0.91097 & 1.0331 \\
\hline 10.000 & 0.087470 & 0.20646 & 0.31930 & 0.42212 & 0.61046 & 0.78828 & 0.93361 & 1.0681 \\
\hline 12.700 & 0.083869 & 0.19930 & 0.30894 & 0.41791 & 0.61670 & 0.80983 & 0.96883 & 1.1137 \\
\hline 13.000 & 0.081553 & 0.19838 & 0.31017 & 0.41911 & 0.61545 & 0.81066 & 0.97017 & 1.1160 \\
\hline 15.000 & 0.079007 & 0.19274 & 0.30440 & 0.41200 & 0.61152 & 0.81318 & 0.97188 & 1.1252 \\
\hline 20.000 & & & & & & & & 1.1000 \\
\hline 25.000 & & & & & & & & 1.0424 \\
\hline 30.000 & & & & & & & & 0.96882 \\
\hline 35.000 & & & & & & & & 0.89044 \\
\hline 40.000 & & & & & & & & 0.82608 \\
\hline 45.000 & & & & & & & & 0.76790 \\
\hline 50.000 & & & & & & & & 0.72454 \\
\hline
\end{tabular}


Table A.7. Measured guidance magnetic force (N) when $h=7.0 \mathrm{~mm}$

\begin{tabular}{|c|c|c|c|c|c|c|c|c|}
\hline $\begin{array}{l}\text { Gap, } \\
\mathrm{m} \text { m }\end{array}$ & $\begin{array}{c}\mathrm{V}=4.55 \\
\mathrm{~m} / \mathrm{s}\end{array}$ & $\begin{array}{c}\mathrm{V}=7.89 \\
\mathrm{~m} / \mathrm{s}\end{array}$ & $\begin{array}{c}\mathrm{V}=10.62 \\
\mathrm{~m} / \mathrm{s}\end{array}$ & $\begin{array}{c}\mathrm{V}=13.32 \\
\mathrm{~m} / \mathrm{s}\end{array}$ & $\begin{array}{c}\mathrm{V}=18.20 \\
\mathrm{~m} / \mathrm{s}\end{array}$ & $\begin{array}{c}\mathrm{V}=24.15 \\
\mathrm{~m} / \mathrm{s}\end{array}$ & $\begin{array}{c}\mathrm{V}=\mathbf{3 0 . 1 0} \\
\mathrm{m} / \mathrm{s}\end{array}$ & $\begin{array}{c}\mathrm{V}=36.10 \\
\mathrm{~m} / \mathrm{s}\end{array}$ \\
\hline 5.0000 & 0.19122 & 0.45731 & 0.73137 & 1.0322 & 1.6304 & 2.2933 & 2.8992 & 3.4594 \\
\hline 6.0000 & 0.16639 & 0.39968 & 0.63375 & 0.88455 & 1.3820 & 1.9332 & 2.4178 & 2.8615 \\
\hline 7.0000 & 0.15097 & 0.34776 & 0.55057 & 0.76025 & 1.1773 & 1.6356 & 2.0328 & 2.3895 \\
\hline 8.0000 & 0.13917 & 0.31218 & 0.48647 & 0.66585 & 1.0152 & 1.3904 & 1.7220 & 2.0064 \\
\hline 9.0000 & 0.13029 & 0.28606 & 0.43460 & 0.58761 & 0.88464 & 1.1986 & 1.4675 & 1.6938 \\
\hline 10.000 & 0.12170 & 0.26143 & 0.39458 & 0.52755 & 0.77599 & 1.0376 & 1.2542 & 1.4431 \\
\hline 13.000 & 0.11148 & 0.22066 & 0.32044 & 0.41785 & 0.56402 & 0.71816 & 0.83196 & 0.92319 \\
\hline 15.000 & 0.10777 & 0.21193 & 0.30006 & 0.37833 & 0.48031 & 0.59664 & 0.66109 & 0.71464 \\
\hline 16.000 & & & & & & & & 0.62420 \\
\hline 17.000 & & & & & & & & 0.56259 \\
\hline 18.000 & & & & & & & & 0.51805 \\
\hline 20.000 & & & & & & & & 0.47121 \\
\hline 22.000 & & & & & & & & 0.45942 \\
\hline 25.000 & & & & & & & & 0.53118 \\
\hline 23.000 & & & & & & & & 0.47426 \\
\hline 22.000 & & & & & & & & 0.46136 \\
\hline 24.000 & & & & & & & & 0.50279 \\
\hline 25.000 & & & & & & & & 0.54166 \\
\hline 26.000 & & & & & & & & 0.57850 \\
\hline 27.000 & & & & & & & & 0.63566 \\
\hline 28.000 & & & & & & & & 0.70825 \\
\hline 29.000 & & & & & & & & 0.78758 \\
\hline 30.000 & & & & & & & & 0.87856 \\
\hline 31.000 & & & & & & & & 0.97932 \\
\hline 32.000 & & & & & & & & 1.1058 \\
\hline 33.000 & & & & & & & & 1.2436 \\
\hline 34.000 & & & & & & & & 1.3905 \\
\hline 35.000 & & & & & & & & 1.5497 \\
\hline 36.000 & & & & & & & & 1.7205 \\
\hline 37.000 & & & & & & & & 1.8941 \\
\hline 38.000 & & & & & & & & 2.0679 \\
\hline 39.000 & & & & & & & & 2.2402 \\
\hline 40.000 & & & & & & & & 2.3956 \\
\hline 41.000 & & & & & & & & 2.5338 \\
\hline 42.000 & & & & & & & & 2.6490 \\
\hline 43.000 & & & & & & & & 2.7376 \\
\hline
\end{tabular}


Table A.7. Cont'd

\begin{tabular}{|c|c|c|c|c|c|c|c|c|}
\hline $\begin{array}{l}\text { Gap, } \\
\mathrm{m} \mathrm{m}\end{array}$ & $\begin{array}{c}\mathrm{V}=4.55 \\
\mathrm{~m} / \mathrm{s}\end{array}$ & $\begin{array}{c}\mathrm{V}=7.89 \\
\mathrm{~m} / \mathrm{s}\end{array}$ & $\begin{array}{c}\mathrm{V}=10.62 \\
\mathrm{~m} / \mathrm{s}\end{array}$ & $\begin{array}{c}\mathrm{V}=13.32 \\
\mathrm{~m} / \mathrm{s}\end{array}$ & $\begin{array}{c}\mathrm{V}=18.20 \\
\mathrm{~m} / \mathrm{s}\end{array}$ & $\begin{array}{c}\mathrm{V}=24.15 \\
\mathrm{~m} / \mathrm{s}\end{array}$ & $\begin{array}{c}\mathrm{V}=\mathbf{3 0 . 1 0} \\
\mathrm{m} / \mathrm{s}\end{array}$ & $\begin{array}{c}\mathrm{V}=36.10 \\
\mathrm{~m} / \mathrm{s}\end{array}$ \\
\hline 44.000 & & & & & & & & 2.7861 \\
\hline 45.000 & & & & & & & & 2.8098 \\
\hline 46.000 & & & & & & & & 2.7861 \\
\hline 46.000 & & & & & & & & 2.7877 \\
\hline 47.000 & & & & & & & & 2.7349 \\
\hline 48.000 & & & & & & & & 2.6488 \\
\hline 49.000 & & & & & & & & 2.5441 \\
\hline 50.000 & & & & & & & & 2.4179 \\
\hline 51.000 & & & & & & & & 2.2653 \\
\hline 52.000 & & & & & & & & 2.1055 \\
\hline 53.000 & & & & & & & & 1.9357 \\
\hline
\end{tabular}


Table A.8. Measured guidance magnetic force $(N)$ when $h=12.7 \mathrm{~mm}$

\begin{tabular}{|c|c|c|c|c|c|c|c|c|}
\hline $\begin{array}{l}\text { Gap, } \\
\mathrm{m} \mathrm{m}\end{array}$ & $\begin{array}{c}\mathrm{V}=4.55 \\
\mathrm{~m} / \mathrm{s}\end{array}$ & $\begin{array}{c}\mathrm{V}=7.89 \\
\mathrm{~m} / \mathrm{s}\end{array}$ & $\begin{array}{c}\mathrm{V}=10.62 \\
\mathrm{~m} / \mathrm{s}\end{array}$ & $\begin{array}{c}\mathrm{V}=13.32 \\
\mathrm{~m} / \mathrm{s}\end{array}$ & $\begin{array}{c}\mathrm{V}=18.20 \\
\mathrm{~m} / \mathrm{s}\end{array}$ & $\begin{array}{c}\mathrm{V}=24.15 \\
\mathrm{~m} / \mathrm{s}\end{array}$ & $\begin{array}{c}\mathrm{V}=30.10 \\
\mathrm{~m} / \mathrm{s}\end{array}$ & $\begin{array}{c}\mathrm{V}=36.10 \\
\mathrm{~m} / \mathrm{s}\end{array}$ \\
\hline 5.0000 & 0.16979 & 0.45445 & 0.74629 & 1.0482 & 1.6583 & 2.3402 & 2.9856 & 3.5008 \\
\hline 6.0000 & 0.15160 & 0.38587 & 0.64142 & 0.89846 & 1.4110 & 1.9835 & 2.5116 & 2.9385 \\
\hline 7.0000 & 0.13681 & 0.33966 & 0.56009 & 0.77435 & 1.2130 & 1.6944 & 2.1361 & 2.4894 \\
\hline 8.0000 & 0.11769 & 0.30203 & 0.49382 & 0.67819 & 1.0556 & 1.4616 & 1.8246 & 2.1221 \\
\hline 9.0000 & 0.10520 & 0.26779 & 0.43972 & 0.60001 & 0.92745 & 1.2662 & 1.5761 & 1.8277 \\
\hline 10.000 & 0.094461 & 0.24160 & 0.38845 & 0.53316 & 0.81830 & 1.1116 & 1.3697 & 1.5795 \\
\hline 12.700 & 0.078118 & 0.19241 & 0.31376 & 0.41773 & 0.61378 & 0.81021 & 0.97368 & 1.1036 \\
\hline 13.000 & 0.078038 & 0.18856 & 0.30458 & 0.40892 & 0.59571 & 0.78456 & 0.94053 & 1.0712 \\
\hline 15.000 & 0.074923 & 0.17032 & 0.27774 & 0.36331 & 0.51582 & 0.65495 & 0.76163 & 0.85348 \\
\hline 20.000 & & & & & & & & 0.59110 \\
\hline 25.000 & & & & & & & & 0.56213 \\
\hline 26.000 & & & & & & & & 0.58183 \\
\hline 27.000 & & & & & & & & 0.60261 \\
\hline 28.000 & & & & & & & & 0.62805 \\
\hline 29.000 & & & & & & & & 0.65752 \\
\hline 30.000 & & & & & & & & 0.69215 \\
\hline 31.000 & & & & & & & & 0.73462 \\
\hline 32.000 & & & & & & & & 0.77862 \\
\hline 33.000 & & & & & & & & 0.82802 \\
\hline 34.000 & & & & & & & & 0.87711 \\
\hline 35.000 & & & & & & & & 0.92915 \\
\hline 38.000 & & & & & & & & 1.0834 \\
\hline 40.000 & & & & & & & & 1.1639 \\
\hline 42.000 & & & & & & & & 1.2147 \\
\hline 44.000 & & & & & & & & 1.2380 \\
\hline 45.000 & & & & & & & & 1.2343 \\
\hline 46.000 & & & & & & & & 1.2158 \\
\hline 47.000 & & & & & & & & 1.1890 \\
\hline 48.000 & & & & & & & & 1.1532 \\
\hline 49.000 & & & & & & & & 1.1144 \\
\hline 50.000 & & & & & & & & 1.0627 \\
\hline
\end{tabular}


Table A.9. Measured drag magnetic force (N) when $Y=5.0 \mathrm{~mm}$

\begin{tabular}{|c|c|c|c|c|c|c|c|c|}
\hline $\begin{array}{c}\text { Height, } \\
\text { m m }\end{array}$ & $\begin{array}{c}\mathrm{V}=4.55 \\
\mathrm{~m} / \mathrm{s}\end{array}$ & $\begin{array}{c}\mathrm{V}=7.89 \\
\mathrm{~m} / \mathrm{s}\end{array}$ & $\begin{array}{c}\mathrm{V}=10.62 \\
\mathrm{~m} / \mathrm{s}\end{array}$ & $\begin{array}{c}\mathrm{V}=13.32 \\
\mathrm{~m} / \mathrm{s}\end{array}$ & $\begin{array}{c}\mathrm{V}=18.20 \\
\mathrm{~m} / \mathrm{s}\end{array}$ & $\begin{array}{c}\mathrm{V}=24.15 \\
\mathrm{~m} / \mathrm{s}\end{array}$ & $\begin{array}{c}\mathrm{V}=30.10 \\
\mathrm{~m} / \mathrm{s}\end{array}$ & $\begin{array}{c}\mathrm{V}=36.10 \\
\mathrm{~m} / \mathrm{s}\end{array}$ \\
\hline 5.0000 & 3.0899 & 4.5607 & 5.2778 & 5.6976 & 5.9508 & 5.8713 & 5.6439 & 5.4027 \\
\hline 6.0000 & 2.7156 & 4.0115 & 4.6392 & 5.0186 & 5.2514 & 5.1931 & 5.0020 & 4.7839 \\
\hline 7.0000 & 2.4139 & 3.5401 & 4.1140 & 4.4653 & 4.6733 & 4.6290 & 4.4703 & 4.2780 \\
\hline 8.0000 & 2.1504 & 3.1631 & 3.6723 & 3.9933 & 4.1989 & 4.1691 & 4.0321 & 3.8626 \\
\hline 9.0000 & 1.9392 & 2.8430 & 3.3110 & 3.6114 & 3.8042 & 3.7907 & 3.6719 & 3.5230 \\
\hline 10.000 & 1.7548 & 2.5734 & 3.0068 & 3.2859 & 3.4736 & 3.4708 & 3.3689 & 3.2403 \\
\hline 12.700 & 1.3775 & 2.0225 & 2.3846 & 2.6338 & 2.7998 & 2.8228 & 2.7617 & 2.6715 \\
\hline 13.000 & 1.3439 & 1.9703 & 2.3329 & 2.5755 & 2.7420 & 2.7733 & 2.7178 & 2.6260 \\
\hline 15.000 & 1.1535 & 1.7049 & 2.0209 & 2.2399 & 2.4076 & 2.4519 & 2.4191 & 2.3380 \\
\hline 20.000 & & & & & & & & 1.8856 \\
\hline 25.000 & & & & & & & & 1.6287 \\
\hline 30.000 & & & & & & & & 1.4599 \\
\hline 35.000 & & & & & & & & 1.3414 \\
\hline 40.000 & & & & & & & & 1.2395 \\
\hline 45.000 & & & & & & & & 1.1352 \\
\hline 50.000 & & & & & & & & 1.0074 \\
\hline
\end{tabular}


Table A.10. Measured drag magnetic force $(N)$ when $Y=12.7 \mathrm{~mm}$

\begin{tabular}{|c|c|c|c|c|c|c|c|c|}
\hline $\begin{array}{c}\text { Height, } \\
\mathrm{m} \mathrm{m}\end{array}$ & $\begin{array}{c}\mathrm{V}=4.55 \\
\mathrm{~m} / \mathrm{s}\end{array}$ & $\begin{array}{c}\mathrm{V}=7.89 \\
\mathrm{~m} / \mathrm{s}\end{array}$ & $\begin{array}{c}\mathrm{V}=10.62 \\
\mathrm{~m} / \mathrm{s}\end{array}$ & $\begin{array}{c}\mathrm{V}=13.32 \\
\mathrm{~m} / \mathrm{s}\end{array}$ & $\begin{array}{c}\mathrm{V}=18.20 \\
\mathrm{~m} / \mathrm{s}\end{array}$ & $\begin{array}{c}\mathrm{V}=24.15 \\
\mathrm{~m} / \mathrm{s}\end{array}$ & $\begin{array}{c}\mathrm{V}=30.10 \\
\mathrm{~m} / \mathrm{s}\end{array}$ & $\begin{array}{c}\mathrm{V}=36.10 \\
\mathrm{~m} / \mathrm{s}\end{array}$ \\
\hline 5.0000 & 2.7672 & 3.9798 & 4.5695 & 4.9081 & 5.0506 & 4.9185 & 4.7044 & 4.4699 \\
\hline 6.0000 & 2.3707 & 3.4231 & 3.9263 & 4.2150 & 4.3393 & 4.2126 & 4.0277 & 3.8128 \\
\hline 7.0000 & 2.0555 & 2.9609 & 3.3931 & 3.6459 & 3.7496 & 3.6363 & 3.4675 & 3.2863 \\
\hline 8.0000 & 1.7866 & 2.5791 & 2.9554 & 3.1830 & 3.2622 & 3.1675 & 3.0208 & 2.8608 \\
\hline 9.0000 & 1.5689 & 2.2634 & 2.5962 & 2.7984 & 2.8714 & 2.7839 & 2.6552 & 2.5075 \\
\hline 10.000 & 1.3802 & 1.9988 & 2.2902 & 2.4781 & 2.5396 & 2.4621 & 2.3552 & 2.2176 \\
\hline 12.700 & 1.0130 & 1.4573 & 1.6869 & 1.8307 & 1.8816 & 1.8267 & 1.7532 & 1.6606 \\
\hline 13.000 & 0.98104 & 1.4158 & 1.6327 & 1.7756 & 1.8265 & 1.7807 & 1.7090 & 1.6166 \\
\hline 15.000 & 0.79730 & 1.1534 & 1.3391 & 1.4644 & 1.5105 & 1.4749 & 1.4251 & 1.3461 \\
\hline 20.000 & & & & & & & & 0.93444 \\
\hline 25.000 & & & & & & & & 0.71183 \\
\hline 30.000 & & & & & & & & 0.57532 \\
\hline 35.000 & & & & & & & & 0.47564 \\
\hline 40.000 & & & & & & & & 0.40846 \\
\hline 45.000 & & & & & & & & 0.34486 \\
\hline 50.000 & & & & & & & & 0.29709 \\
\hline
\end{tabular}


Table A.11. Measured drag magnetic force $(N)$ when $h=7.0 \mathrm{~mm}$

\begin{tabular}{|c|c|c|c|c|c|c|c|c|}
\hline $\begin{array}{l}\text { Gap, } \\
\mathbf{m} \mathbf{~ m}\end{array}$ & $\begin{array}{c}\mathrm{V}=4.55 \\
\mathrm{~m} / \mathrm{s}\end{array}$ & $\begin{array}{c}\mathrm{V}=7.89 \\
\mathrm{~m} / \mathrm{s}\end{array}$ & $\begin{array}{c}\mathrm{V}=10.62 \\
\mathrm{~m} / \mathrm{s}\end{array}$ & $\begin{array}{c}\mathrm{V}=13.32 \\
\mathrm{~m} / \mathrm{s}\end{array}$ & $\begin{array}{c}\mathrm{V}=18.20 \\
\mathrm{~m} / \mathrm{s}\end{array}$ & $\begin{array}{c}\mathrm{V}=24.15 \\
\mathrm{~m} / \mathrm{s}\end{array}$ & $\begin{array}{c}\mathrm{V}=30.10 \\
\mathrm{~m} / \mathrm{s}\end{array}$ & $\begin{array}{c}\mathrm{V}=36.10 \\
\mathrm{~m} / \mathrm{s}\end{array}$ \\
\hline 5.0000 & 2.4131 & 3.5329 & 4.0949 & 4.4551 & 4.6617 & 4.6124 & 4.4564 & 4.2658 \\
\hline 6.0000 & 2.3374 & 3.4004 & 3.9352 & 4.2630 & 4.4429 & 4.3721 & 4.2004 & 4.0160 \\
\hline 7.0000 & 2.2673 & 3.2988 & 3.8024 & 4.1042 & 4.2653 & 4.1765 & 4.0084 & 3.8195 \\
\hline 8.0000 & 2.2186 & 3.2060 & 3.6976 & 3.9909 & 4.1253 & 4.0257 & 3.8568 & 3.6667 \\
\hline 9.0000 & 2.1715 & 3.1380 & 3.6068 & 3.8878 & 4.0121 & 3.9046 & 3.7416 & 3.5404 \\
\hline 10.000 & 2.1342 & 3.0766 & 3.5359 & 3.8045 & 3.9206 & 3.8075 & 3.6456 & 3.4514 \\
\hline 12.700 & 2.0487 & 2.9530 & 3.3947 & 3.6450 & 3.7452 & 3.6279 & 3.4661 & 3.2807 \\
\hline 13.000 & 2.0465 & 2.9492 & 3.3866 & 3.6339 & 3.7346 & 3.6174 & 3.4529 & 3.2693 \\
\hline 15.000 & 2.0084 & 2.8832 & 3.3136 & 3.5574 & 3.6574 & 3.5421 & 3.3874 & 3.1996 \\
\hline 17.000 & & & & & & & & 3.1612 \\
\hline 20.000 & & & & & & & & 3.1324 \\
\hline 22.000 & & & & & & & & 3.1280 \\
\hline 25.000 & & & & & & & & 3.1244 \\
\hline 26.000 & & & & & & & & 3.1268 \\
\hline 27.000 & & & & & & & & 3.1356 \\
\hline 28.000 & & & & & & & & 3.1439 \\
\hline 29.000 & & & & & & & & 3.1416 \\
\hline 30.000 & & & & & & & & 3.1497 \\
\hline 31.000 & & & & & & & & 3.1568 \\
\hline 32.000 & & & & & & & & 3.1568 \\
\hline 35.000 & & & & & & & & 3.1518 \\
\hline 40.000 & & & & & & & & 2.9977 \\
\hline 45.000 & & & & & & & & 2.5574 \\
\hline 50.000 & & & & & & & & 1.8590 \\
\hline
\end{tabular}


Table A.12. Measured drag magnetic force $(N)$ when $h=12.7 \mathrm{~mm}$

\begin{tabular}{|c|c|c|c|c|c|c|c|c|}
\hline $\begin{array}{l}\text { Gap, } \\
\text { m m }\end{array}$ & $\begin{array}{c}\mathrm{V}=4.55 \\
\mathrm{~m} / \mathrm{s}\end{array}$ & $\begin{array}{c}\mathrm{V}=7.89 \\
\mathrm{~m} / \mathrm{s}\end{array}$ & $\begin{array}{c}\mathrm{V}=10.62 \\
\mathrm{~m} / \mathrm{s}\end{array}$ & $\begin{array}{c}\mathrm{V}=13.32 \\
\mathrm{~m} / \mathrm{s}\end{array}$ & $\begin{array}{c}\mathrm{V}=18.20 \\
\mathrm{~m} / \mathrm{s}\end{array}$ & $\begin{array}{c}\mathrm{V}=24.15 \\
\mathrm{~m} / \mathrm{s}\end{array}$ & $\begin{array}{c}\mathrm{V}=30.10 \\
\mathrm{~m} / \mathrm{s}\end{array}$ & $\begin{array}{c}\mathrm{V}=36.10 \\
\mathrm{~m} / \mathrm{s}\end{array}$ \\
\hline 5.0000 & 1.3715 & 2.0248 & 2.3827 & 2.6163 & 2.7915 & 2.8030 & 2.7596 & 2.6502 \\
\hline 6.0000 & 1.2988 & 1.9054 & 2.2245 & 2.4369 & 2.5863 & 2.5708 & 2.5234 & 2.4080 \\
\hline 7.0000 & 1.2261 & 1.7999 & 2.0951 & 2.2932 & 2.4162 & 2.3824 & 2.3231 & 2.2141 \\
\hline 8.0000 & 1.1730 & 1.7116 & 1.9946 & 2.1750 & 2.2757 & 2.2347 & 2.1749 & 2.0624 \\
\hline 9.0000 & 1.1283 & 1.6430 & 1.9075 & 2.0744 & 2.1626 & 2.1101 & 2.0519 & 1.9459 \\
\hline 10.000 & 1.0857 & 1.5840 & 1.8357 & 1.9908 & 2.0695 & 2.0165 & 1.9469 & 1.8411 \\
\hline 12.700 & 1.0074 & 1.4657 & 1.6939 & 1.8303 & 1.8864 & 1.8246 & 1.7553 & 1.6566 \\
\hline 13.000 & 1.0024 & 1.4542 & 1.6756 & 1.8171 & 1.8685 & 1.8045 & 1.7324 & 1.6420 \\
\hline 15.000 & 0.96331 & 1.3938 & 1.6080 & 1.7374 & 1.7872 & 1.7157 & 1.6522 & 1.5528 \\
\hline 20.000 & & & & & & & & 1.4401 \\
\hline 25.000 & & & & & & & & 1.3995 \\
\hline 30.000 & & & & & & & & 1.3726 \\
\hline 35.000 & & & & & & & & 1.3360 \\
\hline 40.000 & & & & & & & & 1.2283 \\
\hline 45.000 & & & & & & & & 1.0341 \\
\hline 50.000 & & & & & & & & 0.77217 \\
\hline
\end{tabular}


Distribution for ANL-95/10

Internal

Y. Cai (10)

R. B. Poeppel

S. S. Chen (10)

D. M. Rote (25)

H. T. Coffey

R. A. Valentin

H. Drucker

M. W. Wambsganss (3)

J. L. He

Z. Wang (10)

J. R. Hull

R. W. Weeks

L. R. Johnson

S. Zhu

C. A. Malefyt

TIS Files

T. M. Mulcahy (5)

External

DOE-OSTI for distribution per UC-330 (91)

ANL Libraries

ANL-E (2)

ANL-W

Manager, Chicago Field Office, DOE

Director, Technology Management Div., DOE-CH

D. L. Bray, DOE-CH

T. Crawford, DOE-CH

Energy Technology Division Review Committee:

H. K. Birnbaum, University of Illinois, Urbana

R. C. Buchanan, University of Cincinnati, Cincinnati, OH

M. S. Dresselhaus, Massachusetts Institute of Technology, Cambridge, MA

B. G. Jones, University of Mlinois, Urbana

C.-Y. Li, Cornell University, Ithaca, NY

S.-N. Liu, Fremont, CA

R. E. Smith, Altran Corp., Huntersville, NC

J. S. Coleman, DOE, Washington, DC

J. T. Harding, DOT, Washington, DC

O. P. Manley, DOE, Washington, DC

F. C. Moon, Cornell University, Ithaca, NY

J. R. Welty, DOE, Washington, DC 